University of Rhode Island

DigitalCommons@URI

Open Access Dissertations

2020

\title{
MODULATION OF RECEPTOR INTERACTING PROTEIN KINASE 1 (RIPK1) SIGNALING DURING DENGUE VIRUS INFECTION
}

Darshika Jeewanthi Udawatte

University of Rhode Island, dudawatte@uri.edu

Follow this and additional works at: https://digitalcommons.uri.edu/oa_diss

\section{Recommended Citation}

Udawatte, Darshika Jeewanthi, "MODULATION OF RECEPTOR INTERACTING PROTEIN KINASE 1 (RIPK1) SIGNALING DURING DENGUE VIRUS INFECTION" (2020). Open Access Dissertations. Paper 1195. https://digitalcommons.uri.edu/oa_diss/1195

This Dissertation is brought to you for free and open access by DigitalCommons@URI. It has been accepted for inclusion in Open Access Dissertations by an authorized administrator of DigitalCommons@URI. For more information, please contact digitalcommons-group@uri.edu. 
MODULATION OF RECEPTOR INTERACTING PROTEIN

KINASE 1 (RIPK1) SIGNALING DURING DENGUE VIRUS

INFECTION

BY

DARSHIKA J. UDAWATTE MUDANNAYAKE

A DISSERTATION SUBMITTED IN PARTIAL FULFILLMENT OF THE

REQUIREMENTS FOR THE DEGREE OF

DOCTOR OF PHILOSOPHY

IN

CELL AND MOLECULAR BIOLOGY

UNIVERSITY OF RHODE ISLAND

2020 
DOCTOR OF PHILOSOPHY DISSERTATION

OF

DARSHIKA J. UDAWATTE MUDANNAYAKE

\section{APPROVED:}

Dissertation Committee:

Major Professor Alan L. Rothman

Arnob Dutta

Marta Gomez-Chiarri

Brenton DeBoef DEAN OF THE GRADUATE SCHOOL 


\begin{abstract}
Dengue virus (DENV) infection is the most prevalent arthropod-borne virus disease. There are estimated 100 million symptomatic cases of dengue disease per year worldwide. A lack of effective antiviral therapies or vaccines makes DENV infections a major global health concern. Therefore, understanding the viral and host factors contributing to the disease pathogenesis is critical. DENV has been shown to effectively counteract host innate immune mechanisms. In particular, DENV protease, NS3 has emerged as an inhibitor of host cellular signaling by targeting crucial host proteins. Here we identified RIPK1 as a novel target of DENV NS3. RIPK1 is a central mediator of innate immune regulation downstream of TNFR1, TLR3, TLR4, RIG-I, and MDA-5. The outcomes of RIPK1-mediated inflammatory signaling include NF- $\kappa$ B and MAPK activation and IRF3/IRF7 phosphorylation. RIPK1 also regulates cell death signaling by modulating extrinsic apoptosis and necroptosis.
\end{abstract}

We observed that RIPK1 levels were significantly decreased in numerous cell types with DENV infection. DENV NS3 was responsible for decreased RIPK1 levels as shown by overexpression experiments. NS3 protease activity was fundamental for this effect, because the overexpression of a catalytically inactive protease mutant (NS2B3-S135A) did not result in a significant RIPK1 reduction. Additionally, both wild type and protease mutant NS3 physically interacted with RIPK1 as shown by coimmunoprecipitation experiments. Consequently, DENV inhibited NF- $\kappa \mathrm{B}$ activation downstream of TNFR1 and TLR3 receptors by targeting RIPK1. Furthermore, we detected that DENV did not induce necroptosis and further suppressed TNFR1- 
induced necroptosis. Our findings add RIPK1 to the list of host proteins targeted by DENV NS3 and expand the knowledge of strategies used by DENV to evade innate immune responses. Manipulation of host cell RIPK1 signaling by DENV may contribute to disease pathogenesis. 


\section{ACKNOWLEDGEMENTS}

I want to take this opportunity to sincerely thank my advisor, Dr. Alan Rothman. He is a role model of an excellent advisor. He was very kind and guided me through my studies patiently. I admire the way he challenged me to think critically and communicate my work eloquently. I am grateful to him for inspiring me to grow as a young scientist.

I also want to thank my former advisor, Dr. Carey Medin for the opportunity to pursue a Ph.D. at URI and for guiding me on numerous projects I was working in my early graduate career.

I am grateful to my committee members Dr. Arnob Dutta and Dr. Marta Gomez -Chiarri for their time, commitment, and invaluable guidance. They both were always available for any questions I had and made sure I was on the right track for graduating.

I would like to thank all the wonderful faculty members at the department of Cell and Molecular Biology for giving feedback and encouraging me at graduate seminars. Special thanks to Dr. Bethany Jenkins for always checking in how I did professionally as well as personally.

I gratefully acknowledge all the faculty, lab managers, and postdocs at ICUBED. Their support through presentation run-throughs, experimental feedback has been vital for my research. I enjoyed a lot working with them all and learned so much from them.

Finally, I want to express my heartfelt gratitude to my phenomenal family, my mother, my late father, my brothers for their unconditional support. They were always there for me from my childhood and encouraged and helped with my studies and 
sports. They always celebrated my achievements together. I always wanted to make them proud. I know, my father would have been very happy and proud of me and I miss him so much. I am grateful to my in-laws for making a long trip from Sri Lanka to the USA to help me with my studies. I could not imagine my life as a new mom without their support. A big THANK YOU to my wonderful husband, for always supporting me, encouraging me when I am down, and above all being a good listener! You are the wind beneath my wings. Lastly, of course, thanks to my little angel Sanaya, for making our lives so much colorful! I love you all. 


\section{DEDICATION}

I dedicate this dissertation to my mother (Sumana Hulangamuwa), my late father (Mahinda Rathnapala), my brothers (Suranga Udawatte, Danushka Udawatte), my husband (Pathum Mudannayake) and my daughter (Sanaya Mudannayake). Thank you amma, appachchi, and my brothers for going through a lot to make me who I am today. Thank you, Pathum, without your constant support and patience I could not have done it. Thank you Sanaya, for being a good girl, when your mommy was busy. I owe it to you all! 


\section{PREFACE}

The following dissertation has been prepared in manuscript format according to the guidelines of the Graduate School of the University of Rhode Island. The dissertation includes five chapters: Chapter 1, Introduction. Chapter 2, "Virus inhibition of RIPK1-mediated innate immune signaling” prepared for submission to mBio. Chapter 3, "Dengue virus downregulates TNFR1- and TLR3-stimulated NF-кB activation by targeting RIPK1" was prepared for submission to PLOS PATHOGENS. Chapter 4, "Additional mechanisms and implications of RIPK1 downregulation by DENV." Chapter 5, Conclusions. 


\section{Table of Contents}

ACKNOWLEDGEMENTS




\section{Table of figures}

\section{CHAPTER 1}

Figure 1. World distribution of Dengue in 2016. 02

Figure 2. The mechanism of Antibody-Dependent Enhancement 05

Figure 3. Structural and non-structural proteins encoded by the DENV

$\begin{array}{ll}\text { genome } & 09\end{array}$

$\begin{array}{lr}\text { Figure 4. DENV life cycle } & 12\end{array}$

\section{CHAPTER 2}

Figure 1. Domain structure of RIPK1 28

Figure 2. Signaling pathways mediated by RIPK1 36

Figure 3. Viral proteins involved in modulating RIPK1 signaling 48

\section{CHAPTER 3}

Figure 1. Endogenous and overexpressed RIPK1 decreases during DENV

$\begin{array}{ll}\text { infection } & 72\end{array}$

Figure 2. DENV NS3 protease interacts with and decreases RIPK1 74

Figure 3. TNF $\alpha$ - and poly(I:C)-driven NF-кB activation is impaired during

$\begin{array}{ll}\text { DENV infection } & 76\end{array}$

\section{CHAPTER 4}

Figure 1. Schematic diagram of the ubiquitin-proteasome system 
Figure 2. Schematic diagram of the autophagy-lysosome pathway with specific inhibitors

Figure 3. RIPK1 is not degraded via proteasomes or lysosomes during DENV infection

Figure 4. RIPK1 is not degraded via autophagy following NS2B3 expression 102

Figure 5. RIPK1 mediated necroptosis induction 104

Figure 6. DENV suppressed necroptosis 106

Figure 7. DENV replication is not affected by RIPK1 overexpression

Figure 8. DENV Replication is not affected by silencing of endogenous RIPK

\section{CHAPTER 5}

Figure 1. Model 1: Cell-intrinsic effects of RIPK1 inhibition by DENV

Figure 2. Model II: The effects of RIPK1 inhibition at a tissue/organism level 134 


\section{CHAPTER 1}

\section{Introduction}

\section{Dengue Epidemiology}

Dengue virus (DENV) infection, the most prevalent arthropod-borne virus disease, represents a major global human health concern. DENV is endemic to more than 100 countries in the world (Fig 1). Three billion people in tropical and subtropical regions in the world are at a higher risk of getting infected with DENV. Approximately 50-100 million people are reported to exhibit symptoms due to DENV infections, annually. The majority of infected individuals develop a mild febrile illness, but approximately 500,000 clinical cases result in more severe dengue hemorrhagic fever/ dengue shock syndrome leading to $25-50,000$ deaths per year $(1,2)$. Significantly, the incidence has increased 30 -fold in the last 50 years due to accelerating geographical spread of the virus. This is evidenced by the identification of new cases of dengue fever in Florida (USA), France, Spain and Japan in higher latitude regions $(3,4)$.

The primary vector of the DENV is a female Aedes aegypti mosquito. These mosquitos feed on the blood of humans primarily during the daytime. A. aegypti get the virus after biting an infected individual. Following 8-10 days of virus incubation, an infected mosquito is capable of disseminating the virus to susceptible individuals for the rest of its life time (5). 


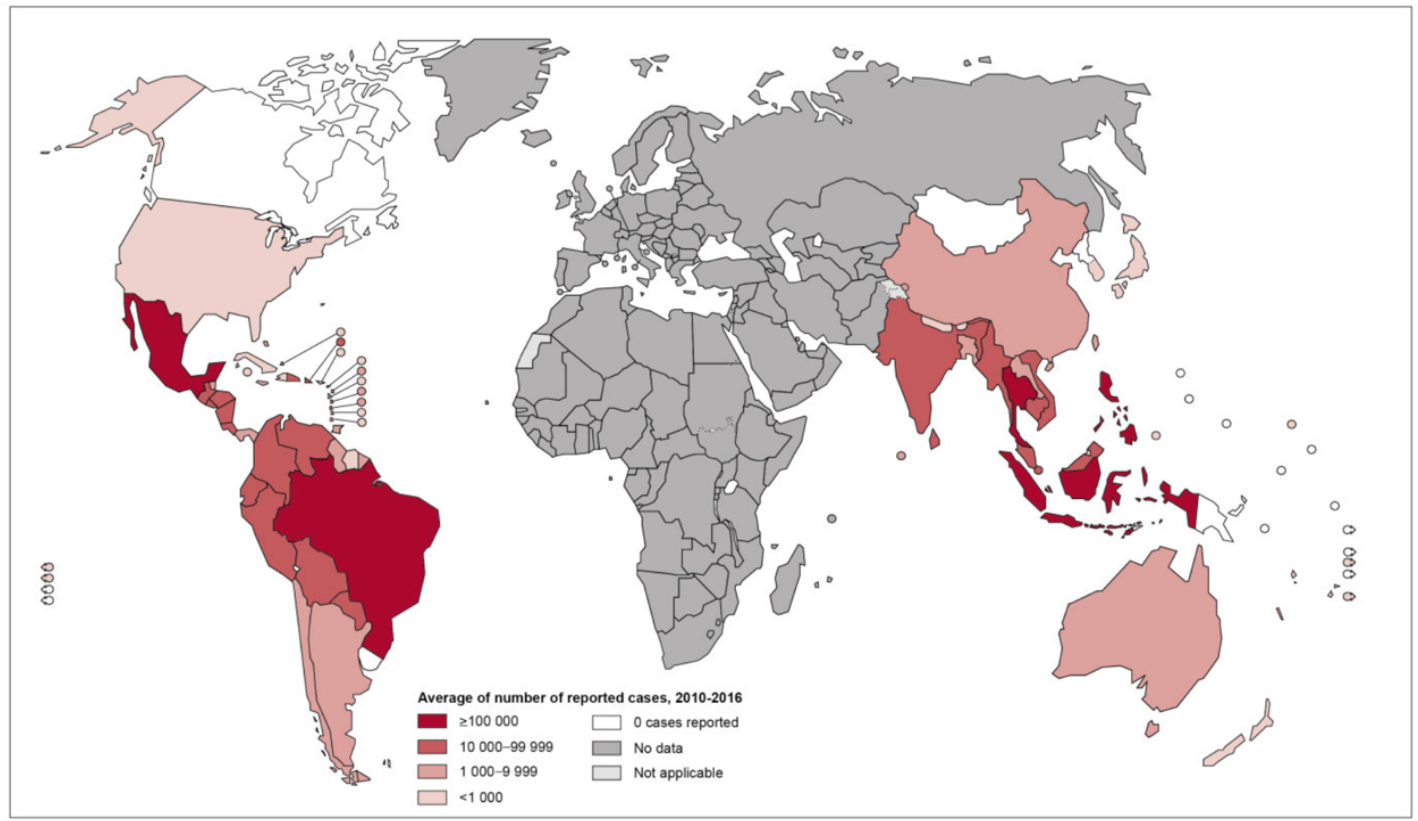

Figure 1. World distribution of Dengue in 2016

https://www.who.int/denguecontrol/epidemiology/en/ 


\section{Dengue disease}

DENV infections are caused by four closely related serotypes (DENV 1, 2, 3, 4). Immune responses following primary DENV infection fully protect against the DENV serotype that caused the primary infection, but only partially, and transiently, protect against heterologous serotypes (6). DENV infection may result in asymptomatic or symptomatic manifestations. Symptomatic cases constitute $\sim 20 \%$ of infections. Symptomatic infections result in a broad spectrum of effects including febrile illness , which may be uncomplicated (dengue fever, DF) or progress to a potentially fatal disease, such as dengue hemorrhagic fever (DHF) or dengue shock syndrome (DSS) $(7,8)$. DF is a mild "flu-like" illness, which could appear 3-10 days after virus infection via a mosquito bite. Other symptoms associated with DF are retro-orbital pain, intense headache, intense joint and muscle pain and nausea $(9,10)$. Even though a majority of patients are able to recover completely after the febrile phase, some $(\sim 3 \%)$ develop severe disease. DHF is distinguished from DF by the appearance of vascular permeability, plasma leakage and bleeding manifestations. Thrombocytopenia and coagulopathy are also associated with severe disease. Severe plasma leakage can result in hypovolemic shock (4). These symptoms may lead to organ impairment and death of the patient. DHF is often associated with hepatomegaly and histopathological reports of human fatal dengue cases indicate that the liver, spleen and lymph nodes are target organs of infection (11). 


\section{Factors contributing to Dengue Disease pathogenesis}

Various factors are considered to contribute to the dengue disease severity. For example, virus virulence, preexisting dengue antibodies, immune dysregulation and host genetic susceptibility are factors known to be associated with dengue pathogenesis. Paradoxically, severe dengue symptoms (e.g., plasma leakage) are not observed when the viremia is at the highest, but when the virus is being cleared, suggesting that host immune responses play an adverse role in disease pathogenesis (12). Some of the components that are known to contribute to dengue pathogenesis are discussed below.

\section{Antibody-dependent enhancement}

Multiple cohort studies have identified secondary DENV infection as an epidemiological risk factor for severe dengue (13-15). However, a majority of tertiary and quaternary infections are clinically silent or mild (16). A potential reason for increased risk with the secondary infection is the presence of non-neutralizing, crossreactive antibodies generated against the primary infection. These antibodies bind the second virus (heterologous serotype) and facilitate infection via $\mathrm{Fc} \gamma$ receptors expressed on cell surfaces. This phenomenon is known as "Antibody-dependent enhancement (ADE)" (Fig 2). Thus, increased numbers of virus-infected cells due to ADE may increase disease pathogenesis in secondary infection $(17,18)$. The only licensed vaccine against dengue, Dengvaxia, increased the risk of severe disease in children when they were subsequently infected by DENV. The vaccination itself acted as a primary infection inducing antibody production, which enhanced virus infection 
in the event of a secondary infection, perhaps via ADE (19).
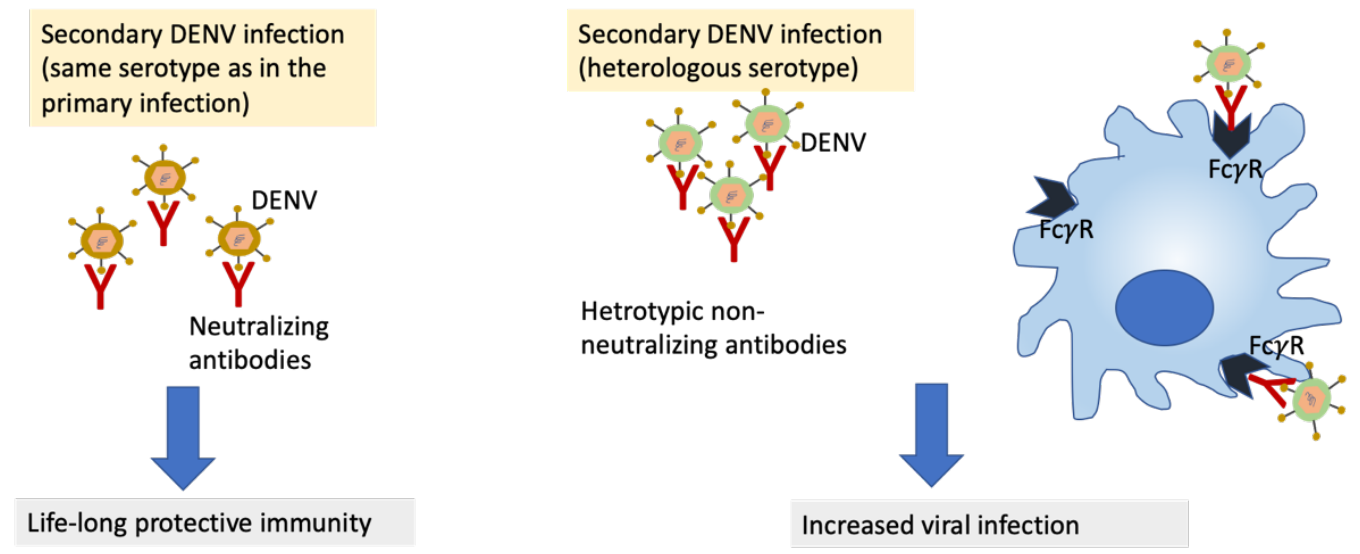

Figure 2. The mechanism of Antibody-Dependent Enhancement

(Adapted from Puccionoi-Sohler et al., 2015)

\section{T cell mediated immunity}

$\mathrm{T}$ cell mediated immune responses during the secondary infection have been proposed to contribute to the severity of dengue disease (18). Virus-specific CD8+ cytotoxic T lymphocytes (CTL) directly lyse virus-infected antigen-presenting cells (APC). Additionally, CTL secrete cytokines such as IFN $\gamma$, which enhances cytotoxicity of CTLs and increases their motility (20). Other cytokines secreted by T cells, such as IL-8 and IL-9, stimulate recruitment and activation of other immune cells. Thus, T cells are important for controlling DENV infections. However, with the encounter of a secondary DENV infection there is a tendency toward expansion of the memory $\mathrm{T}$ cell repertoire from the previous infection. These $\mathrm{T}$ cells may exhibit a lower avidity to the current serotype and induce "skewed" immune responses, which could be deleterious to the host (18). These responses may result in an altered cytokine profile which could exacerbate the disease. This is evidenced by the detection of 
increased $\mathrm{T}$ cell activation in DHF than in DF patients. Patients experiencing severe dengue have altered cytokine profiles as compared to patients exhibiting milder disease (21). Taken together, these data indicate that the level of $\mathrm{T}$ cell response correlates with the disease severity (22).

\section{Cytokine dysregulation}

During primary DENV infection inflammatory cytokines are secreted from infected cells, which is important for attracting NK cells, $\mathrm{T}$ and $\mathrm{B}$ cells and the initiation of adaptive immunity. The level of cytokines released during primary infection is not likely detrimental to the host. However, during secondary infection cross-reactive $\mathrm{T}$ cells from the primary infection are expanded and secrete inflammatory cytokines rapidly (18). Studies have demonstrated that proinflammatory cytokines and vasoactive cytokines are elevated in patients with DHF (23). Levels of TNF $\alpha$, IL-1 $\beta$, IFN $\gamma$, IL-8, IL-6, IL-10 and free VEGF-A were elevated in patients with DHF compared to patients with DF $(10,18,24-26)$. The magnitude of the cytokine levels correlated with the disease severity $(18,23)$. These cytokines, especially $\mathrm{TNF} \alpha$, increase endothelial vascular permeability contributing to the plasma leakage syndrome $(23,27)$.

\section{Complement activation}

Complement activation as a result of immune complexes (virus-antibody) or immune activation and cytokine production has been proposed to be involved in the pathogenesis of plasma leakage in DHF (28). A significant reduction in complement protein levels with a concurrent increase in complement fragments was reported in 
patients with DHF. The degree of the complement activation correlated with the severity of the disease (29). Certain complement fragments such as C3a and C5a are known to enhance vascular permeability contributing to the plasma leakage seen in DHF. Antibodies to the DENV non-structural protein 1 (NS1) were demonstrated to form immune complexes with DENV NS1 protein in the circulation and also on the surface of infected cells leading to complement activation (30). Therefore, rapid complement activation during secondary infection is likely to contribute to the severity of dengue disease.

\section{Viral virulence}

Differences in virulence in naturally circulating DENV strains and serotypes are speculated to contribute to dengue disease (31). Viral genetic differences are reported to be associated with differences in virulence between DENV strains (32-34). A study done on children with acute DENV infections reported secondary DENV2 caused more severe disease than DENV1 or DENV4, suggesting that virus genotype affects outcome (35). Enhanced pathogenicity was attributable to increased replication of DENV2 compared to DENV1. Another study found that primary infection with DENV3 from the south east Asia region (SEA) and secondary infection with DENV2, DENV3 and DENV4 also from the SEA region, as well as DENV2 and DENV3 from non-SEA region increased the risk of severe dengue disease (36). To make things more complicated, extensive diversity is seen within DENV serotypes resulting in various genotypes. For example, among different DENV1 strains isolated from the 2014 Dengue outbreak in China (DENV1A-E), DENV1B had the highest replication efficiency and the highest mortality in suckling mice (37). Therefore, virulence of 
different DENV strains is directly associated with disease severity.

\section{Other factors}

Genetics of the host may also contribute to disease severity. Genome wide association studies found polymorphisms within MICB (Major histocompatibility complex class I polypeptide-related sequence B) and PLCE1 (phospholipase C, epsilon 1) significantly associated with DSS (38). Human leucocyte antigen (HLA) is one of the genetic factors that impacts the immune responses against DENV. DENV infection has been reported to induce the expression of HLA class I and II molecules on infected cells. Thus, immune responses generated from peptides presented by HLA may be responsible for the immunopathology of DENV infection (39). A study done on DENV patients and healthy controls from Malaysia reported that HLA-B*53 is associated with disease susceptibility, while HLA-A*03 and HLA-B*10 may confer protection (40).

Furthermore, cross-reactivity of anti-NS1 antibodies with thrombocytes, endothelial cells and fibrinogen is believed to contribute to hemorrhage and coagulopathy (41). Some chronic diseases such as diabetes mellitus also likely increase the risk for severe dengue disease (42). One speculation for this effect is the further damage of the impaired vasculature in diabetic patients during dengue. Overall severe dengue disease is a result of complex interactions between the virus and the host. However, dissecting the role of some host factors such as host immune responses is complicated by the lack of an experimental animal model that is able to mimic the full spectrum of the disease seen in humans. 


\section{DENV structure}

DENV is an icosahedral, lipid-enveloped virus. Mature DENV is reported to be $500 \AA$ in diameter (43). DENV contains a positive-sense single-stranded RNA genome of $10.5 \mathrm{~kb}$, which can be directly translated inside a living cell. DENV RNA is a dynamic molecule and adapts both linear and circular conformations in an infected cell (44). The DENV genome codes for 3 structural proteins and 7 non-structural proteins (Fig 3).

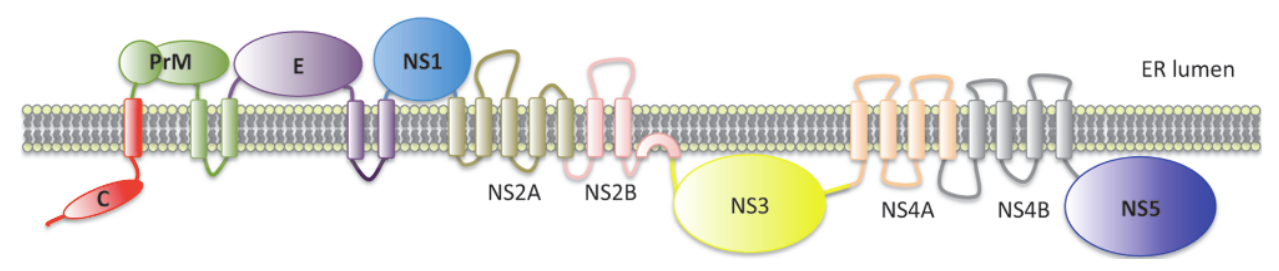

Figure 3. Structural and non-structural proteins encoded by the DENV genome (Maririang et al., 2013)

The DENV structure is formed by three structural proteins coded by its genome. They are the capsid protein $(\mathrm{C})$, prM (membrane) and the envelope protein (E). The DENV genome also encodes for seven nonstructural proteins: NS1, NS2A, NS2B, NS3, NS4A, NS4B and NS5. Capsid (C) is a highly basic protein with 100 amino acids. Capsid protein is involved in packaging the viral genome and forming the nucleocapsid core $(45,46)$. prM ( $\sim 165$ amino acids $)$ and $\mathrm{E}(\sim 495$ amino acids $)$ are glycoproteins each having two transmembrane helices (43). prM is cleaved by host 
furin during the maturation of virus particles yielding the pr peptide and the M protein (47). The E protein contains one or more cellular receptor binding sites (48).

NS1 protein is involved in virus replication, and also can reside on the host cell surface or be released from the cell in a hexameric conformation $(49,50)$. NS1 can be used as a diagnostic marker to detect early dengue since it is secreted into the blood before the production of DENV-specific antibodies (51). The concentration of NS1 in serum correlates with severity of the disease (30). NS1 is also known to activate the NF- $\mathbf{B}$ pathway downstream of TLR4 (52).

NS2A is a hydrophobic protein that is cleaved by host proteases at the N terminus and by the DENV protease NS3, at the C terminus (53). NS2A is reported to be involved in viral replication, virus assembly, immune evasion and disease pathogenesis (54). NS2B is also a hydrophobic protein that acts as a cofactor for NS3 proteolytic activity (55). The N-terminal 180 acids of NS3 contains a serine protease domain (56). The C-terminal domain of NS3 is involved in viral RNA replication (57). The region spanning from amino acids 180 to 618 of NS3 contains a RNA helicase and a NTPase motif $(57,58)$.

NS4A is cleaved from NS3 at the N terminus and from the $2 \mathrm{~K}$ fragment at the C terminus by NS3. NS4A is essential for viral replication (59). NS4B is a hydrophobic transmembrane protein which is important for viral replication (60). However, studies on the exact role of NS4B in viral replication and pathogenesis are still needed. NS5 is the largest protein encoded by the DENV genome. NS5 has methyltransferase and RNA-dependent RNA polymerase functions. NS5 is also reported to be translocated to the host cell nucleus where it manipulates the host cell's 
splicing machinery (61). Interestingly, NS5 and other DENV proteins are implicated in host innate immune evasion by different strategies, which will be discussed later in the Chapter 1.

\section{DENV life cycle}

DENV infects a range of human cells including dendritic cells, macrophages, monocytes, B cells, T cells, hepatocytes, epithelial cells and endothelial cells (62-64). DENV enters human cells via receptor mediated endocytosis. DC-SIGN, mannose receptor, $\mathrm{CD} 14, \mathrm{Fc} \gamma$ receptor and heparan sulfate are known to act as receptors for DENV attachment and entry (65-69). The acidic $\mathrm{pH}$ in endosomes triggers fusion of viral and endosomal membranes releasing the viral genome into the cytosol $(70,71)$. Since the DENV genome is a plus strand RNA, protein translation can initiate immediately following the release of the genome. The genome is translated into one polypeptide that gets processed into individual viral proteins by host and viral proteases. Viral replication and assembly take place in membranous structures associated with the ER (72). Immature virus particles contain E, prM, the lipid membrane and the nucleocapsid. Since these immature particles are not able to induce host cell fusion, they are noninfectious. After assembly, the immature virions exit from the ER through the trans-Golgi network (Fig 4). During this process, they undergo protease- and $\mathrm{pH}$-dependent maturation rendering the virions mature $(73,74)$. The $\mathrm{E}$ protein undergoes positional reorganization and prM is cleaved by the cellular endoprotease, furin (47). The resulting small membrane-anchored M portion remains associated with the virion. The cleavage of prM and the disassociation of the pr 
peptide are important for fusion with the host cell membranes during subsequent virion entry into a new cell $(47,70)$.

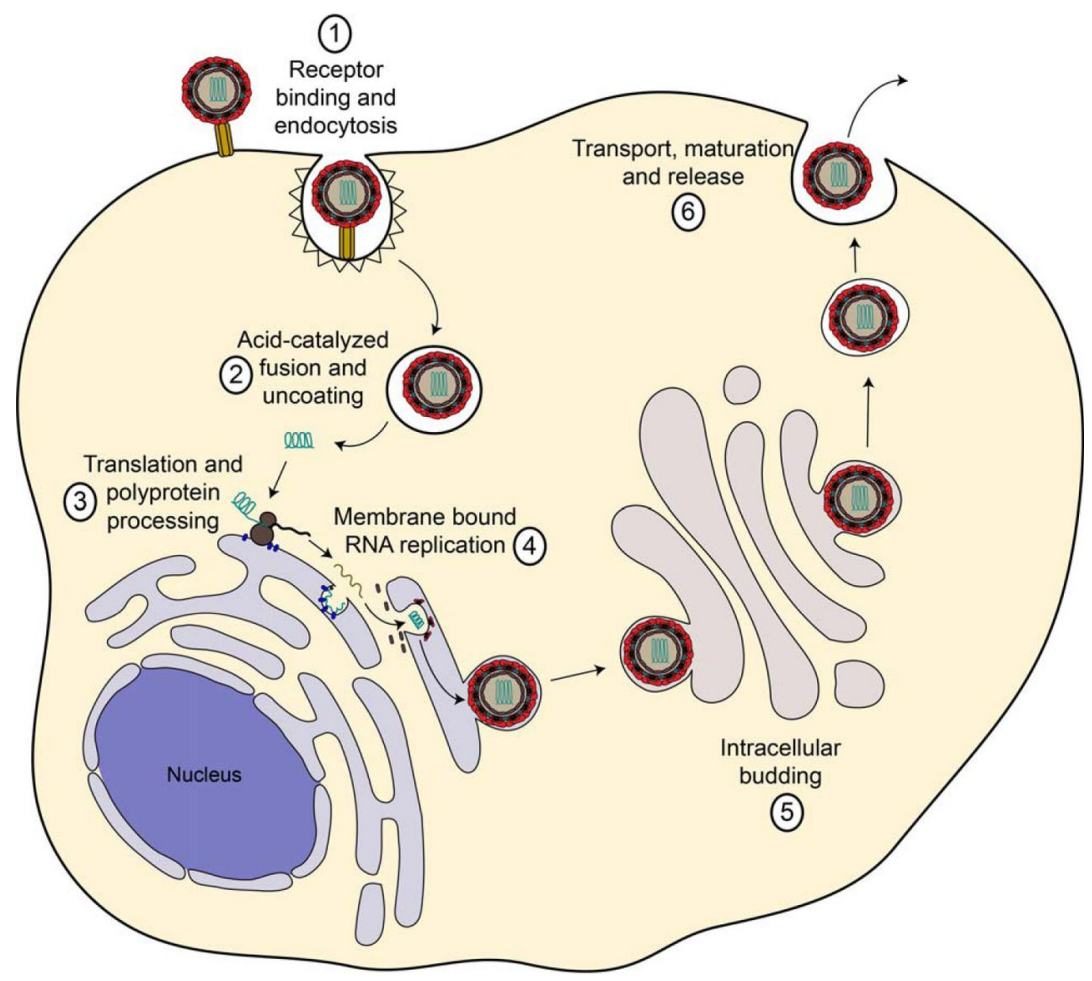

Figure 4. DENV life cycle. The DENV attaches to receptors on host cells and internalizes by receptor mediated endocytosis. In endosomes, due to the acidic $\mathrm{pH}$, viral and endosomal membranes fuse, releasing the viral genome into the cytosol. Viral RNA translation and replication take place at the membranous structures associated with the endoplasmic reticulum. Assembled viral particles exit the host cell via the trans-Golgi apparatus. (Adapted from Gerald G et al., 2017)

\section{DENV evasion of innate immune responses}

During the DENV life cycle, viral RNA and viral proteins (pathogenassociated molecular patterns/ PAMPs) are released into the host cell cytosol. Pattern 
recognition receptors in the host cell such as TLR3 (Toll like receptor 3), TLR4 (Toll like receptor 4), RIG-I (Retinoic acid-inducible gene 1 like receptor) and MDA-5 (Melanoma differentiation associated protein 5) recognize these PAMPs and initiate signaling cascades that culminate in the production of antiviral effectors such as interferons (IFN) and pro-inflammatory cytokines. Once secreted, IFNs will bind to IFNRs (IFN receptor) on both infected and uninfected cells and signal for the induction of "interferon-stimulated genes" (ISG) via the JAK-STAT (Janus kinaseSignal transducer and activator of transcription) pathway (75-77). DENV has evolved different strategies to inhibit these signaling cascades to evade host immune responses (78).

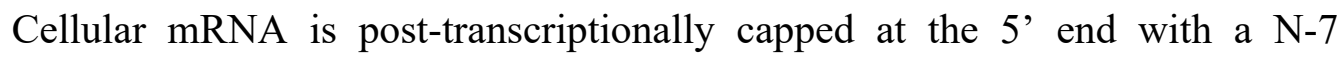
methyl guanosine and one or two 2'-O methyl nucleotides $(79,80)$. DENV NS5 also catalyzes both N-7 and 2'-O methylations sequentially to mimic cellular mRNA and to hide sensing by host Pattern Recognition Receptors/ PRRs (81-83).

DENV generate detectable amounts of intracellular dsRNA as an intermediate of their replication (84). The localization of DENV dsRNA is important for recognition by PRRs. However, DENV RNA is reported to be concealed in DENVinduced membranous structures up to $72 \mathrm{hrs}$ post-infection (85). This may give DENV an added advantage to hide from host immune responses. Once these RNA species leak into the cytosol they can be recognized by RIG-I/MDA-5 and TLR3 receptors. RIG-I/MDA-5 signal for IFN production, NF- $\mathbf{k B}$ and MAPK activation via the mitochondrial associated protein MAVS (Mitochondrial antiviral signaling protein). It has been reported that DENV NS4A interacts with MAVS and blocks the 
association of RIG-I and MAVS, inhibiting IFN production (86). Another study found that DENV NS2A and NS4B inhibited RIG-I/MDA-5-mediated IFN production by blocking TBK1 activation downstream of MAVS (87).

STING (Stimulator of IFN genes) is an adapter molecule in the cGAS-DNA (Cyclic GMP-AMP synthase) sensing pathway. Activation of the cGAS/STING pathway leads to the production of IFNs via IRF phosphorylation and proinflammatory cytokine production via NF- $\mathbf{B B}$ activation (88). STING is also known to interact with RIG-I and MAVS to enhance anti-viral responses $(89,90)$. DENV NS2B3 protease complex is known to interact with and cleave STING, downregulating IFN responses (91). DENV protease cofactor NS2B is also known to decrease cGAS levels by interacting with it and promoting cGAS for autophagosome-mediated degradation (92).

DENV NS4B protein inhibits IFN-induced STAT1 phosphorylation and nuclear translocation, impairing the transcriptional activation of the ISGF3 (Interferon stimulated gene factor 3) complex that is important for the expression of antiviral genes (93). Moreover, DENV NS5 is known to interact with STAT2 and promote it for proteasomal degradation, impeding ISGF3 activation (94).

The mitochondrion has emerged as an important organelle in antiviral signaling. DENV has been reported to manipulate mitochondrial dynamics to counteract antiviral responses and establish infections. DENV NS2B3 interacted with and cleaved mitochondrial proteins MFN1 and MFN2 (95). This cleavage resulted in fission of mitochondria and inhibition of MAVS-mediated antiviral responses. In contrast, studies done by our group have shown that mitochondrial elongation as a 
result of decreasing levels of mitochondrial protein DRP1 resulted in increased viral replication (96). Consistent with these results another study demonstrated that DENV NS4B inhibited DRP1 activation leading to mitochondrial elongation and impairment of RIG-I-mediated immune responses (97).

DENV was also shown to block NF- $\mathbf{B}$ activation downstream of TNFR and TLR3 by unknown mechanisms $(98,99)$. The attenuation of NF- $\mathbf{B}$ activation resulted in diminished pro-inflammatory cytokine production. Nevertheless, how this inhibition was achieved by DENV was not known.

Collectively, these studies demonstrate that DENV proteins and RNA antagonize host innate immune responses and further damage infected cells. It's plausible to assume that DENV may defeat host immunity at the first line of defense. The inhibition of innate immune mechanisms in the initial phase of infection may contribute to disease pathogenesis. However, there are still many unanswered questions related to the evasion of innate immune mechanisms by DENV.

\section{Objectives of the dissertation}

DENV has evolved efficient strategies to counteract innate immune mechanisms. Particularly, individual DENV proteins are shown to target crucial host proteins to inhibit signaling pathways. RIPK1 (Receptor interacting protein kinase 1) has emerged as a central regulator in cell death and inflammation. Various viruses have evolved strategies to inhibit RIPK1-mediated signaling. However, no studies had been done to investigate RIPK1-mediated signaling in DENV infection. We observed a decrease in RIPK1 levels during DENV infection. Therefore, the overall goal of this 
dissertation was to understand the effect of RIPK1-mediated signaling in DENV infection. In particular, we hypothesized that RIPK1-mediated signaling will be inhibited by DENV. The specific aims of this study are as follow:

Specific aim 1: Determining the mechanism by which DENV infection causes decreased levels of RIPK1

Specific aim 2: Determining the role of DENV in RIPK1 mediated NF- $\mathbf{k B}$ activation Specific aim 3 Determining the role of RIPK1 in cell death during DENV infection 


\section{References}

1. Bhatt S, Gething PW, Brady OJ, Messina JP, Farlow AW, Moyes CL, et al. The global distribution and burden of dengue. Nature [Internet]. 2013;496(7446):504-7. Available from: http://dx.doi.org/10.1038/nature12060

2. Wilder-Smith A, Ooi E-E, Vasudevan SG, Gubler DJ. Update on dengue: epidemiology, virus evolution, antiviral drugs, and vaccine development. Curr Infect Dis Rep. 2010 May;12(3):157-64.

3. Islam R, Salahuddin M, Ayubi MS, Hossain T, Majumder A, Taylor-Robinson AW, et al. Dengue epidemiology and pathogenesis: images of the future viewed through a mirror of the past. Virol Sin. 2015 Oct;30(5):326-43.

4. Jing Q, Wang M. Dengue epidemiology. Glob Heal J. 2019;3(2):37-45.

5. Solomon T, Mallewa M. Dengue and other emerging flaviviruses. J Infect. 2001 Feb;42(2):104-15.

6. SABIN AB. Research on dengue during World War II. Am J Trop Med Hyg. 1952 Jan;1(1):30-50.

7. Teixeira MG, Barreto ML. Diagnosis and management of dengue. BMJ. 2009 Nov;339:b4338.

8. Guzmán MG, Kourí G. Dengue: an update. Lancet Infect Dis. 2002 Jan;2(1):33-42.

9. Kautner I, Robinson MJ, Kuhnle U. Dengue virus infection: epidemiology, pathogenesis, clinical presentation, diagnosis, and prevention. J Pediatr. 1997 Oct;131(4):516-24.

10. Kalayanarooj S, Vaughn DW, Nimmannitya S, Green S, Suntayakorn S, Kunentrasai N, et al. Early clinical and laboratory indicators of acute dengue illness. J Infect Dis. 1997 Aug;176(2):313-21.

11. Póvoa TF, Alves AMB, Oliveira CAB, Nuovo GJ, Chagas VLA, Paes M V. The pathology of severe dengue in multiple organs of human fatal cases: histopathology, ultrastructure and virus replication. PLoS One. 2014;9(4):e83386.

12. Green S, Rothman A. Immunopathological mechanisms in dengue and dengue hemorrhagic fever. Curr Opin Infect Dis. 2006;19(5):429-36. 
13. Kouri GP, Guzmán MG, Bravo JR, Triana C. Dengue haemorrhagic fever/dengue shock syndrome: lessons from the Cuban epidemic, 1981. Bull World Health Organ. 1989;67(4):375-80.

14. Burke DS, Nisalak A, Johnson DE, Scott RM. A prospective study of dengue infections in Bangkok. Am J Trop Med Hyg. 1988 Jan;38(1):172-80.

15. Endy TP, Nisalak A, Chunsuttiwat S, Libraty DH, Green S, Rothman AL, et al. Spatial and temporal circulation of dengue virus serotypes: a prospective study of primary school children in Kamphaeng Phet, Thailand. Am J Epidemiol. $2002 \mathrm{Jul} ; 156(1): 52-9$.

16. Gibbons R V, Kalanarooj S, Jarman RG, Nisalak A, Vaughn DW, Endy TP, et al. Analysis of repeat hospital admissions for dengue to estimate the frequency of third or fourth dengue infections resulting in admissions and dengue hemorrhagic fever, and serotype sequences. Am J Trop Med Hyg. 2007 Nov;77(5):910-3.

17. Halstead SB. Neutralization and antibody-dependent enhancement of dengue viruses. Adv Virus Res. 2003;60:421-67.

18. Mathew A, Rothman AL. Understanding the contribution of cellular immunity to dengue disease pathogenesis. Immunol Rev. 2008;225(1):300-13.

19. Borges MB, Marchevsky RS, Carvalho Pereira R, da Silva Mendes Y, Almeida Mendes LG, Diniz-Mendes L, et al. Detection of post-vaccination enhanced dengue virus infection in macaques: An improved model for early assessment of dengue vaccines. PLoS Pathog. 2019 Apr;15(4):e1007721.

20. Bhat P, Leggatt G, Waterhouse N, Frazer IH. Interferon- $\gamma$ derived from cytotoxic lymphocytes directly enhances their motility and cytotoxicity. Cell Death Dis. 2017 Jun;8(6):e2836.

21. Sellahewa KH. Pathogenesis of Dengue Haemorrhagic Fever and Its Impact on Case Management. 2013;2013.

22. Zivna I, Green S, Vaughn DW, Kalayanarooj S, Stephens HAF, Chandanayingyong D, et al. T cell responses to an HLA-B*07-restricted epitope on the dengue NS3 protein correlate with disease severity. J Immunol. 2002 Jun;168(11):5959-65.

23. Rothman AL. Immunity to dengue virus: A tale of original antigenic sin and tropical cytokine storms. Nat Rev Immunol [Internet]. 2011;11(8):532-43. Available from: http://dx.doi.org/10.1038/nri3014 
24. Green S, Vaughn DW, Kalayanarooj S, Nimmannitya S, Suntayakorn S, Nisalak A, et al. Elevated plasma interleukin-10 levels in acute dengue correlate with disease severity. J Med Virol. 1999 Nov;59(3):329-34.

25. Hober D, Poli L, Roblin B, Gestas P, Chungue E, Granic G, et al. Serum levels of tumor necrosis factor-alpha (TNF-alpha), interleukin-6 (IL-6), and interleukin-1 beta (IL-1 beta) in dengue-infected patients. Am J Trop Med Hyg. 1993 Mar;48(3):324-31.

26. Mustafa AS, Elbishbishi EA, Agarwal R, Chaturvedi UC. Elevated levels of interleukin-13 and IL-18 in patients with dengue hemorrhagic fever. FEMS Immunol Med Microbiol. 2001 Apr;30(3):229-33.

27. Anderson R, Wang S, Osiowy C, Issekutz AC. Activation of endothelial cells via antibody-enhanced dengue virus infection of peripheral blood monocytes. J Virol. 1997 Jun; 71(6):4226-32.

28. Avirutnan P, Malasit P, Seliger B, Bhakdi S, Husmann M. Dengue virus infection of human endothelial cells leads to chemokine production, complement activation, and apoptosis. J Immunol. 1998 Dec;161(11):6338-46.

29. Malasit P. Complement and dengue haemorrhagic fever/shock syndrome. Southeast Asian J Trop Med Public Health. 1987 Sep;18(3):316-20.

30. Avirutnan P, Punyadee N, Noisakran S, Komoltri C, Thiemmeca S, Auethavornanan K, et al. Vascular leakage in severe dengue virus infections: a potential role for the nonstructural viral protein NS1 and complement. J Infect Dis. 2006 Apr;193(8):1078-88.

31. Prommalikit $\mathrm{O}$, Thisyakorn U. DENGUE VIRUS VIRULENCE AND DISEASES SEVERITY. Southeast Asian J Trop Med Public Health. 2015;46 Suppl 1:35-42.

32. Cologna R, Rico-Hesse R. American genotype structures decrease dengue virus output from human monocytes and dendritic cells. J Virol. 2003 Apr;77(7):3929-38.

33. Leitmeyer KC, Vaughn DW, Watts DM, Salas R, Villalobos I, Chacon de, et al. Dengue virus structural differences that correlate with pathogenesis. J Virol. 1999 Jun;73(6):4738-47.

34. Sánchez IJ, Ruiz BH. A single nucleotide change in the E protein gene of dengue virus 2 Mexican strain affects neurovirulence in mice. J Gen Virol. 1996 Oct; 77 ( Pt 10:2541-5. 
35. Vaughn DW, Green S, Kalayanarooj S, Innis BL, Nimmannitya S, Suntayakorn S, et al. Dengue Viremia Titer, Antibody Response Pattern, and Virus Serotype Correlate with Disease Severity. (1):2-9.

36. Soo K, Khalid B, Ching S, Chee H. Meta-Analysis of Dengue Severity during Infection by Different Dengue Virus Serotypes in Primary and Secondary Infections. 2016;4-14.

37. Zou C, Huang C, Zhang J, Wu Q, Ni X, Sun J, et al. Virulence difference of five type I dengue viruses and the intrinsic molecular mechanism. PLoS Negl Trop Dis. 2019;13(3).

38. Khor CC, Chau TNB, Pang J, Davila S, Long HT, Ong RTH, et al. Genomewide association study identifies susceptibility loci for dengue shock syndrome at MICB and PLCE1. Nat Genet. 2011 Oct;43(11):1139-41.

39. Wang WH, Urbina AN, Chang MR, Assavalapsakul W, Lu PL, Chen YH, et al. Dengue hemorrhagic fever - A systemic literature review of current perspectives on pathogenesis, prevention and control. J Microbiol Immunol Infect [Internet]. 2020;(xxxx). Available from: https://doi.org/10.1016/j.jmii.2020.03.007

40. Appanna R, Ponnampalavanar S, Lum Chai See L, Sekaran SD. Susceptible and protective HLA class 1 alleles against dengue fever and dengue hemorrhagic fever patients in a Malaysian population. PLoS One. 2010 Sep;5(9).

41. Nasar S. Dengue proteins with their role in pathogenesis, and strategies for developing an effective anti - dengue treatment : A review. 2019;(November):115 .

42. Lee I-K, Hsieh C-J, Lee C-T, Liu J-W. Diabetic patients suffering dengue are at risk for development of dengue shock syndrome/severe dengue: Emphasizing the impacts of co-existing comorbidity(ies) and glycemic control on dengue severity. J Microbiol Immunol Infect. 2020 Feb;53(1):69-78.

43. Kuhn RJ, Zhang W, Rossmann MG, Pletnev S V, Corver J, Lenches E, et al. Structure of dengue virus: implications for flavivirus organization, maturation, and fusion. Cell. 2002 Mar;108(5):717-25.

44. Villordo SM, Filomatori C V, Sánchez-Vargas I, Blair CD, Gamarnik A V. Dengue virus RNA structure specialization facilitates host adaptation. PLoS Pathog. 2015 Jan;11(1):e1004604.

45. Dokland T, Walsh M, Mackenzie JM, Khromykh AA, Ee K-H, Wang S. West Nile virus core protein; tetramer structure and ribbon formation. Structure. 2004 Jul;12(7):1157-63. 
46. Ma L, Jones CT, Groesch TD, Kuhn RJ, Post CB. Solution structure of dengue virus capsid protein reveals another fold. Proc Natl Acad Sci U S A. 2004 Mar;101(10):3414-9.

47. Stadler K, Allison SL, Schalich J, Heinz FX. Proteolytic activation of tick-borne encephalitis virus by furin. J Virol. 1997 Nov;71(11):8475-81.

48. Pokidysheva E, Zhang Y, Battisti AJ, Bator-Kelly CM, Chipman PR, Xiao C, et al. Cryo-EM reconstruction of dengue virus in complex with the carbohydrate recognition domain of DC-SIGN. Cell. 2006 Feb;124(3):485-93.

49. Flamand M, Megret F, Mathieu M, Lepault J, Rey FA, Deubel V. Dengue virus type 1 nonstructural glycoprotein NS1 is secreted from mammalian cells as a soluble hexamer in a glycosylation-dependent fashion. J Virol. 1999 Jul;73(7):6104-10.

50. Gutsche I, Coulibaly F, Voss JE, Salmon J, d'Alayer J, Ermonval M, et al. Secreted dengue virus nonstructural protein NS1 is an atypical barrel-shaped high-density lipoprotein. Proc Natl Acad Sci U S A. 2011 May;108(19):8003-8.

51. Kassim FM, Izati MN, TgRogayah TAR, Apandi YM, Saat Z. Use of dengue NS1 antigen for early diagnosis of dengue virus infection. Southeast Asian J Trop Med Public Health. 2011 May;42(3):562-9.

52. Modhiran N, Watterson D, Muller DA, Panetta AK, Sester DP, Liu L, et al. Dengue virus NS1 protein activates cells via Toll-like receptor 4 and disrupts endothelial cell monolayer integrity. Sci Transl Med. 2015 Sep;7(304):304ra142.

53. Falgout B, Markoff L. Evidence that flavivirus NS1-NS2A cleavage is mediated by a membrane-bound host protease in the endoplasmic reticulum. J Virol. 1995 Nov;69(11):7232-43.

54. Gopala Reddy SB, Chin W-X, Shivananju NS. Dengue virus NS2 and NS4: Minor proteins, mammoth roles. Biochem Pharmacol. 2018 Aug;154:54-63.

55. Falgout B, Pethel M, Zhang YM, Lai CJ. Both nonstructural proteins NS2B and NS3 are required for the proteolytic processing of dengue virus nonstructural proteins. J Virol. 1991 May;65(5):2467-75.

56. Wengler G, Czaya G, Färber PM, Hegemann JH. In vitro synthesis of West Nile virus proteins indicates that the amino-terminal segment of the NS3 protein contains the active centre of the protease which cleaves the viral polyprotein after multiple basic amino acids. J Gen Virol. 1991 Apr;72 ( Pt 4):851-8. 
57. Xu T, Sampath A, Chao A, Wen D, Nanao M, Chene P, et al. Structure of the Dengue virus helicase/nucleoside triphosphatase catalytic domain at a resolution of 2.4 A. J Virol. 2005 Aug;79(16):10278-88.

58. Luo D, Xu T, Watson RP, Scherer-Becker D, Sampath A, Jahnke W, et al. Insights into RNA unwinding and ATP hydrolysis by the flavivirus NS3 protein. EMBO J. 2008 Dec;27(23):3209-19.

59. Miller S, Sparacio S, Bartenschlager R. Subcellular localization and membrane topology of the Dengue virus type 2 Non-structural protein 4B. J Biol Chem. 2006 Mar;281(13):8854-63.

60. Płaszczyca A, Scaturro P, Neufeldt CJ, Cortese M, Cerikan B, Ferla S, et al. A novel interaction between dengue virus nonstructural protein 1 and the NS4A$2 \mathrm{~K}-4 \mathrm{~B}$ precursor is required for viral RNA replication but not for formation of the membranous replication organelle. PLoS Pathog. 2019 May;15(5):e1007736.

61. De Maio FA, Risso G, Iglesias NG, Shah P, Pozzi B, Gebhard LG, et al. The Dengue Virus NS5 Protein Intrudes in the Cellular Spliceosome and Modulates Splicing. PLoS Pathog. 2016 Aug;12(8):e1005841.

62. King AD, Nisalak A, Kalayanrooj S, Myint KS, Pattanapanyasat K, Nimmannitya S, et al. B cells are the principal circulating mononuclear cells infected by dengue virus. Southeast Asian J Trop Med Public Health [Internet]. 1999 Dec;30(4):718-728. Available from: http://europepmc.org/abstract/MED/10928366

63. Silveira GF, Wowk PF, Cataneo AHD, dos Santos PF, Delgobo M, Stimamiglio $\mathrm{MA}$, et al. Human $\mathrm{T}$ Lymphocytes Are Permissive for Dengue Virus Replication. J Virol. 2018;92(10):e02181-17.

64. Martina BEE, Koraka P, Osterhaus ADME. Dengue virus pathogenesis: An integrated view. Clin Microbiol Rev. 2009;22(4):564-81.

65. Navarro-Sanchez E, Altmeyer R, Amara A, Schwartz O, Fieschi F, Virelizier JL, et al. Dendritic-cell-specific ICAM3-grabbing non-integrin is essential for the productive infection of human dendritic cells by mosquito-cell-derived dengue viruses. EMBO Rep. 2003 Jul;4(7):723-8.

66. Miller JL, de Wet BJM, Martinez-Pomares L, Radcliffe CM, Dwek RA, Rudd $\mathrm{PM}$, et al. The mannose receptor mediates dengue virus infection of macrophages. PLoS Pathog. 2008 Feb;4(2):e17.

67. Chen Y, Maguire T, Hileman RE, Fromm JR, Esko JD, Linhardt RJ, et al. Dengue virus infectivity depends on envelope protein binding to target cell 
heparan sulfate. Nat Med. 1997 Aug;3(8):866-71.

68. Chen YC, Wang SY, King CC. Bacterial lipopolysaccharide inhibits dengue virus infection of primary human monocytes/macrophages by blockade of virus entry via a CD14-dependent mechanism. J Virol. 1999 Apr;73(4):2650-7.

69. Guzman MG, Alvarez M, Halstead SB. Secondary infection as a risk factor for dengue hemorrhagic fever/dengue shock syndrome: an historical perspective and role of antibody-dependent enhancement of infection. Arch Virol. 2013 Jul;158(7):1445-59.

70. Harrison SC. Viral membrane fusion. Nat Struct Mol Biol. 2008 Jul;15(7):6908.

71. Stiasny K, Heinz FX. Flavivirus membrane fusion. J Gen Virol. 2006 Oct;87(Pt 10):2755-66.

72. Chatel-Chaix L, Bartenschlager R. Dengue virus- and hepatitis C virus-induced replication and assembly compartments: the enemy inside--caught in the web. $\mathrm{J}$ Virol. 2014 Jun;88(11):5907-11.

73. Li L, Lok S-M, Yu I-M, Zhang Y, Kuhn RJ, Chen J, et al. The flavivirus precursor membrane-envelope protein complex: structure and maturation. Science. 2008 Mar;319(5871):1830-4.

74. Yu I-M, Zhang W, Holdaway HA, Li L, Kostyuchenko VA, Chipman PR, et al. Structure of the immature dengue virus at low $\mathrm{pH}$ primes proteolytic maturation. Science. 2008 Mar;319(5871):1834-7.

75. Jensen S, Thomsen AR. Sensing of RNA viruses: a review of innate immune receptors involved in recognizing RNA virus invasion. J Virol. 2012 Mar;86(6):2900-10.

76. Doly J, Civas A, Navarro S, Uze G. Type I interferons: expression and signalization. Cell Mol Life Sci. 1998 Oct;54(10):1109-21.

77. Haller O, Kochs G, Weber F. The interferon response circuit: induction and suppression by pathogenic viruses. Virology. 2006 Jan;344(1):119-30.

78. Ivashkiv LB, Donlin LT. Regulation of type I interferon responses. Nat Rev Immunol. 2014 Jan;14(1):36-49.

79. Furuichi Y, LaFiandra A, Shatkin AJ. 5'-Terminal structure and mRNA stability. Nature. 1977 Mar;266(5599):235-9. 
80. Hyde JL, Diamond MS. Innate immune restriction and antagonism of viral RNA lacking 2'-O methylation. Virology. 2015 May;479-480:66-74.

81. Hyde JL, Gardner CL, Kimura T, White JP, Liu G, Trobaugh DW, et al. A viral RNA structural element alters host recognition of nonself RNA. Science. 2014 Feb;343(6172):783-7.

82. Egloff M-P, Decroly E, Malet H, Selisko B, Benarroch D, Ferron F, et al. Structural and functional analysis of methylation and 5'-RNA sequence requirements of short capped RNAs by the methyltransferase domain of dengue virus NS5. J Mol Biol. 2007 Sep;372(3):723-36.

83. Liu L, Dong H, Chen H, Zhang J, Ling H, Li Z, et al. Flavivirus RNA cap methyltransferase: structure, function, and inhibition. Front Biol (Beijing). 2010 Aug;5(4):286-303.

84. Westaway EG, Mackenzie JM, Kenney MT, Jones MK, Khromykh AA. Ultrastructure of Kunjin virus-infected cells: colocalization of NS1 and NS3 with double-stranded RNA, and of NS2B with NS3, in virus-induced membrane structures. J Virol. 1997 Sep;71(9):6650-61.

85. Uchida L, Espada-Murao LA, Takamatsu Y, Okamoto K, Hayasaka D, Yu F, et al. The dengue virus conceals double-stranded RNA in the intracellular membrane to escape from an interferon response. Sci Rep. 2014 Dec;4:7395.

86. He Z, Zhu X, Wen W, Yuan J, Hu Y, Chen J, et al. Dengue Virus Subverts Host Innate Immunity by Targeting Adaptor Protein MAVS. J Virol. 2016 Aug;90(16):7219-30.

87. Dalrymple NA, Cimica V, Mackow ER. Dengue Virus NS Proteins Inhibit RIGI/MAVS Signaling by Blocking TBK1/IRF3 Phosphorylation: Dengue Virus Serotype 1 NS4A Is a Unique Interferon-Regulating Virulence Determinant. MBio. 2015 May;6(3):e00553-15.

88. Abe T, Barber GN. Cytosolic-DNA-mediated, STING-dependent proinflammatory gene induction necessitates canonical NF- $\kappa \mathrm{B}$ activation through TBK1. J Virol. 2014 May;88(10):5328-41.

89. Ishikawa H, Barber GN. STING is an endoplasmic reticulum adaptor that facilitates innate immune signalling. Nature. 2008 Oct;455(7213):674-8.

90. Zhong B, Yang Y, Li S, Wang Y-Y, Li Y, Diao F, et al. The adaptor protein MITA links virus-sensing receptors to IRF3 transcription factor activation. Immunity. 2008 Oct;29(4):538-50. 
91. Aguirre S, Maestre AM, Pagni S, Patel JR, Savage T, Gutman D, et al. DENV Inhibits Type I IFN Production in Infected Cells by Cleaving Human STING. PLoS Pathog. 2012;8(10).

92. Aguirre S, Luthra P, Sanchez-Aparicio MT, Maestre AM, Patel J, Lamothe F, et al. Dengue virus NS2B protein targets cGAS for degradation and prevents mitochondrial DNA sensing during infection. Nat Microbiol [Internet]. 2017;2(March):1-11. Available

from: http://dx.doi.org/10.1038/nmicrobiol.2017.37

93. Muñoz-Jordan JL, Sánchez-Burgos GG, Laurent-Rolle M, García-Sastre A. Inhibition of interferon signaling by dengue virus. Proc Natl Acad Sci U S A. 2003 Nov;100(24):14333-8.

94. Ashour J, Laurent-Rolle M, Shi P-Y, Garcia-Sastre A. NS5 of Dengue Virus Mediates STAT2 Binding and Degradation. J Virol. 2009;83(11):5408-18.

95. Yu CY, Liang JJ, Li JK, Lee YL, Chang BL, Su CI, et al. Dengue Virus Impairs Mitochondrial Fusion by Cleaving Mitofusins. PLoS Pathog. 2015;11(12):1-24.

96. Barbier V, Lang D, Valois S, Rothman AL, Medin CL. Dengue virus induces mitochondrial elongation through impairment of Drp1-triggered mitochondrial fission. Virology [Internet]. 2017;500(November 2016):149-60. Available from: http://dx.doi.org/10.1016/j.virol.2016.10.022

97. Bender S, Neufeldt CJ. Dengue Virus Perturbs Mitochondrial Morphodynamics to Dampen Innate Immune Article Dengue Virus Perturbs Mitochondrial Morphodynamics to Dampen Innate Immune Responses. 2016;342-56.

98. Chang TH, Chen SR, Yu CY, Lin YS, Chen YS, Kubota T, et al. Dengue virus serotype 2 blocks extracellular signal-regulated kinase and nuclear factor- $\kappa \mathrm{B}$ activation to downregulate cytokine production. PLoS One. 2012;7(8):4-11.

99. Wati S, Rawlinson SM, Ivanov RA, Dorstyn L, Beard MR, Jans DA, et al. Tumour necrosis factor alpha (TNF- $\alpha)$ stimulation of cells with established dengue virus type 2 infection induces cell death that is accompanied by a reduced ability of TNF- $\alpha$ to activate nuclear factor $\kappa b$ and reduced sphingosine kinase-1 activity. J Gen Virol. 2011;92(4):807-18. 


\section{CHAPTER 2}

This manuscript was prepared for submission to mBio

\section{Virus inhibition of RIPK1-mediated innate immune signaling}

Darshika J. Udawatte ${ }^{1}$, Alan L. Rothman ${ }^{1 *}$

${ }^{1}$ Institute for Immunology and Informatics, Department of Cell and Molecular

Biology, University of Rhode Island, Providence, RI, USA

*Corresponding author

E-mail:alan_rothman@uri.edu (A. Rothman) 


\section{Introduction}

RIPK1 was first discovered by Stanger et al. as a Fas binding protein important for programmed cell death in response to Fas ligation (1). Since then it has emerged as a central molecule regulating several biological pathways leading to cell death and inflammation. Its role is of particular interest in immune regulation. The primary goal of the immune system is to protect the host from invading pathogens. For this purpose, the innate immune system in particular has evolved multiple signaling networks that culminate in the production of cytokines, chemokines, and interferons. RIPK1 is located at the intersection of several signaling pathways and initiates signaling from both membrane-bound receptors and intracellular pattern recognition receptors that are important in pathogen recognition. Consequently, pathogens including viruses target RIPK1 to evade host immune responses. Thereby these pathogens have managed to establish effective infections. Accordingly, there is an unexpected diversity in the strategies exploited by viruses to target RIPK1. This review aims to summarize current knowledge of RIPK1 signaling in innate immune regulation. Furthermore, we explore various mechanisms utilized by viruses to inhibit RIPK1 signaling, with the goal of understanding subsequent outcomes that ultimately benefit viruses.

\section{The structure of RIPK1}

RIPK1 is a member of the receptor-interacting serine/threonine family. RIPK1 harbors an N-terminal kinase domain, an RHIM (RIP homotypic interaction motif)containing intermediate domain (ID), and a C-terminal death domain (DD) (13)(Fig.1). The kinase activity and the ability of RIPK1 to interact with other DD- 
containing and RHIM-containing proteins make it a multifunctional protein involved in many cellular pathways $(4,5)$. RIPK1 mediates signaling downstream of TNFR1, TLR3, TLR4, RIG-I/MDA-5, and ZBP1. These signaling events culminate in NF-кB-, MAPK-, and IRF3/7-mediated cytokine, chemokine, and interferon production, which is vital for controlling infections. In the sections below, we discuss in detail major signaling events mediated by RIPK1.

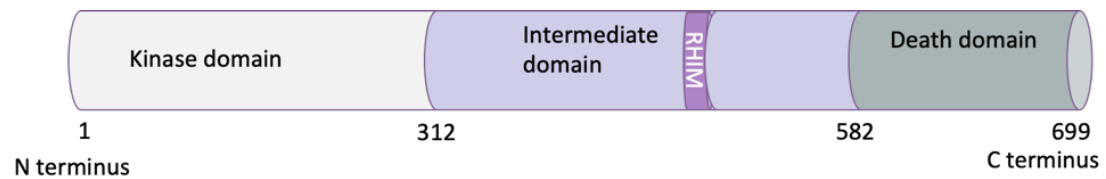

Figure 1. Domain structure of RIPK1. RIPK1 consists of an N-terminal kinase domain, an intermediate domain and a C-terminal death domain. (Adapted from Ofengeim D \& Yuan J, 2013)

\section{RIPK1 signaling downstream of TNFR1}

TNFa ligation with TNFR1 (TNF Receptor 1) initiates signaling cascades leading to NF- $\mathbf{k B}$ activation, MAPK activation, extrinsic apoptosis and necroptosis (Fig 2). RIPK1 acts as a critical signal transducer in the NF- $\mathbf{k B}$ pathway downstream of TNFR1. NF- $\mathbf{k B}$ signaling is vital for the regulation of the immune system. NF- $\mathbf{k B}$ family members (p50, p52, RelA, c-Rel, and RelB) regulate the transcription of proinflammatory cytokines and anti-microbial effectors such as IL-6, IL-8, IL-10, CCL5, TNFa, CCR5, etc. (7). They also regulate genes involved in cellular proliferation, differentiation, and survival (8-11). Thereby, NF- $\mathbf{B B}$ transcription factors regulate various aspects of both innate and adaptive immune responses. Pathogens have evolved mechanisms to downregulate the NF- $\mathbf{k B}$ activation in order to evade the host 
immune and inflammatory responses (12). For example, human rotavirus and DENV antagonize the NF- $\mathbf{k B}$ pathway leading to downregulated cytokine responses $(13,14)$.

The role of RIPK1 in TNFa signaling is well studied. Upon TNFa ligation, TRADD (TNFR1 associated death domain protein) binds to the cytoplasmic death domain (DD) of TNFR1 (TNF receptor 1). TRADD recruits TRAF2/ TRAF5 (TNF associated factors) along with RIPK1 and cIAP proteins (Cellular inhibitor of apoptosis). Ubiquitination of RIPK1 by TRAF2 and/or cIAPs creates a platform for recruiting TAK1, TAK binding proteins (TAB1 and TAB2) and the IKK complex (NEMO, IKKa, IKKß) (15-17).This protein complex downstream of TNFR1 is known as complex I (Fig 1). The IKK complex phosphorylates IкB $\alpha$ and promotes it for proteasomal-mediated degradation. This liberates NF- $\mathbf{k B}$ transcription factors, from the inhibitor IкB $\alpha$ and allows them to translocate into the nucleus resulting in induction of antiviral genes. Studies done on mice with a genetic mutation in RIPK1 destroying its kinase activity, demonstrated intact NF- $\mathbf{k B}$ responses following $\mathrm{TNFa}$ stimulation. Treatment with Necrostatin-1, a specific inhibitor of RIPK1 kinase activity did not affect TNFa-induced NF- $\mathrm{KB}$ responses in mice $(18,19)$. These data indicate that the kinase activity of RIPK1 is dispensable for NF- $\mathbf{\kappa B}$ activation.

MAPKs (Mitogen associated protein kinases) consist of three groups, known as Erk1/2 (Extracellular signal-regulated kinases), JNKs (Jun N-terminal kinases), and p38 $(20,21)$. The MAPK pathway culminates in AP-1 transcription and induces the expression of genes important for host defense during pathogen invasion. AP-1 regulates the expression of pro-inflammatory cytokines and chemokines such as IL-2, IFN $\gamma$, TNF $\alpha$, IL-6, IL-4, GM-CSF, CXCL8. Thereby AP-1 regulates leukocyte 
activation and differentiation $(22,23)$. Therefore, numerous pathogens target the MAPK pathway to evade the aforementioned host immune responses. For example, DENV did not activate Erk 1/2 phosphorylation and even impaired the basal level of p-Erk1/2 in A549 cells (14).

RIPK1 is placed at a crucial point in MAPK signal transduction downstream of TNFR1. RIPK1 ubiquitination in complex I by TRAF2 or cIAPs leads to the assembly of a TAK1, TAB2, TAB3 complex. TAK1 phosphorylates MAPKs such as p38, JNK, and Erk leading to the expression of additional transcription factors, ATF2, JUN, and TCF, which translocate into the nucleus facilitating AP-1 transcription (24). The ID of RIPK1 is necessary and sufficient for the activation of MAPKs upon TNF $\alpha$ stimulation (25). Conversely, another study demonstrated that RIPK1 mediated TNF $\alpha$ induced p38 MAPK activation by recruiting MEKK3 (Mitogen-activated protein kinase kinase kinase 3) to TNFR1 (26). The authors showed that RIPK1 transiently interacted with MEKK3 upon TNF $\alpha$ stimulation. Even though this interaction occurred via the RIPK1 ID, the kinase activity of RIPK1 was important for a stable interaction. A RIPK1- MEKK3 interaction was observed in cells expressing wild type RIPK1 but not in cells expressing kinase-inactive RIPK1.These reports suggest that there may be more than 1 routes of MAPK activation in complex I via RIPK1. Targeted disruption of the rip1 gene (which codes for RIPK1) in Mouse embryonic fibroblasts prevented p38 MAPK activation and IL-6 production in response to TNF $\alpha$ (26). exhibiting the vital role of RIPK1 in regulating MAPK-AP-1 signaling downstream of TNFR1. 


\section{RIPK1 signaling downstream of TLR3 and TLR4}

Stimulation of toll like receptors (TLRs) can lead to potent innate immune responses via NF-kB activation. TLR4, the immune sensor for bacterial LPS, triggers NF-אB activation via either MyD88 (Myeloid differentiation primary response gene 88)-dependent or TRIF (TIR domain-containing adapter inducing interferon $\beta$ )dependent signaling pathways $(27,28)$. TLR3 participates in recognition of pathogenassociated double-stranded (ds) RNA and the synthetic analog of viral ds RNA, poly (I:C). Unlike TLR4, TLR3 induces NF-kB activation only via TRIF (29). In both TLR3 and TLR4 signaling, TRIF interacts with RIPK1 via a conserved four amino acid motif (VQLG) in the C-terminal RHIM domain of TRIF (30). TRIF also recruits TRAF6 and TBK1 via its $\mathrm{N}$ terminus (29). These interactions result in IKK activation and IкB phosphorylation, liberating NF- $\mathbf{K B}$, which translocates to the nucleus and initiates transcription of genes involved in immune responses (31). TRIF-RIPK1 interaction results in recruitment of TAK1 leading to the activation of MAPKs and AP-1 activation leading to enhanced immune responses (32). Even though this tethering of signaling molecules by RIPK1 (scaffolding function) is sufficient for NF$\mathbf{\kappa B}$ and MAPK activation, a RIPK1 kinase activity-dependent mechanism was recently reported (33). The kinase activities of RIPK1 and RIPK3 promoted sustained activation of Erk, cFos and NF- $\mathbf{B}$ in LPS-stimulated macrophages. Regulation was induced in the absence of caspase 8 activity and was dependent on TRIF. Even though the speculation is that this signaling initiated from a death signaling complex involving RIPK1, (necrosome), the detailed molecular mechanism remains to be 
elucidated. It is tempting to conjecture that similar RIPK kinase activity-dependent signaling could occur downstream of TLR3 as well.

RIPK3 has been shown to inhibit RIPK1-mediated NF- $\mathbf{k B}$ activation by competitive binding to TRIF downstream of TLR3 and TLR4 (29). The RIPK3-TRIF interaction could potentially inhibit RIPK1-driven MAPK activation, even though this has not been investigated so far. Therefore, it could be of interest to study the effect of RIPK3 on TLR3/TLR4-stimulated MAPK pathway.

TLR3 and TLR4 activate signaling pathways that culminate in the production of IFNs and IFN-inducible genes through IRF3/IRF7 phosphorylation, which is central to antiviral innate immune responses (34). Even though RIPK1 interacts with TRIF, involvement of RIPK1 in TRIF-dependent IRF3/IRF7 signaling is somewhat less clear. Overexpression of the RHIM domain of RIPK1 alone was sufficient to induce TRIF-mediated NF-kB activation as measured using a luciferase reporter. However, the activity of an IFN $\beta$ luciferase reporter was not induced with overexpression of either a WT or RHIM mutant RIPK1 (29). ISRE reporter luciferase activity increased in HEK293 cells with overexpression of TRIF but not with overexpression of RIPK1 (35). This RIPK1-independent response in IRF3/7 phosphorylation could be due to the ability of TRIF to directly interact with both IRF3 and the IRF3-activating kinase, TBK1 (31) However, RIPK1-dependent regulation of IRF3/7 activation was shown by studies done by Hyun et al. (36). The authors suggested that the Human T lymphotropic virus (HTLV-1) Tax protein prevented TLR3-induced IRF3 phosphorylation by competitively binding to TRIF (36). 
Therefore, more mechanistic studies would be needed to resolve discrepancies regarding RIPK1 regulation of IRF3/7 activation downstream of TLR3 and TLR4.

\section{RIPK1 signaling downstream of RIG-I and MDA-5}

The RNA helicases RIG-I (Retinoic acid-inducible gene 1) and MDA-5 (Melanoma differentiation-associated protein 5) are known to initiate signaling pathways culminating in the production of type I interferons (IFN $\alpha$, IFN $\beta$, IFN $\varepsilon$, IFNк) and pro-inflammatory cytokines during the early stages of viral infections (37). It has been reported that RIG-I most strongly recognizes short 5'ppp dsRNA, while MDA5 recognizes preferentially long dsRNA $(38,39)$. RIG-I most potently detects influenza viruses, filoviruses, and rhabdoviruses while MDA5 is essential for the recognition of picornaviruses, arteriviruses, and hepatitis D virus (40-44). These receptors are also involved in recognizing non-viral pathogens; MDA5 has been reported to respond to Malaria parasites (45). Nevertheless, viruses have evolved strategies to impair signaling downstream of RIG-I/MDA-5. For example, the DENV protease NS3 was shown to cleave mitochondrial associated proteins MFN1 and MFN2 impairing efficient RLR signaling (46). Influenza A H1N1 viral protein NS1 directly interacts with RIG-I and prevents its activation, inhibiting IFN $\beta$ production (47).

RIPK1 is involved in NF- $\mathbf{B}$, MAPK, IRF3 and IRF7 activation downstream of RIG-I and MDA5. RIG-I and MDA5 signaling merge at the mitochondria through MAVS (Mitochondrial antiviral signaling protein), which is located at the mitochondrial membrane (48). TRADD and FADD are required to recruit RIPK1 to 
MAVS following RIG-I/MDA-5 stimulation (49). RIPK1 signaling to NF- $\mathbf{B}$ proceeds through the IKK complex, while signaling to IRF3/IRF7 proceeds through TBK1 and $\operatorname{IKK} \varepsilon(50,51)$. Activation of MAPK downstream of RIG-I involves TRAF2, TAK1, and the kinase activity of RIPK1 (52). RIG-I and MDA-5 activate NF- $\mathbf{k B}$ and p38 MAPK through a common upstream pathway involving RIPK1 and only diverge downstream of TAK1. Therefore, RIPK1 functions as an essential adaptor molecule in RIG-I and MDA-5 signal transduction by facilitating the association of other proteins (51).

\section{RIPK1 signaling in cell death - Ripoptocide}

Viruses are obligate intracellular pathogens that require living cells. Hence, cell death can be an important immune defense against infection. RIPK1 regulates cell death pathways known as "ripoptocide" involving both apoptosis and necroptosis (53). Apoptosis is a non-inflammatory form of cell death having morphological changes such as cell shrinkage, chromatin condensation, and plasma membrane blebbing (54). Apoptosis can be induced by extrinsic or intrinsic stimuli. Extrinsic apoptosis is mediated by death receptors such as TNFR1 whereas intrinsic apoptosis is driven by intrinsic stresses such as DNA damage, growth factor withdrawal, or ER stress leading to mitochondrial outer membrane permeabilization $(54,55)$. RIPK1 is involved in regulating extrinsic apoptosis downstream of TNFR1. Deubiquitination of RIPK1 leads to the formation of a complex with Pro-Caspase 8 and FADD in response to TNF $\alpha$ stimulation, which is referred to as complex IIa (Fig 2) (6). Assembly of complex IIa leads to auto-processing and maturation of pro-caspase 8 into caspase 8 , 
which initiates extrinsic apoptosis. A similar complex known as the ripoptosome assembles in response to TLR3 and TLR4 stimulation $(56,57)$. The core of the ripoptosome consists of RIPK1, FADD, and Caspase 8 (57). The ripoptosome can also recruit additional proteins such as cFLIP (FLICE like inhibitory protein) and RIPK3 depending on the cell type and stimulus (57). As in complex IIa, the ripoptosome promotes caspase 8 activation. Mature caspase 8 , in turn, activates downstream caspases such as caspase 3 resulting in extrinsic apoptosis. Active caspase 8 also cleaves RIPK1 downstream of residue Asp 324 in the ID during apoptosis. The Cterminal $38 \mathrm{kDa}$ cleavage product generated from this cleavage is known to facilitate interactions between FADD and TRADD, further contributing to extrinsic apoptosis. The expression of RIPK1 mutants resistant to caspase 8 cleavage protected cells against $\mathrm{TNF} \alpha$-induced apoptosis demonstrating the pro-apoptotic nature of cleaved RIPK1 (58). The induction of apoptosis by RIPK1 contributes to virus clearance by eliminating infected cells, however, it's an immunologically silent form of cell death because it does not cause inflammation.

Necroptosis is considered as an anti-viral defense mechanism because it can initiate a strong pro-inflammatory response. Necroptosis is morphologically characterized by swelling of organelles followed by plasma membrane rupture (59) $(60,61)$. Necroptosis protects the host both by limiting pathogen replication in infected cells and by promoting inflammatory responses that stimulate host adaptive immunity (62). Necroptotic cell death is driven by a protein complex known as the "necrosome". The necrosome includes RIPK1 and RIPK3, which interact with and phosphorylate each other. Activated/phosphorylated RIPK3 recruits and 
phosphorylates MLKL (Mixed lineage domain-like protein). Phosphorylated MLKL forms tetramers, translocates to the cell membrane and further polymerizes to form amyloid-like structures (63). These polymerization events result in cell membrane permeabilization and cell lysis (64). How MLKL polymers disrupt membrane integrity is unclear. Necrosomes are formed downstream of TNFR1, TLR3, and TLR4 in the absence of caspase 8 activity. Even though RIPK1 participates in extrinsic apoptosis and necroptosis, the loss of RIPK1 also sensitizes cells to TNF $\alpha$-induced apoptosis $(65,66)$ perhaps due to NF-kB inhibition. Therefore, a goal of future studies should be to understand what factors regulate the final effects of RIPK1 leading to cell survival or cell death. Additionally, whether RIPK1 signal for cell death downstream of RIG-I/ MDA-5 has yet to be explored.

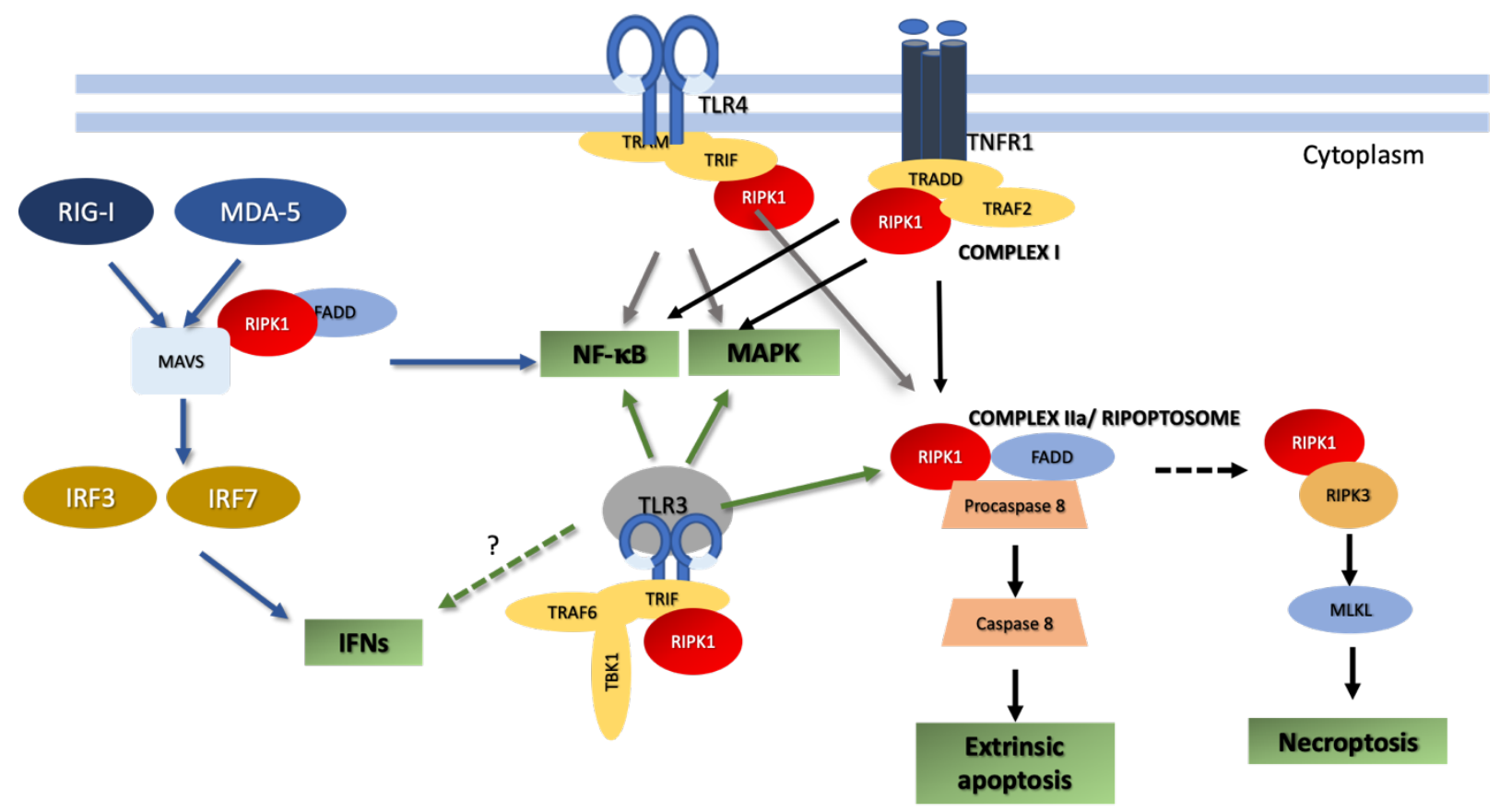


Figure 2. Signaling pathways mediated by RIPK1. TNFR1 stimulation leads to the assembly of complex I, which signals for the NF- $\mathrm{B}$ and MAPK activation. When RIPK1 is deubiquitinated in the complex I, signaling is diverted into caspase 8 maturation and extrinsic apoptosis in complex IIa. In the absence of caspase 8 activity, RIPK1 signaling results in induction of necroptosis. TLR4 and TLR3 stimulation results in RIPK1-regulated NF- $\kappa \mathrm{B}$ and MAPK activation. Extrinsic apoptosis could take place in the ripoptosome downstream of TLR3 and TLR4. When caspase 8 activity is depleted, RIPK1 signals for necroptosis downstream of TLR3 and TLR4. RIG-I/MDA-5 signals for IFN induction, NF-кB and MAPK activation via RIPK1.

\section{Viral strategies in modulating RIPK1 signaling}

RIPK1 is placed at a crucial point in controlling cell death and inflammation. RIPK1-mediated signaling governs the outcome of signaling pathways initiated by

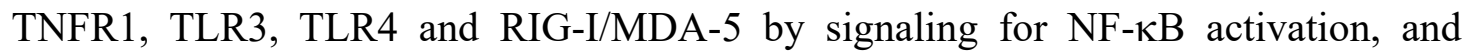
MAPK and IRF3/7 phosphorylation. In the event of an infection, activation of these pathways results in release of pro-inflammatory cytokines, chemokines and interferons setting an antiviral state. RIPK1 is also involved in destroying replication niches of pathogens by signaling for extrinsic apoptosis or necroptosis. Therefore, RIPK1 has emerged as an attractive target for inhibition by viruses. Here we have summarized current knowledge in viral strategies that modulate RIPK1-mediated signaling by virus family. 


\section{Herpesviruses}

Members of the Herpesviridae family have double stranded DNA genomes. They are categorized into $\alpha, \beta$, and $\gamma$ herpesviruses based on their host range, genome and replication strategies (67). Most vertebrates get infected with one or more herpesviruses during their lifetime. Herpesviruses commonly establish a life-long infection in the host. Human herpes simplex virus-1 (HSV-1), an $\alpha$ herpesvirus, is associated with genital herpes, herpes encephalitis and ocular HSV causing blindness (68). Human cytomegalovirus (CMV) is a $\beta$ herpesvirus that causes a wide spectrum of pathological outcomes. Congenital CMV infections are often associated with serious complications including microcephaly and mental retardation. Immunocompromised patients can develop encephalitis, pneumonitis and graft rejection as a result of CMV infections (69). Epstein-Barr virus (EBV) is a human $\gamma$ herpesvirus. It's the primary cause of infectious mononucleosis. EBV infections are also associated with 200,000 malignancies (Burkitt's lymphoma, non-Hodgkin's lymphoma, nasopharyngeal carcinoma, gastric adenocarcinoma) worldwide every year (70). Several members of the herpesvirus family have been shown to impair RIPK1-mediated signaling.

\subsection{Herpes simplex virus-1 (HSV-1)}

Murine HSV-1 induces necroptosis, which restricts viral propagation (71). In contrast, human HSV-1 has evolved to escape necroptosis-mediated restriction by at least three mechanisms. In one mechanism, the human HSV-1 protein ICP6 promotes RIPK1 aggregation and then its degradation by the autophagosome, a 
process known as aggrephagy (72). A conserved motif in all the human herpesviruses known as the "induced protein aggregation motif (IPAM)" is needed for this aggregate formation. Expression of wild-type ICP6 alone was sufficient to induce aggregate formation in human fibroblasts while expression of a mutant IPAM ( $\triangle$ IPAM) ICP6 failed to do so (73). However, no experiments were shown to indicate if IPAM of ICP6 was important for RIPK1 interaction. In a second mechanism it was shown that HSV-1 proteins ICP6 and ICP10 both harbor RHIM domains and disrupt the RIPK1-RIPK3 association by competing for RIPK1 binding (74). This effect allows HSV-1 to prevent necrosome formation. Recently an additional mechanism of necroptosis inhibition by HSV-1 ICP6 via the RHIM domain was discovered. Wild type HSV-1 inhibited translocation of necrosomes to detergent-resistant membranes as compared with HSV-1 lacking ICP6 ( $\triangle \mathrm{ICP} 6)$ or having and ICP6 lacking the RHIM domain (ICP6- $\triangle$ RHIM) (75). Collectively, these data show numerous strategies exploited by HSV-1 to prolong cell survival by targeting RIPK1. Furthermore, these studies may shed light on similar mechanisms shared by other viruses.

\subsection{Cytomegalovirus (CMV)}

The infection of mice with Murine cytomegalovirus (MCMV) is a wellestablished model for understanding human CMV infections (76). MCMV M45, the homolog of HCMV UL45, has emerged as a viral inhibitor of RIPK1-mediated signaling. Mutational studies done on M45 have revealed a RHIM-like domain in the N-terminus of MCMV M45 (aa 61-69). Overexpressed WT (wild type) but not 
$\triangle$ RHIM M45 co-immunoprecipitated with RIPK1 indicating that M45 interacts with RIPK1 via its RHIM domain (77). This strong interaction between RIPK1 and M45 resulted in blocking of RIPK1 ubiquitination as shown by in vitro ubiquitination assays (19). TNF $\alpha$-induced NF-кB activation and TNF $\alpha$-induced p38 phosphorylation were inhibited as a result of the RIPK1-M45 interaction (78). NF$\mathbf{\kappa} \mathrm{B}$ activation downstream of TLR3 was also blocked by M45. Furthermore, M45 blocked caspase-independent cell death following TNF $\alpha$ stimulation in a RHIMdependent manner. Similarly, MCMV expressing WT M45 but not $\triangle$ RHIM M45 blocked TRIF-induced apoptosis by blocking the RIPK1-TRIF interaction (77). Interestingly, another study found an additional mechanism of RIPK1 degradation by M45. Muscolino et al. showed that M45 physically interacted with RIPK1 via its IPAM motif and caused RIPK1 to aggregate (73). This interaction caused RIPK1 to accumulate in the insoluble fraction of cell lysates following MCMV infection in an M45-dependent manner. RIPK1 levels were higher in autophagy-deficient ATG5 ${ }^{-/}$ cells following MCMV infection, indicating that RIPK1 was subjected to degradation by autophagy. Further studies revealed that M45 promoted RIPK1 degradation which was blocked by inhibition of lysosome function by $\mathrm{NH}_{4} \mathrm{Cl}$ (73). In agreement with previous studies, the authors also detected inhibition of necroptosis due to low levels of RIPK1. Both IPAM and RHIM sequences were needed for cell survival suggesting that these two sequences have independent roles. Infections with MCMV expressing $\triangle \mathrm{IPAM}$ or $\triangle \mathrm{RHIM}$ M45 resulted in less viral replication in mice relative to infections with WT MCMV. Therefore, M45 promoted viral replication in cell culture and facilitated viral replication in mice by 
inhibiting RIPK1-mediated cell death. RIPK3 also harbors a RHIM domain and drives signaling for necroptosis. Thus, M45 RHIM-mediated interactions could negatively affect RIPK3 signaling as well. Further efforts should be made to understand if M45 can regulate RIPK3 signaling. Moreover, how RIPK1 overexpression affects viral replication could be explored.

\subsection{Epstein-Barr virus (EBV)}

EBV is known to manipulate the host cell's death signaling pathways to facilitate viral replication. EBV suppressed necroptosis by targeting RIPK1 (79). Latent membrane protein 1 (LMP1) of EBV directly interacted with RIPK1 in an RHIM-independent manner. Furthermore, both K48 and K63 ubiquitination of RIPK1 increased in the presence of LMP1 as shown by in vitro ubiquitination assays. K48 ubiquitination resulted in a decrease of the RIPK1 half-life. LMP1 increased the expression of TRAF2, which amplified RIPK1 K63 ubiquitination. Therefore, LMP1 inhibited TNFR1-stimulated necroptosis by redirecting RIPK1 signaling towards NF-кB activation by promoting K-63 ubiquitination. However, LMP1 is also known to upregulate TNFAIP3/A20 (TNFo-induced protein 3), which could deubiquitinate RIPK1 $(80,81)$. Therefore, studies on the direct effect of low levels of RIPK1 and LMP1-RIPK1 interaction on EBV replication and cell death could be beneficial. 


\section{Flaviviruses}

Flaviviruses are single-stranded positive-sense RNA viruses, having a genome size of $\sim 11 \mathrm{~kb}$. Flaviviruses are mainly transmitted to vertebrate hosts by infected mosquitos or ticks. Mosquito-borne flaviviruses include Yellow fever virus, Dengue virus, Japanese encephalitis virus, West Nile virus and Zika virus. Tick-borne viruses include Tick-borne encephalitis virus, Powassan virus, Louping ill virus, and Omsk hemorrhagic fever virus (82). Ongoing research on understanding humanflavivirus interactions has exposed a protective role of RIPK1 for the host. Some flaviviruses have evolved strategies to target RIPK1 in order to evade host responses while these mechanisms remain to be elucidated for other flaviviruses. WNV is an encephalitic virus of global concern (83). In humans, $\sim 20 \%$ of WNV infections cause rashes, arthralgia and myalgia while $<1 \%$ of infections cause cognitive and neurological impairments that can lead to death (84). ZIKV is an emerging flavivirus which is associated with fetal abnormalities and severe neurological injuries in adults $(85,86)$.

\subsection{West Nile virus (WNV)}

RIPK1 together with RIPK3 signals for chemokine expression and for recruitment of infiltrating antiviral leukocytes in the central nervous system during WNV infection. Mice expressing a kinase dead form of RIPK1 exhibited increased susceptibility to WNV infection (87). Even though the molecular mechanisms for this effect are not completely understood, these data suggest a protective role of RIPK1 
against WNV (87). Additionally, the levels of RIPK1 upon WNV infection could be monitored to learn if WNV impede RIPK1 mediated signaling.

\subsection{Zika virus (ZIKV)}

The fate of RIPK1 in ZIKV-infected cells has not been directly addressed. However, a protective role of RIPK1 against ZIKV was recently reported. RIPK1 together with RIPK3 diminished ZIKV infection by activating antiviral gene networks including IRF1-dependent Irg1 expression (88). The full nature of this mechanism remains to be elucidated. However, RIPK1 kinase activity-deficient mice $\left(\mathrm{RIPK} 1^{\mathrm{KD} / \mathrm{KD}}\right)$ had higher viral titers in whole brain homogenates upon infection with ZIKV. Inhibition of kinase activity in vivo by treatment with pharmacological inhibitors also increased brain viral burden. Furthermore, RIPK $1^{\mathrm{KD} / \mathrm{KD}}$ neuronal cultures exhibited enhanced replication of ZIKV relative to wild-type controls. Interestingly, no differences were observed in ZIKV replication in primary BMDM or dendritic cells from wild-type versus RIPK1 ${ }^{\mathrm{KD} / \mathrm{KD}}$ mice or with inhibition of the kinase activity of RIPK1, suggesting that these effects are cell-type specific (88).

\section{Retroviruses}

Retroviruses are enveloped RNA viruses (89). Retroviruses are able to reverse transcribe their RNA genomes into DNA that integrates into the host cell genome during the intracellular virus life cycle. It is estimated approximately $8 \%$ of the human genome consists of endogenous retroviruses (90). Retroviruses are further categorized into oncoretroviruses, lentiviruses and spumaviruses (91). Human Immunodeficiency 
Virus 1 (HIV-1) is a lentivirus while Human T-Cell Lymphotropic Virus-1 (HTLV-1) is an oncoretrovirus. HIV-1 causes acquired immunodeficiency syndrome (AIDS). Approximately 37 million people were living with HIV-1 worldwide as of 2017 (92). Infection of T-lymphocytes by HTLV-1 can cause adult T-cell leukemia (ATL) or HTLV-1 associated myelopathy (HAM) $(93,94)$. Both HIV-1 and HTLV-1 have been shown to modulate RIPK1 signaling.

\subsection{Human Immunodeficiency Virus 1(HIV-1)}

The HIV-1 protease (PR) plays an important role in the virus life cycle by cleaving viral poly-peptides Gag and Gag-Pol into mature proteins (95). One study examined the effect of HIV-PR expression on RIPK1-mediated signaling (96) HIV-1 PR was shown to decrease both endogenous and overexpressed RIPK1. A catalytically inactive PR and the PR inhibitor Saquinavir (SQV) prevented this cleavage. Mass spectroscopy studies revealed that PR cleaves RIPK1 at the ID domain. RIPK1 cleavage was confirmed in HIV-1-infected T cell lines and primary CD4+ T cells. PR cleavage of RIPK1 disrupted NF- $\mathbf{k B}$ activation as measured by luciferase reporter assays, and this activation was restored by the addition of SQV. Furthermore, PR overexpression impaired RIPK1-RIPK3 interaction as demonstrated by a yeast twohybrid system. These data suggest that RIPK1 cleavage by PR can block necrosome formation inhibiting necroptosis. However, this study did not assess the effect of PR on RIPK1-mediated MAPK pathway activation. Collectively these data indicate that HIV-1 PR can block multiple immune pathways by cleaving RIPK1. However, the effect of RIPK1 cleavage on HIV-1 replication remains to be studied. 


\subsection{Human T-Cell Lymphotropic Virus -1}

The HTLV-1-encoded Tax protein is a multifunctional protein that is crucial for T cell transformation by HTLV-1 (97). Moreover, Tax inhibits innate immune signaling by multiple mechanisms via RIPK1. Type I IFNs and ISGs are capable of inhibiting HTLV-1 replication. Therefore, viral evasion of IFN production and signaling probably represents a survival strategy. More progeny viruses were recovered following VSV infection in primary MEF and Jurkat cells overexpressing Tax protein relative to controls, demonstrating inhibition of host immune responses by Tax (36). HTLV-1-infected cells produced less IFN $\beta$ than uninfected cells upon stimulation with poly(I:C). Yeast two hybrid screens and mutational constructs revealed a Tax interaction with RIPK1 via the RHIM in the ID domain of RIPK1(36). However, they did not test for the presence of a RHIM domain in Tax protein. The Tax-RIPK1 interaction prevented the RIPK1-IRF7 interaction and inhibited IRF7 phosphorylation, downregulating the production of IFN $\alpha$ and IFN $\beta$. In contrast, Tax did not prevent RIPK1-RIG-I/MDA-5 interactions, and NF- $\mathrm{B}$ signaling was unaffected as shown by luciferase assays (36). HTLV-1 is known to induce persistent activation of NF- $\mathbf{B}$, which contributes to the T-cell transformation (98). It was shown that Tax prevented TLR3-induced IRF3 phosphorylation but not NF-кB signaling by competitively binding to TRIF. However, this observation is inconsistent, since TRIF is located upstream of both IRF3 and NF-кB pathways. Therefore, it is reasonable to hypothesize Tax might be inhibiting IFR3 phosphorylation at an additional step in TLR3 signaling. 


\section{Other viruses}

\subsection{Human Rhinovirus (HRV)}

$\mathrm{HRV}$ is the major causative agent of the common cold and asthma exacerbations (99). There are approximately 170 serologically distinct HRV types in circulation (100). HRV is a single-stranded positive-sense RNA virus. The HRV genome encodes for three proteases $(2 \mathrm{~A}, 3 \mathrm{CD}, 3 \mathrm{C})$, which are important for viral polyprotein maturation (101). These proteases have also been shown to cleave host proteins. The HRV16 3C protease restricted host cell apoptosis and prolonged cell survival by cleaving RIPK1 in HeLa cells (102). The addition of a 3C protease inhibitor, Rupintrivir, decreased RIPK1 cleavage. 3C-mediated RIPK1 cleavage was increased upon caspase 8 activation by ActoD relative to untreated cells. However, this observation of increased RIPK1 cleavage with activation of Caspase 8 was not reproduced in HRV16-infected cells. Even though apoptosis induced with ActoD treatment decreased upon HRV16 infection, no evidence was shown this was related to RIPK1 cleavage. Additional studies may require for elucidating the direct effect of RIPK1 cleavage on cell death as well as HRV16 replication. Finally, given that the level of full-length RIPK1 is decreased during HRV16 infection, it would be interesting to learn if RIPK1-mediated innate immune signaling such as NF-кB and MAPK pathways are disrupted. Therefore, there is an opening to investigate the inhibition of RIPK1-mediated immune responses by HRV. 


\subsection{Ebola virus (EBOV)}

EBOV is a negative-strand RNA virus belonging to the Filoviridae family (103). Ebola virus causes Ebola Virus Disease, a hemorrhagic fever with a high fatality rate. Damaging host immune responses due to robust EBOV replication contributes to the disease severity. This excessive viral replication reflects the capability of EBOV to suppress innate immune mechanisms. For example, EBOV effectively blocks IFN production $(104,105)$. EBOV has been shown to disrupt RIPK1-mediated signaling by encoding a miRNA (miR-T2-3p) targeting RIPK1 (106). In vitro experimental studies in HeLa cells demonstrated that a mimic of miRNA miR-T2-3p downregulated RIPK1 transcript levels. In light of this observation, it is tempting to hypothesize that EBOV-encoded miRNA blocks RIPK1mediated innate immune responses to enhance viral replication. Perhaps RIPK1 inhibition could be responsible for inhibition of IFN production by EBOV. Thus, it will be of interest to study the link between RIPK1 downregulation and IFN inhibition during EBOV infection. Also, the effect of RIPK1 inhibition on EBOV replication could be further explored.

\subsection{Vaccinia virus (VACV)}

VACV belongs to the poxvirus family. It has a large linear ds DNA genome. VACV is the primary component of the smallpox vaccine. VACV is mostly used as a tool in the research setting for vaccine development (107). RIPK1 has been shown to play a protective role in VACV infection by inducing necroptosis. Caspase 8 inhibition by VACV also promotes necroptosis in infected cells (108). Mice 
expressing a kinase inactive RIPK1 mutant failed to control VACV replication in vivo. They had increased viral titers in the spleen and the liver, due to lack of necroptosis (109). This study provides genetic evidence that the kinase activity of RIPK1 is essential for viral-initiated necroptosis. However, further efforts should be made to understand RIPK-mediated NF- $\mathrm{BB}$, MAPK activation and cytokine production during VACV infection.

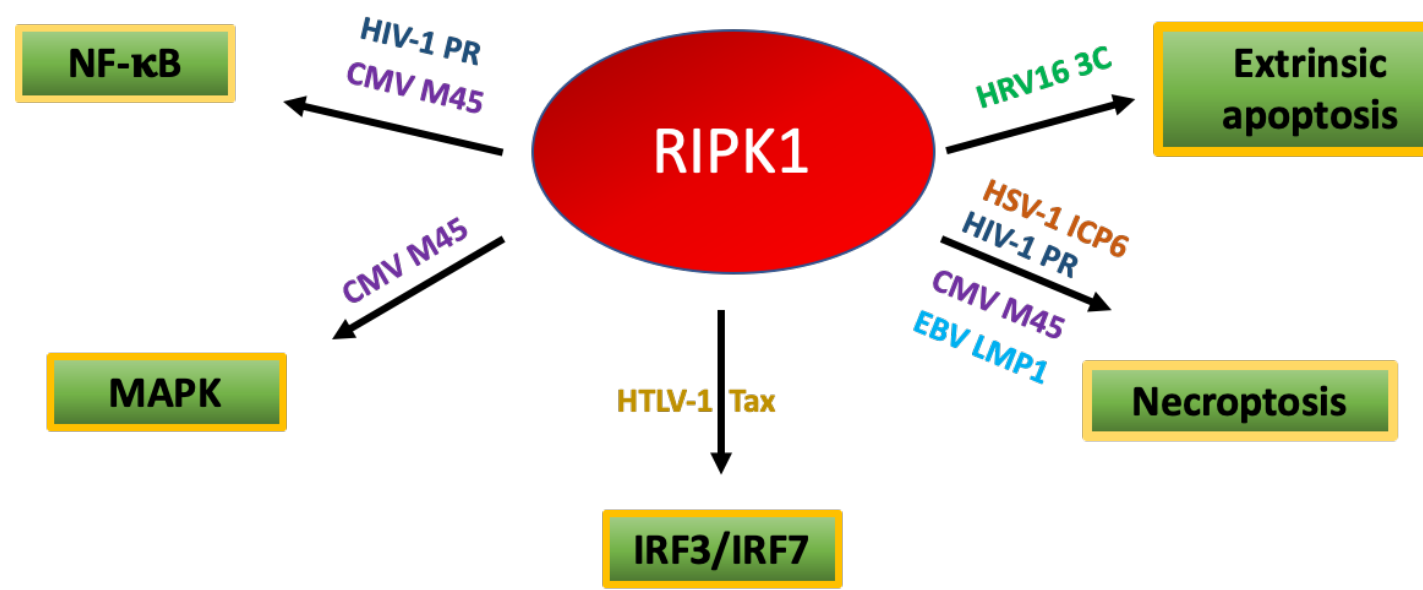

Figure 3. Viral proteins involved in modulating RIPK1 signaling. HIV-1 PR, CMV M45 proteins block NF-אB activation. CMV M45 blocks MAPK activation and downstream signaling. HTLV-1 Tax protein blocks IRF3/IRF7 by binding to RIPK1. HSV-1 ICP6, HIV-1 PR, CMV M45, EBV LMP1 all are shown to block necroptosis by targeting RIPK1. HRV 3C protease is shown to block extrinsic apoptosis by cleaving RIPK1. 


\section{Concluding remarks}

As discussed in this review, RIPK1 plays a crucial role in cell death and inflammatory responses. RIPK1 is placed at an intersection of multiple pathways of signal transduction initiated from death receptors and pattern recognition receptors. Signaling initiated from these receptors is important for the induction of immune responses. Importantly, new properties of RIPK1 signaling are emerging. For example, it was previously reported that RIPK1 was not involved in TRIF-mediated IRF3/IRF7 signaling. In contrast, Hyun. J. et al., suggest a role of RIPK1 phosphorylating IRF3 downstream of TLR3 and TRIF (36). Additionally, it has been long postulated that the kinase activity of RIPK1 is dispensable for NF- $\mathbf{B}$ activation (110). Nevertheless, a RIPK1 kinase activity-dependent mechanism of NF- $\mathbf{k B}$ activation and induction of inflammatory responses due to TLR4 stimulation was recently reported (33). RIPK1 is involved in driving signaling for extrinsic apoptosis in response to TNF $\alpha$ stimulation. However, RIPK1 was also reported to be implicated in protecting TNF $\alpha$ stimulated cell death in hepatocytes suggesting opposing roles of RIPK1 in the same pathway (114). Furthermore, RIPK1 was shown to induce antiviral gene networks by undefined mechanisms (88).

Evidence demonstrating that RIPK1 is involved in suppressing cell death and inflammation while also promoting the same supports RIPK1 as a critical regulator in cell death and inflammation signaling network. Under normal conditions, RIPK1 regulation of cell death and inflammation seem to be tightly regulated to allow homeostasis. However, in the setting of viral infection, this homeostasis appears to be disturbed. In most viral infections, RIPK1-mediated signaling protects the host by 
either inducing cell death or inflammatory cytokine, IFN secretion. For example, RIPK1 kinase activity-deficient mice had higher viral titers than wild-type mice following ZIKV and VACV infections, and these mice showed increased susceptibility to WNV infection $(88,109,111)$. If the overall effect of RIPK1 is to inhibit infection, RIPK1 becomes an attractive target for inhibition by viruses, especially due to the fact that many signaling pathways can be blocked simultaneously. It is surprising yet fascinating to observe the wide spectrum of mechanisms utilized by viruses to inhibit RIPK1. As shown in Fig 3, numerous viral proteins are implicated in RIPK1-mediated signaling. Additionally, understanding viral strategies used for evasion of RIPK1 signaling has revealed the multifunctionality of viral proteins. This is exemplified by the identification of distinct motifs such as RHIM and IPAM domains in viral proteins. For example, the IPAM motif is present in more than 70 viral R1 homologs of herpesviruses and baculoviruses suggesting that its function of inducing protein aggregation might be widely conserved (73). Understanding viral strategies of RIPK1 inhibition could potentially point towards unexplored viral-host interactions. Seeing such a variety of strategies evolved in viruses indicates the possibility that RIPK1 inhibition is more important for viral survival than has been known.

Since RIPK1 controls the outcome of many signaling pathways, the sum of the diverse functions attributable to RIPK1 may cooperatively contribute to the outcome. Therefore, it may be helpful to investigate the outcome of all the possible arms of innate immune responses controlled by RIPK1 during pathogen invasions. In particular, how the outcome of RIPK1 signaling affects viral replication could be studied. Physiologic extracellular signals that initiate RIPK1-mediated signaling could 
differ between in vivo and in vitro experimental models. For example, extracellular $\mathrm{pH}$, oxidants, and $\mathrm{Ca}^{2+}$ are known to trigger necroptosis (112). Therefore, distinct outcomes due to RIPK1 inhibition between these experimental models could be different. For example, even though RIPK1 kinase-deficient mice exhibited high viral titers following ZIKV infections, similar results were not observed in BMDM s or DCs after infecting with ZIKV (88).

How RIPK1 inhibition might benefit the virus over the host should also be more fully addressed. For example, necroptosis and inflammatory signaling regulated by RIPK1 may control viral replication but could be deleterious to the host and contribute to disease pathogenesis. For example, necroptosis following IAV infection has been speculated to contribute to pulmonary tissue damage and acute respiratory distress syndrome (ARDS) (113). At this point, however, there is still a limited understanding of specific effects of RIPK1 inhibition in disease pathogenesis during viral infections.

Overall, in this review, we discussed various strategies exploited by viruses to inhibit RIPK1-mediated signaling. Viral modulation of RIPK1-mediated signaling may lead to inhibition of NF- $\mathbf{\kappa}$ B responses, MAPK signaling, IFN induction and cell death mechanisms. It is likely that most viruses benefit by inhibiting these pathways because in vivo viral replication increases by RIPK1 inhibition. Understanding the impact of inhibition of RIPK1 signaling on the host and the virus may facilitate the development of the next generation of immunotherapeutic strategies against virus infections. 


\section{References}

1. Stanger BZ, Leder P, Lee TH, Kim E, Seed B. RIP: A novel protein containing a death domain that interacts with Fas/APO-1 (CD95) in yeast and causes cell death. Cell. 1995;81(4):513-23.

2. Ermolaeva MA, Michallet MC, Papadopoulou N, Utermöhlen O, Kranidioti K, Kollias G, et al. Function of TRADD in tumor necrosis factor receptor 1 signaling and in TRIF-dependent inflammatory responses. Nat Immunol. 2008;9(9):1037-46.

3. Park YH, Jeong MS, Park HH, Jang SB. Formation of the death domain complex between FADD and RIP1 proteins in vitro. Biochim Biophys Acta Proteins Proteomics [Internet]. 2013;1834(1):292-300. Available from: http://dx.doi.org/10.1016/j.bbapap.2012.08.013

4. Sun X, Yin J, Starovasnik MA, Fairbrother WJ, Dixit VM. Identification of a novel homotypic interaction motif required for the phosphorylation of receptorinteracting protein (RIP) by RIP3. J Biol Chem. 2002;277(11):9505-11.

5. Kaiser WJ, Upton JW, Mocarski ES. Receptor-Interacting Protein Homotypic Interaction Motif-Dependent Control of NF- $\kappa B$ Activation via the DNADependent Activator of IFN Regulatory Factors. J Immunol. 2008;181(9):6427-34.

6. Ofengeim D, Yuan J. Regulation of RIP1 kinase signalling at the crossroads of inflammation and cell death. Nat Rev Mol Cell Biol. 2013;14(11):727-36.

7. Gilmore TD. Introduction to NF- $\kappa \mathrm{B}$ : Players, pathways, perspectives. Oncogene. 2006;25(51):6680-4.

8. Poligone B, Baldwin AS. Positive and negative regulation of NF-kappaB by COX-2: roles of different prostaglandins. J Biol Chem. 2001 Oct;276(42):38658-64.

9. Catley MC, Chivers JE, Cambridge LM, Holden N, Slater DM, Staples KJ, et al. IL-1beta-dependent activation of NF-kappaB mediates PGE2 release via the expression of cyclooxygenase- 2 and microsomal prostaglandin $E$ synthase. FEBS Lett. 2003 Jul;547(1-3):75-9.

10. Vincenti MP, Coon CI, Brinckerhoff CE. Nuclear factor kappaB/p50 activates an element in the distal matrix metalloproteinase 1 promoter in interleukin1beta-stimulated synovial fibroblasts. Arthritis Rheum. 1998 Nov;41(11):198794. 
11. Hayden MS, West AP, Ghosh S. NF- $\kappa B$ and the immune response. Oncogene. 2006;25(51):6758-80.

12. Zhao J, He S, Minassian A, Li J, Feng P. Recent advances on viral manipulation of NF-KB signaling pathway. Curr Opin Virol. 2015;15:103-11.

13. Morelli M, Dennis AF, Patton JT. Putative E3 ubiquitin ligase of human rotavirus inhibits NF- $\kappa$ B activation by using molecular mimicry to target $\beta$ TrCP. MBio. 2015 Jan;6(1).

14. Chang TH, Chen SR, Yu CY, Lin YS, Chen YS, Kubota T, et al. Dengue virus serotype 2 blocks extracellular signal-regulated kinase and nuclear factor- $\kappa \mathrm{B}$ activation to downregulate cytokine production. PLoS One. 2012;7(8):4-11.

15. Hsu H, Huang J, Shu HB, Baichwal V, Goeddel D V. TNF-dependent recruitment of the protein kinase RIP to the TNF receptor-1 signaling complex. Immunity. 1996 Apr;4(4):387-96.

16. Micheau O, Tschopp J. Induction of TNF receptor I-mediated apoptosis via two sequential signaling complexes. Cell. 2003;114(2):181-90.

17. Shu HB, Takeuchi M, Goeddel D V. The tumor necrosis factor receptor 2 signal transducers TRAF2 and c-IAP1 are components of the tumor necrosis factor receptor 1 signaling complex. Proc Natl Acad Sci U S A. 1996 Nov;93(24):13973-8.

18. Degterev A, Hitomi J, Germscheid M, Ch'en IL, Korkina O, Teng X, et al. Identification of RIP1 kinase as a specific cellular target of necrostatins. Nat Chem Biol. 2008;4(5):313-21.

19. Holler N, Zaru R, Micheau O, Thome M, Attinger A, Valitutti S, et al. Fas triggers an alternative, caspase-8-independent cell death pathway using the kinase RIP as effector molecule. Nat Immunol. 2000 Dec;1(6):489-95.

20. Matsuda S, Gotoh Y, Nishida E. Signaling pathways mediated by the mitogenactivated protein (MAP) kinase kinase/MAP kinase cascade. J Leukoc Biol. 1994 Nov;56(5):548-53.

21. Kyriakis JM, Avruch J. Protein kinase cascades activated by stress and inflammatory cytokines. Bioessays. 1996 Jul;18(7):567-77.

22. Sabio G, Davis RJ. TNF and MAP kinase signalling pathways. Semin Immunol. 2014 Jun;26(3):237-45.

23. Foletta VC, Segal DH, Cohen DR. Transcriptional regulation in the immune system : all roads lead to AP-1. 1998;63(February):139-52. 
24. Shi J, Sun S. Tumor Necrosis Factor Receptor-Associated Factor Regulation of Nuclear Factor $\kappa$ B and Mitogen-Activated Protein Kinase Pathways. 2018;9(August):1-13.

25. Yuasa T, Ohno S, Kehrl JH, Kyriakis JM. Tumor necrosis factor signaling to stress-activated protein kinase (SAPK)/Jun NH2-terminal kinase (JNK) and p38. Germinal center kinase couples TRAF2 to mitogen-activated protein kinase/ERK kinase kinase 1 and SAPK while receptor interacting protein asso. J Biol Chem. 1998 Aug;273(35):22681-92.

26. Lee TH, Huang Q, Oikemus S, Shank J, Ventura J, Cusson N, et al. The Death Domain Kinase RIP1 Is Essential for Tumor Necrosis Factor Alpha Signaling to p38 Mitogen-Activated Protein Kinase. 2003;23(22):8377-85.

27. Fitzgerald KA, Palsson-McDermott EM, Bowie AG, Jefferies CA, Mansell AS, Brady G, et al. Mal (MyD88-adapter-like) is required for Toll-like receptor-4 signal transduction. Nature [Internet]. 2001;413(6851):78-83. Available from: https://doi.org/10.1038/35092578

28. Oshiumi H, Matsumoto M, Funami K, Akazawa T, Seya T. TICAM-1, an adaptor molecule that participates in Toll-like receptor 3-mediated interferonbeta induction. Nat Immunol. 2003 Feb;4(2):161-7.

29. Meylan E, Burns K, Hofmann K, Blancheteau V, Martinon F, Kelliher M, et al. RIP1 is an essential mediator of Toll-like receptor 3-induced NF $\kappa \mathrm{B}$ activation. Nat Immunol. 2004;5(5):503-7.

30. Kaiser WJ, Offermann MK. Apoptosis Induced by the Toll-Like Receptor Adaptor TRIF Is Dependent on Its Receptor Interacting Protein Homotypic Interaction Motif. J Immunol. 2005;174(8):4942-52.

31. Sato S, Sugiyama M, Yamamoto M, Watanabe Y, Kawai T, Takeda K, et al. Toll/IL-1 receptor domain-containing adaptor inducing IFN-beta (TRIF) associates with TNF receptor-associated factor 6 and TANK-binding kinase 1, and activates two distinct transcription factors, NF-kappa B and IFN-regulatory factor-3, in the Toll-like r. J Immunol. 2003 Oct;171(8):4304-10.

32. Sen GC, Sarkar SN. Transcriptional signaling by double-stranded RNA : role of TLR3. 2005;16:1-14.

33. Najjar M, Saleh D, Zelic M, Nogusa S, Shah S, Tai A, et al. RIPK1 and RIPK3 Kinases Promote Cell-Death-Independent Inflammation by Toll-like Receptor 4. Immunity [Internet]. 2016;45(1):46-59. Available from: http://dx.doi.org/10.1016/j.immuni.2016.06.007

34. Doyle S, Vaidya S, O'Connell R, Dadgostar H, Dempsey P, Wu T, et al. IRF3 
mediates a TLR3/TLR4-specific antiviral gene program. Immunity. 2002 Sep;17(3):251-63.

35. Cusson-Hermance N, Khurana S, Lee TH, Fitzgerald KA, Kelliher MA. Rip1 mediates the trif-dependent Toll-like receptor 3- and 4-induced NF-??B activation but does not contribute to interferon regulatory factor 3 activation. $\mathrm{J}$ Biol Chem. 2005;280(44):36560-6.

36. Hyun J, Ramos JC, Toomey N, Balachandran S, Lavorgna A, Harhaj E, et al. Oncogenic Human T-Cell Lymphotropic Virus Type 1 Tax Suppression of Primary Innate Immune Signaling Pathways. J Virol. 2015;89(9):4880-93.

37. Brisse M, Ly H. Comparative Structure and Function Analysis of the RIG-ILike Receptors : 2019;10(July):1-27.

38. Yoneyama M, Kikuchi M, Natsukawa T, Shinobu N, Imaizumi T, Miyagishi M, et al. The RNA helicase RIG-I has an essential function in double-stranded RNA-induced innate antiviral responses. 2004;5(7).

39. Kato H, Takeuchi O, Mikamo-satoh E, Hirai R, Kawai T, Matsushita K, et al. Length-dependent recognition of double- stranded ribonucleic acids by retinoic acid - inducible gene-I and melanoma diff erentiation - associated gene 5 . 2008;205(7):1601-10.

40. Kato H, Takeuchi O, Sato S, Yoneyama M, Yamamoto M, Matsui K, et al. Differential roles of MDA5 and RIG-I helicases in the recognition of RNA viruses. 2006;441(May):101-5.

41. Furr SR, Moerdyk-Schauwecker M, Grdzelishvili VZ, Marriott I. RIG-I mediates nonsegmented negative-sense RNA virus-induced inflammatory immune responses of primary human astrocytes. Glia. 2010 Oct;58(13):16209.

42. Spiropoulou CF, Ranjan P, Pearce MB, Sealy TK, Albariño CG, Gangappa S, et al. RIG-I activation inhibits ebolavirus replication. Virology. 2009 Sep;392(1):11-5.

43. van Kasteren PB, Beugeling C, Ninaber DK, Frias-Staheli N, van Boheemen S, García-Sastre A, et al. Arterivirus and Nairovirus Ovarian Tumor DomainContaining Deubiquitinases Target Activated RIG-I To Control Innate Immune Signaling. J Virol [Internet]. 2012 Jan 15;86(2):773 LP - 785. Available from: http://jvi.asm.org/content/86/2/773.abstract

44. Zhang Z, Filzmayer C, Ni Y, Sültmann H, Mutz P, Hiet M-S, et al. Hepatitis D virus replication is sensed by MDA 5 and induces IFN- $\beta / \lambda$ responses in hepatocytes. J Hepatol. 2018 Jul;69(1):25-35. 
45. Ye W, Chew M, Hou J, Lai F, Leopold SJ, Loo HL, et al. Microvesicles from malaria-infected red blood cells activate natural killer cells via MDA5 pathway. PLoS Pathog. 2018 Oct;14(10):e1007298.

46. Yu CY, Liang JJ, Li JK, Lee YL, Chang BL, Su CI, et al. Dengue Virus Impairs Mitochondrial Fusion by Cleaving Mitofusins. PLoS Pathog. 2015;11(12):1-24.

47. Mibayashi M, Martínez-Sobrido L, Loo Y-M, Cárdenas WB, Gale MJ, GarcíaSastre A. Inhibition of retinoic acid-inducible gene I-mediated induction of beta interferon by the NS1 protein of influenza A virus. J Virol. 2007 Jan;81(2):514-24.

48. Kawai T, Takahashi K, Sato S, Coban C, Kumar H, Kato H, et al. IPS-1, an adaptor triggering RIG-I- and Mda5-mediated type I interferon induction. Nat Immunol. 2005;6(10):981-8.

49. Weinlich R, Green DR. The Two Faces of Receptor Interacting Protein Kinase1. Mol Cell [Internet]. 2014;56(4):469-80. Available from: http://dx.doi.org/10.1016/j.molcel.2014.11.001

50. Balachandran S, Thomas E, Barber GN. A FADD-dependent innate immune mechanism in mammalian cells. Nature. 2004;432(7015):401-5.

51. Rajput A, Kovalenko A, Bogdanov K, Yang SH, Kang TB, Kim JC, et al. RIG-I RNA helicase activation of irf3 transcription factor is negatively regulated by caspase-8-mediated cleavage of the RIP1 protein. Immunity. 2011;34(3):34051 .

52. Mikkelsen SS, Jensen SB, Chiliveru S, Melchjorsen J, Julkunen I, Gaestel M, et al. RIG-I-mediated activation of p38 MAPK is essential for viral induction of interferon and activation of dendritic cells. Dependence on TRAF2 and TAK1. J Biol Chem. 2009;284(16):10774-82.

53. Ang RL, Chan M, Ting AT. Ripoptocide - A Spark for Inflammation. Front cell Dev Biol. 2019;7:163.

54. Jorgensen I, Rayamajhi M, Miao EA. Programmed cell death as a defence against infection. Nat Rev Immunol. 2017;17(3):151-64.

55. Orzalli MH, Kagan JC. Apoptosis and Necroptosis as Host Defense Strategies to Prevent Viral Infection. Trends Cell Biol [Internet]. 2017;27(11):800-9.

Available from: http://dx.doi.org/10.1016/j.tcb.2017.05.007

56. Feoktistova M, Geserick P, Kellert B, Dimitrova DP, Langlais C, Hupe M, et al. cIAPs block Ripoptosome formation, a RIP1/caspase- 8 containing intracellular cell death complex differentially regulated by cFLIP isoforms. Mol Cell. 2011 
Aug;43(3):449-63.

57. Tenev T, Bianchi K, Darding M, Broemer M, Langlais C, Wallberg F, et al. The Ripoptosome, a signaling platform that assembles in response to genotoxic stress and loss of IAPs. Mol Cell. 2011 Aug;43(3):432-48.

58. Lin Y, Devin A, Rodriguez Y, Liu ZG. Cleavage of the death domain kinase RIP by Caspase- 8 prompts TNF-induced apoptosis. Genes Dev. 1999;13(19):251426.

59. Vandenabeele P, Galluzzi L, Vanden Berghe T, Kroemer G. Molecular mechanisms of necroptosis: An ordered cellular explosion. Nat Rev Mol Cell Biol [Internet]. 2010;11(10):700-14. Available from: http://dx.doi.org/10.1038/nrm2970

60. Kaiser WJ, Sridharan H, Huang C, Mandal P, Upton JW, Gough PJ, et al. Tolllike receptor 3-mediated necrosis via TRIF, RIP3, and MLKL. J Biol Chem. 2013 Oct;288(43):31268-79.

61. Dhuriya YK, Sharma D. Necroptosis: a regulated inflammatory mode of cell death. J Neuroinflammation. 2018 Jul;15(1):199.

62. Cho YS, Challa S, Moquin D, Genga R, Ray TD, Guildford M, et al. Phosphorylation-Driven Assembly of the RIP1-RIP3 Complex Regulates Programmed Necrosis and Virus-Induced Inflammation. Cell [Internet]. 2009;137(6):1112-23. Available from: http://dx.doi.org/10.1016/j.cell.2009.05.037

63. Johnston A, Wang Z. Necroptosis: MLKL Polymerization. J Nat Sci. 2018 Jul;4(7).

64. De Almagro MC, Goncharov T, Izrael-Tomasevic A, Duttler S, Kist M, Varfolomeev E, et al. Coordinated ubiquitination and phosphorylation of RIP1 regulates necroptotic cell death. Cell Death Differ [Internet]. 2017;24(1):26-37. Available from: http://dx.doi.org/10.1038/cdd.2016.78

65. Suda J, Dara L, Yang L, Aghajan M, Song Y, Kaplowitz N, et al. Knockdown of RIPK1 Markedly Exacerbates Murine Immune-Mediated Liver Injury through Massive Apoptosis of Hepatocytes, Independent of Necroptosis and Inhibition of NF-кB. J Immunol [Internet]. 2016;197(8):3120-9. Available from: http://www.jimmunol.org/lookup/doi/10.4049/jimmunol.1600690

66. Farooq M, Filliol A, Simoes Eugénio M, Piquet-Pellorce C, Dion S, RaguenesNicol C, et al. Depletion of RIPK1 in hepatocytes exacerbates liver damage in fulminant viral hepatitis. Cell Death Dis [Internet]. 2019;10(1). Available from: http://dx.doi.org/10.1038/s41419-018-1277-3 
67. Whitley RJ. Herpesviruses. In: Baron S, editor. Galveston (TX); 1996.

68. Gottlieb SL, Giersing BK, Hickling J, Jones R, Deal C, Kaslow DC. Meeting report: Initial World Health Organization consultation on herpes simplex virus (HSV) vaccine preferred product characteristics, March 2017. Vaccine. 2019 Nov;37(50):7408-18.

69. Rafailidis PI, Mourtzoukou EG, Varbobitis IC, Falagas ME. Severe cytomegalovirus infection in apparently immunocompetent patients: a systematic review. Virol J. 2008 Mar;5:47.

70. Hjalgrim H, Askling J, Rostgaard K, Hamilton-Dutoit S, Frisch M, Zhang J-S, et al. Characteristics of Hodgkin's lymphoma after infectious mononucleosis. $\mathrm{N}$ Engl J Med. 2003 Oct;349(14):1324-32.

71. Huang Z, Wu SQ, Liang Y, Zhou X, Chen W, Li L, et al. RIP1/RIP3 binding to HSV-1 ICP6 initiates necroptosis to restrict virus propagation in mice. Cell Host Microbe [Internet]. 2015;17(2):229-42. Available from:

http://dx.doi.org/10.1016/j.chom.2015.01.002

72. Lamark T, Johansen T. Aggrephagy: selective disposal of protein aggregates by macroautophagy. Int J Cell Biol. 2012;2012:736905.

73. Muscolino E, Schmitz R, Loroch S, Caragliano E, Schneider C, Rizzato M, et al. Herpesviruses induce aggregation and selective autophagy of host signalling proteins NEMO and RIPK1 as an immune-evasion mechanism.

74. Guo H, Omoto S, Harris PA, Finger JN, Bertin J, Gough PJ, et al. Herpes simplex virus suppresses necroptosis in human cells. Cell Host Microbe [Internet]. 2015;17(2):243-51. Available from: http://dx.doi.org/10.1016/j.chom.2015.01.003

75. Ali M, Roback L, Mocarski ES, Samuel CE. cro Herpes simplex virus 1 ICP6 impedes TNF receptor 1 - induced necrosome assembly during compartmentalization to detergent-resistant membrane vesicles. 2019;294:9911004.

76. Krmpotic A, Bubic I, Polic B, Lucin P, Jonjic S. Pathogenesis of murine cytomegalovirus infection. Microbes Infect. 2003 Nov;5(13):1263-77.

77. Upton JW, Kaiser WJ, Mocarski ES. Cytomegalovirus M45 cell death suppression requires receptor-interacting protein (RIP) homotypic interaction motif (RHIM)-dependent interaction with RIP1. J Biol Chem. 2008;283(25):16966-70.

78. Mack C, Sickmann A, Lembo D, Brune W. Inhibition of proinflammatory and 
innate immune signaling pathways by a cytomegalovirus RIP1-interacting protein. Proc Natl Acad Sci U S A. 2008;105(8):3094-9.

79. Liu X, Li Y, Peng S, Yu X, Li W, Shi F, et al. Epstein-Barr virus encoded latent membrane protein 1 suppresses necroptosis through targeting RIPK1/3 ubiquitination article. Cell Death Dis [Internet]. 2018;9(2). Available from: http://dx.doi.org/10.1038/s41419-017-0081-9

80. Laherty CD, Hu HM, Opipari AW, Wang F, Dixit VM. The Epstein-Barr virus LMP1 gene product induces A20 zinc finger protein expression by activating nuclear factor kappa B. J Biol Chem. 1992 Dec;267(34):24157-60.

81. Wertz IE, O’Rourke KM, Zhou H, Eby M, Aravind L, Seshagiri S, et al. Deubiquitination and ubiquitin ligase domains of A20 downregulate NF-kappaB signalling. Nature. 2004 Aug;430(7000):694-9.

82. Gould EA, Solomon T. Pathogenic flaviviruses. Lancet (London, England). 2008 Feb;371(9611):500-9.

83. May FJ, Davis CT, Tesh RB, Barrett ADT. Phylogeography of West Nile virus: from the cradle of evolution in Africa to Eurasia, Australia, and the Americas. J Virol. 2011 Mar;85(6):2964-74.

84. Sejvar JJ. Clinical manifestations and outcomes of West Nile virus infection. Viruses. 2014 Feb;6(2):606-23.

85. Coyne CB, Lazear HM. Zika virus - reigniting the TORCH. Nat Rev Microbiol. 2016;14(11):707-15.

86. Hygino da Cruz LC, Nascimento OJM, Lopes FPPL, da Silva IRF. Neuroimaging Findings of Zika Virus-Associated Neurologic Complications in Adults. Am J Neuroradiol. 2018 Nov;39(11):1967 LP - 1974.

87. Daniels BP, Snyder AG, Olsen TM, Orozco S, Oguin TH, Tait SWG, et al. RIPK3 Restricts Viral Pathogenesis via Cell Death-Independent Neuroinflammation. Cell. 2017;169(2):301-313.e11.

88. Daniels BP, Kofman SB, Smith JR, Norris GT, Snyder AG, Kolb JP, et al. The Nucleotide Sensor ZBP1 and Kinase RIPK3 Induce the Enzyme IRG1 to Promote an Antiviral Metabolic State in Neurons. Immunity. 2019;50(1):6476.e4.

89. Vogt VM. Retroviral Virions and Genomes. In: Coffin JM, Hughes SH, Varmus HE, editors. Cold Spring Harbor (NY); 1997.

90. Lander ES, Linton LM, Birren B, Nusbaum C, Zody MC, Baldwin J, et al. 
Initial sequencing and analysis of the human genome. Nature. 2001 Feb;409(6822):860-921.

91. Weiss RA. Retrovirus classification and cell interactions. J Antimicrob Chemother. 1996 May;37 Suppl B:1-11.

92. UNAIDS, Global AIDS Update. In UNAIDS, Geneva; 2018.

93. Yoshida M, Miyoshi I, Hinuma Y. Isolation and characterization of retrovirus from cell lines of human adult T-cell leukemia and its implication in the disease. Proc Natl Acad Sci U S A. 1982 Mar;79(6):2031-5.

94. Nakayama D, Katamine S, Kanazawa H, Shibuya N, Kawase K, Moriuchi R, et al. Amplification of HTLV-1-related sequences among patients with neurological disorders in highly endemic Nagasaki: lack of evidence for association of HTLV-1 with multiple sclerosis. Jpn J Cancer Res. 1990 Mar;81(3):238-46.

95. Ozen A, Haliloğlu T, Schiffer CA. Dynamics of preferential substrate recognition in HIV-1 protease: redefining the substrate envelope. J Mol Biol. 2011 Jul;410(4):726-44.

96. Wagner RN, Reed JC, Chanda SK. HIV-1 protease cleaves the serine-threonine kinases RIPK1 and RIPK2. Retrovirology. 2015;12(1):1-16.

97. Tanaka A, Takahashi C, Yamaoka S, Nosaka T, Maki M, Hatanaka M. Oncogenic transformation by the tax gene of human T-cell leukemia virus type I in vitro. Proc Natl Acad Sci U S A. 1990 Feb;87(3):1071-5.

98. Sun S-C, Yamaoka S. Activation of NF-kappaB by HTLV-I and implications for cell transformation. Oncogene. 2005 Sep;24(39):5952-64.

99. Jacobs SE, Lamson DM, St George K, Walsh TJ. Human rhinoviruses. Clin Microbiol Rev. 2013 Jan;26(1):135-62.

100. McIntyre CL, Knowles NJ, Simmonds P. Proposals for the classification of human rhinovirus species A, B and C into genotypically assigned types. J Gen Virol. 2013 Aug;94(Pt 8):1791-806.

101. Fuchs R, Blaas D. Uncoating of human rhinoviruses. Rev Med Virol. 2010 Sep;20(5):281-97.

102. Croft SN, Walker EJ, Ghildyal R. Human Rhinovirus 3C protease cleaves RIPK1, concurrent with caspase 8 activation. Sci Rep [Internet]. 2018;8(1):111. Available from: http://dx.doi.org/10.1038/s41598-018-19839-4 
103. Regnery RL, Johnson KM, Kiley MP. Virion nucleic acid of Ebola virus. J Virol. 1980 Nov;36(2):465-9.

104. Gupta M, Mahanty S, Ahmed R, Rollin PE. Monocyte-derived human macrophages and peripheral blood mononuclear cells infected with ebola virus secrete MIP-1alpha and TNF-alpha and inhibit poly-IC-induced IFN-alpha in vitro. Virology. 2001 May;284(1):20-5.

105. Harcourt BH, Sanchez A, Offermann MK. Ebola virus selectively inhibits responses to interferons, but not to interleukin-1beta, in endothelial cells. J Virol. 1999 Apr;73(4):3491-6.

106. Teng Y, Wang Y, Zhang X, Liu W, Fan H, Yao H. Systematic Genome-wide Screening and Prediction of microRNAs in EBOV During the 2014 Ebolavirus Outbreak. Nat Publ Gr [Internet]. 2015;(May):1-17. Available from: http://dx.doi.org/10.1038/srep09912

107. Jacobs BL, Langland JO, Kibler K V, Denzler KL, White SD, Holechek SA, et al. Vaccinia virus vaccines: past, present and future. Antiviral Res. 2009 Oct;84(1):1-13.

108. Li M, Beg AA. Induction of necrotic-like cell death by tumor necrosis factor alpha and caspase inhibitors: novel mechanism for killing virus-infected cells. J Virol. 2000 Aug;74(16):7470-7.

109. Polykratis A, Hermance N, Zelic M, Roderick J, Kim C, Van T-M, et al. Cutting Edge: RIPK1 Kinase Inactive Mice Are Viable and Protected from TNFInduced Necroptosis In Vivo. J Immunol. 2014;193(4):1539-43.

110. Lee TH, Shank J, Cusson N, Kelliher MA. The kinase activity of Rip1 is not required for tumor necrosis factor-alpha-induced IkappaB kinase or p38 MAP kinase activation or for the ubiquitination of Rip1 by Traf2. J Biol Chem. 2004 Aug;279(32):33185-91.

111. Daniels BP, Kofman SB, Smith JR, Norris GT, Annelise G, Kolb JP, et al. HHS Public Access. 2020;50(1):64-76.

112. Belizário J, Vieira-Cordeiro L, Enns S. Necroptotic Cell Death Signaling and Execution Pathway: Lessons from Knockout Mice. Mediators Inflamm. 2015;2015:128076.

113. Balachandran S, Rall F. crossm Benefits and Perils of Necroptosis in Influenza Virus Infection. 2020;(January):1-9.

114. Filliol A, Piquet-Pellorce C, Le Seyec J, Farooq M, Genet V, Lucas-Clerc C, et al. RIPK1 protects from TNF- $\alpha$-mediated liver damage during hepatitis. Cell 
Death Dis [Internet]. 2016;7(11):1-13. Available from:

http://dx.doi.org/10.1038/cddis.2016.362 


\section{CHAPTER 3}

This manuscript was prepared for submission to PLOS PATHOGENS

\section{Dengue virus downregulates TNFR1- and TLR3-stimulated NF-KB activation by targeting RIPK1}

Darshika J. Udawatte ${ }^{1}$, Diane M. Lang ${ }^{1}$, Carey L. Medin ${ }^{1}$, Alan L. Rothman ${ }^{1 *}$

${ }^{1}$ Institute for Immunology and Informatics, Department of Cell and Molecular

Biology, University of Rhode Island, Providence, RI, USA

*Corresponding author

E-mail:alan_rothman@uri.edu (A. Rothman)

SHORT TITLE: RIPK1, a novel target of Dengue virus 


\begin{abstract}
Dengue virus (DENV) infection is the most prevalent arthropod-borne virus disease which is endemic in more than 100 countries. Several DENV proteins have been shown to target crucial host proteins to evade innate immune responses in order to establish a productive infection in humans. Here we report that the DENV protease, NS3, targets RIPK1 (Receptor Interacting Protein Kinase I), a central mediator of inflammation and cell death, and decreases intracellular protein levels during DENV infection. Furthermore, the decrease in RIPK1 protein results in the inhibition of TNFR- and TLR3-induced NF-кB activation. Our data demonstrate a novel mechanism by which DENV suppresses normal cellular functions to evade host innate immune responses. This perturbation may benefit DENV and contribute to the disease pathogenesis.
\end{abstract}

\title{
Author summary
}

Dengue virus infections are a major global health concern and approximately 3 billion people are at risk of infection. Dengue virus is able to establish successful infections in humans by evading host innate immune mechanisms. Understanding these evasion strategies would be helpful for designing effective therapeutics against dengue infection and disease. Here we report a novel target of Dengue virus, RIPK1. Dengue viral protease interacted with and decreased levels of RIPK1, disrupting the NF-кB signaling pathway involved in multiple innate immune responses. Our study provides new insights into critical host - pathogen interactions of an emerging viral 
pathogen.

\section{Introduction}

Dengue is the most prevalent arthropod-borne viral disease, with an estimated 400 million infections occurring annually (1). Infected individuals may develop severe symptoms leading to dengue hemorrhagic fever (DHF), dengue shock syndrome (DSS), and even death. The causative agent of dengue, dengue virus, is known to infect dendritic cells, macrophages, monocytes, B cells, T cells, hepatocytes, epithelial and endothelial cells (2-4). The magnitude of DENV replication and its regulation of immune responses contribute to the disease pathogenesis. Effective antiviral drugs and vaccines are not available to treat the dengue disease, which emphasizes the importance of understanding DENV-host interactions (5). DENV refers to a group of four closely related positive-sense, single-stranded RNA viruses or serotypes (DENV 1, 2, 3, 4), belonging to the Flaviviridae family. Upon entry into the host cell, the released viral genome is translated into one polypeptide, which gets cleaved into individual structural (capsid, PrM, and envelope) and non-structural proteins (NS1, NS2A, NS2B, NS3, NS4A, NS4B, NS5) by the viral protease complex, NS2B3, and host proteases (6). The individual DENV proteins generated are known to interact with numerous host proteins and interfere with host antiviral immune responses. DENV protease NS3 interacts with and cleaves STING and downregulates RLR (RIG-I like receptors) signaling (7). DENV protease also cleaves the mitochondrial proteins MFN1 and MFN2 and thereby impairs mitochondrial dynamics as well as efficient RLR signaling (8).

RIPK1 has emerged as an important regulator that controls multiple cellular 
pathways involved in inflammation and cell death (9). RIPK1 is involved in innate immune responses to bacterial and viral infections by inducing apoptosis or necroptosis or by inducing inflammatory signaling (10). Activation of death receptors such as TNFR1 leads to the formation of a multi-protein complex including RIPK1, complex I, which facilitates the activation of NF- $\mathbf{k B}$ and MAPK pathways to promote cell survival by inducing anti-apoptotic gene expression and the induction of proinflammatory cytokine gene expression (11). The scaffolding function of RIPK1 is critical for NF- $\mathbf{k B}$ activation. RIPK1 is also involved in mediating TRIF-dependent TLR3- and TLR4-induced NF- $\mathrm{\kappa B}$ activation $(12,13)$. RIPK1 can drive extrinsic apoptosis by activating caspase- 8 via the formation of a distinct multi-protein complex, complex IIa (14), and can drive signaling to necroptosis through formation of a complex with RIPK3 (complex IIb) $(15,16)$. RIPK1 also has been shown to regulate IRF3 transcription downstream of RIG-I/ MDA-5 complexes in response to RNA viruses (17). These pathways are crucial for mounting innate immune responses during viral infections. This central role of RIPK1 makes it an ideal target for inhibition by viruses, as has been shown for HIV-1 (18), human Rhinovirus 3C (19), and Epstein-Barr virus (20). However, no association between RIPK1 and DENV infection has been reported to date. Therefore, the objective of this study was to evaluate the effect of DENV infection on RIPK1 signaling. We show that RIPK1 is targeted by DENV protease NS3, which results in decreased RIPK1 protein levels during DENV infection. Consequently, TNF $\alpha$ - and poly (I:C)- induced NF-кB activation is impaired during DENV infection which may benefit viral replication. 


\section{Results}

\section{RIPK1 protein levels decrease with DENV infection}

DENV is known to infect hepatocytes and the liver is one of the major organs affected during DHF (21). We tested the effect of DENV infection on the human hepatoma cell line, Huh7. A time-course analysis of DENV2 infection revealed a reduction in intracellular RIPK1 protein concomitant with the expression of DENV NS3 as early as $6 \mathrm{~h}$ post-infection (Fig 1A). In order to see if this was a general effect, we infected cell lines originated from different human tissues with DENV2 as well as monocyte-derived dendritic cells (MoDC), which is a relevant primary cell system (22). We observed a significant decrease in endogenous RIPK1 protein levels with DENV2 infection in all the cells tested (Fig 1B). Overexpressed Flag-tagged RIPK1 was also decreased in a dose-response manner in DENV2-infected HEK 293T cells (Fig 1C). This effect was specific for RIPK1 since endogenous or overexpressed RIPK3 levels were not affected by DENV infection (Fig 1D). Different strains of DENV1 and DENV2 decreased RIPK1 significantly in Huh7 cells; however, no significant decrease was observed in cells infected with several strains of DENV3 or DENV4 (Fig 1E \& F).

Next, we investigated if DENV inhibited RIPK1 at a transcriptional level. A time-course study was done with DENV2 infection in Huh7 cells. We did not see a decrease in RIPK1 transcript levels, indicating that the downregulation of RIPK1 occurred at the post-transcriptional level (Fig $1 \mathrm{G} \& \mathrm{H}$ ). 


\section{RIPK1 is reduced by DENV protease}

Negative regulation of RIPK1 by caspase 8 is well known. During activation of death receptors, active caspase 8 cleaves RIPK1 in the intermediate domain at Asp 324 (23). Therefore, we first tested if active caspase 8 plays a role in decreasing RIPK1 levels during DENV infection. Caspase 8 inhibition by zVAD-FMK was not sufficient to restore the decreased RIPK1 levels during DENV infection (S1). These data suggest that the decrease in RIPK1 in DENV-infected cells is not a result of cleavage by caspase 8.

RIPK1 is known to be targeted by several viral proteases to counteract its functions and enhance viral replication $(18,19)$. Therefore, to evaluate the mechanism of RIPK1 reduction during DENV infection, we tested whether expression of the DENV NS2B3 protease complex was sufficient to reduce RIPK1 levels. We cotransfected a Flag-tagged RIPK1 and a plasmid encoding DENV NS2B3. We observed a dose response in RIPK1 reduction with the expression of DENV NS2B3 (Fig 2A, 2B). However, we did not detect the accumulation of a cleaved product of RIPK1 using antibodies targeting either the C-terminal or N-terminal segment of RIPK1. In order to determine if the protease activity was important for this effect, we created a catalytically inactive protease mutant, NS2B3-S135A (S2, (24)) Transfection of NS4B5-GFP, a target of DENV protease, confirmed the lack of protease activity of the mutant NS2B3 construct (25). Levels of neither endogenous nor overexpressed RIPK1 were affected upon transfection of NS2B3-S135A, demonstrating that protease activity of NS2B3 was required for the reduction of RIPK1 levels (Fig 2C). 
In order to evaluate if the reduction in RIPK1 is due to a direct effect of NS2B3 on RIPK1, we next performed co-immunoprecipitation experiments to detect a physical interaction between RIPK1 and NS2B3. HEK 293T cells were co-transfected with a Flag-tagged RIPK1 plasmid and a plasmid expressing either V5-tagged wild type (WT) DENV NS2B3 or NS2B3-S135A. DENV NS3 protein coimmunoprecipitated with RIPK1 when pulled down with anti-Flag (Fig 2D, lane 3). As expected, the reciprocal immunoprecipitation using anti-V5 antibodies confirmed this interaction. Strikingly, a physical interaction between RIPK1 and NS2B3-S135A was also detected using specific antibodies (Fig 2D, lane 4). This suggests that NS3 protease activity was not required for this protein-protein interaction even though it was necessary for decreasing RIPK1 levels (Fig 2C). We then validated the interaction of RIPK1 and NS3 in the context of DENV infection. HEK 293T cells transiently expressing Flag-RIPK1 were infected with DENV2 for 48hrs, then RIPK1 was immunoprecipitated using an anti-Flag antibody. We detected DENV NS3 bound to RIPK1 by western blot analysis (Fig 2E lane 2). We performed the reciprocal immunoprecipitation using an anti-DENV NS3 antibody and detected RIPK1 bound to DENV-NS3 by western blot analysis, verifying the interaction (Fig 2E).

\section{DENV impairs TNFR- and TLR3-induced NF-kB activation}

RIPK1 is an adapter molecule downstream of TNFR and TLRs and plays an important role in downstream signaling leading to NF- $\mathbf{k B}$ activation (3). Having established that DENV NS3 decreases RIPK1, we examined whether the loss of RIPK1 disrupts NF- $\mathbf{k B}$ activation during DENV infection. First, in order to test how 
NF- $\mathrm{\kappa B}$ activation is affected downstream of TNFR, Huh7 cells were transfected with a plasmid encoding a luciferase gene driven by NF- $\mathbf{k B}$ response elements and a plasmid expressing Renilla luciferase as a control. Cells were stimulated with TNFa either prior to or after DENV infection. Cells were cultured for $48 \mathrm{hrs}$ post-infection and the luciferase activity was measured as described in Methods. NF- $\mathbf{k B}$ activation in response to TNFa was significantly attenuated in DENV-infected cells as compared to uninfected cells when TNFa was added either before or after infection (Fig. 3A). We then assessed NF- $\mathbf{k B}$ luciferase activity in response to TNFa stimulation with overexpression of RIPK1 in HEK 293T cells. NF-кB luciferase activity was significantly reduced with DENV infection but this was restored by overexpression of RIPK1 (Fig 3B).

We then examined the effect of DENV infection on NF- $\mathrm{KB}$ activation in response to TLR3 stimulation. HEK 293T cells stably expressing TLR3 were transfected with the luciferase reporter plasmids with or without the Flag-RIPK1 plasmid and then infected with DENV (MOI=3). They were further stimulated with poly I:C for $24 \mathrm{hrs}$ and luciferase activity was measured. DENV infection impaired poly I:C-induced NF-אB activation relative to uninfected cells (Fig 3C). Overexpression of RIPK1 increased NF- $\mathbf{k B}$ activity in both uninfected and DENVinfected cells. However, even with RIPK1 overexpression, there was a significant decrease in NF- $\mathbf{k B}$ activity in the presence of DENV relative to uninfected cells (Fig 3C). These results demonstrate that DENV infection impairs NF- $\mathbf{k B}$ activation downstream of both TNFR and TLR3 by decreasing RIPK1 protein levels.

We further investigated if DENV NS2B3 downregulated NF- $\mathbf{\text { B }}$ activation by 
targeting RIPK1. NF- $\mathbf{k B}$ luciferase assays were performed with co-transfection of Flag-RIPK1 and WT NS2B3 or NS2B3-S135A. Increased NF- $\mathbf{B B}$ activity due to overexpression of RIPK1 was attenuated by expression of WT NS2B3 but not by NS2B3-S135A (Fig 3D). These data indicate that expression of DENV NS2B3 is sufficient to inhibit NF- $\mathrm{kB}$ activation by RIPK1, but that the physical interaction between NS2B3 and RIPK1 is insufficient for this effect. 


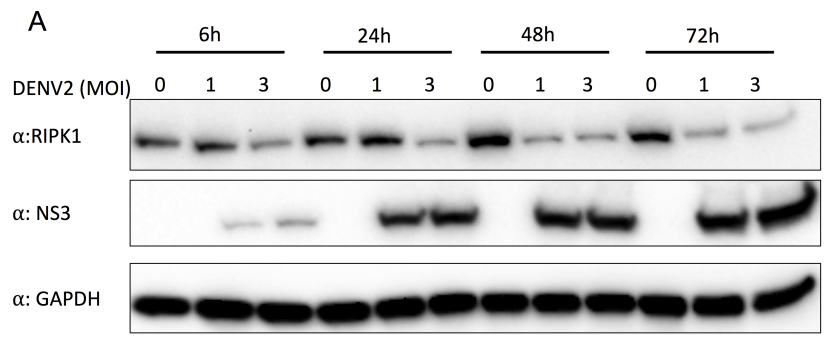

C
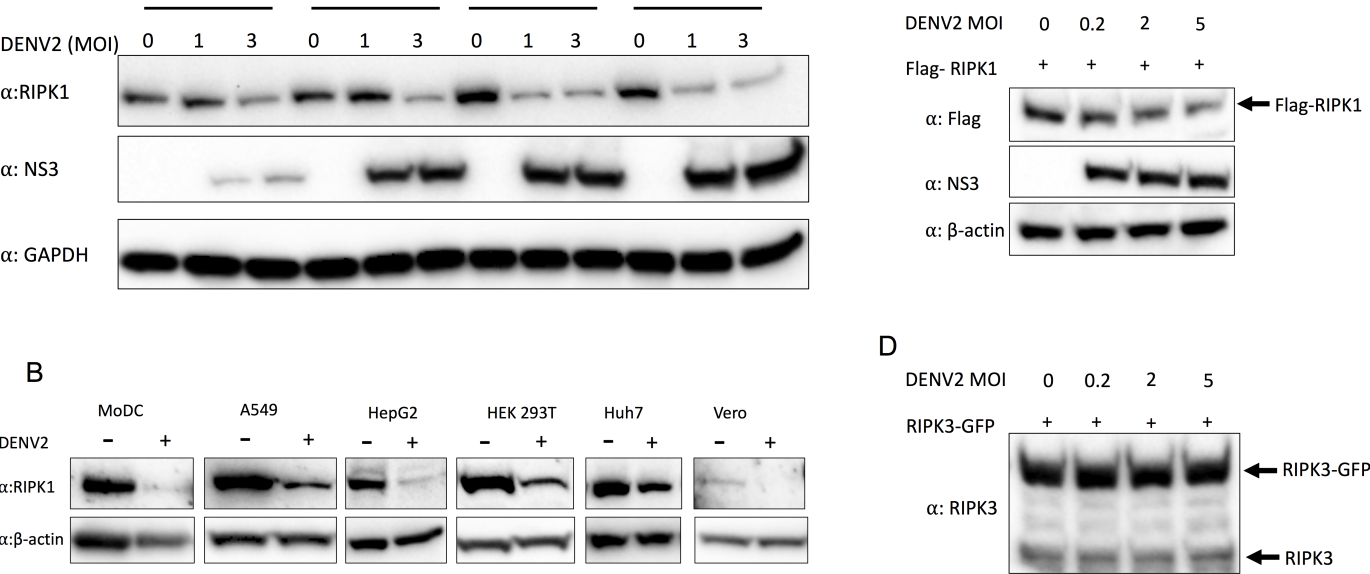

D
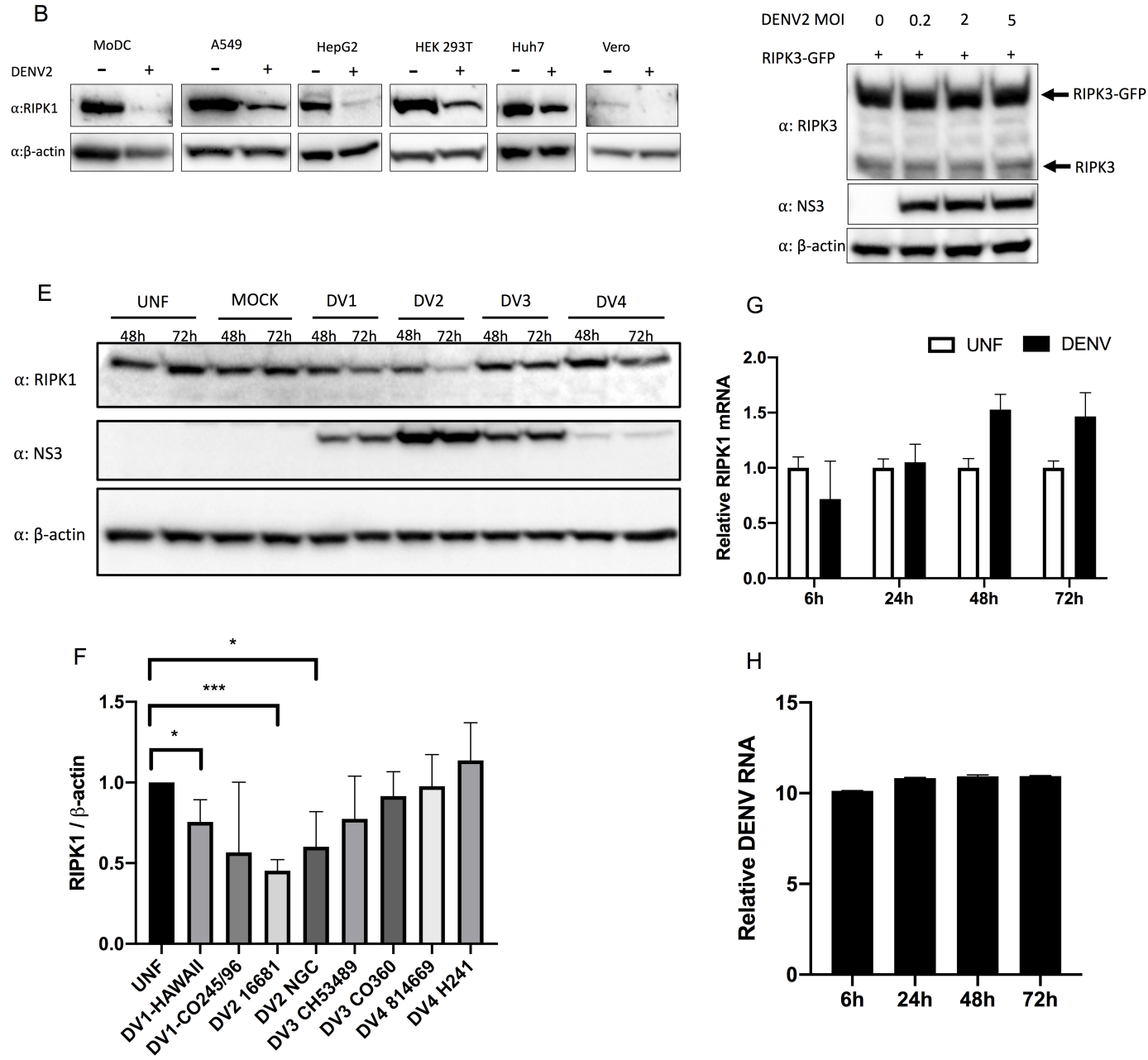

Figure 1. Endogenous and overexpressed RIPK1 decreases during DENV infection. (A) Time course study of DENV2 infection in human Huh7 cells with MOI 
of 1 and 3 for the indicated hrs. Cell lysates were harvested for western blot analysis using the indicated antibodies. (B) Western blot analysis of RIPK1 in indicated cells infected with DENV2 $(\mathrm{MOI}=2)$ and cultured for $48 \mathrm{hrs}$. $\boldsymbol{\beta}$-actin was used as a loading control. (C) Western blot analysis of overexpressed RIPK1 and (D) RIPK3 followed by DENV2 infection in HEK $293 \mathrm{~T}$ cells at $48 \mathrm{~h}$ post-infection. (E) Western blot analysis of Huh7 cells infected with different DENV strains for 48 or $72 \mathrm{hrs}$ and probed with antibodies to RIPK1 and DENV NS3. (F) RIPK1 band intensities at 72hrs p.i. were normalized to $\boldsymbol{\beta}$-actin and were quantified by Image Lab software from 3 independent experiments. Data are mean $\pm \mathrm{SD}$ and were compared by Student's $t$ test (GraphPad Prism 8). (G) RT-qPCR analysis of total RNA isolated from Huh7 cells infected with DENV2 (MOI=2) for $(\mathrm{G})$ RIPK1or $(\mathrm{H})$ intracellular DENV RNA for the indicated time points. Data are mean $\pm \mathrm{SD}$ ( $\mathrm{n}=2$ experiments) and were compared by Student's $t$ test (GraphPad Prism 8). Western blots are representative data from a minimum of 3 independent experiments (panels A-E). 

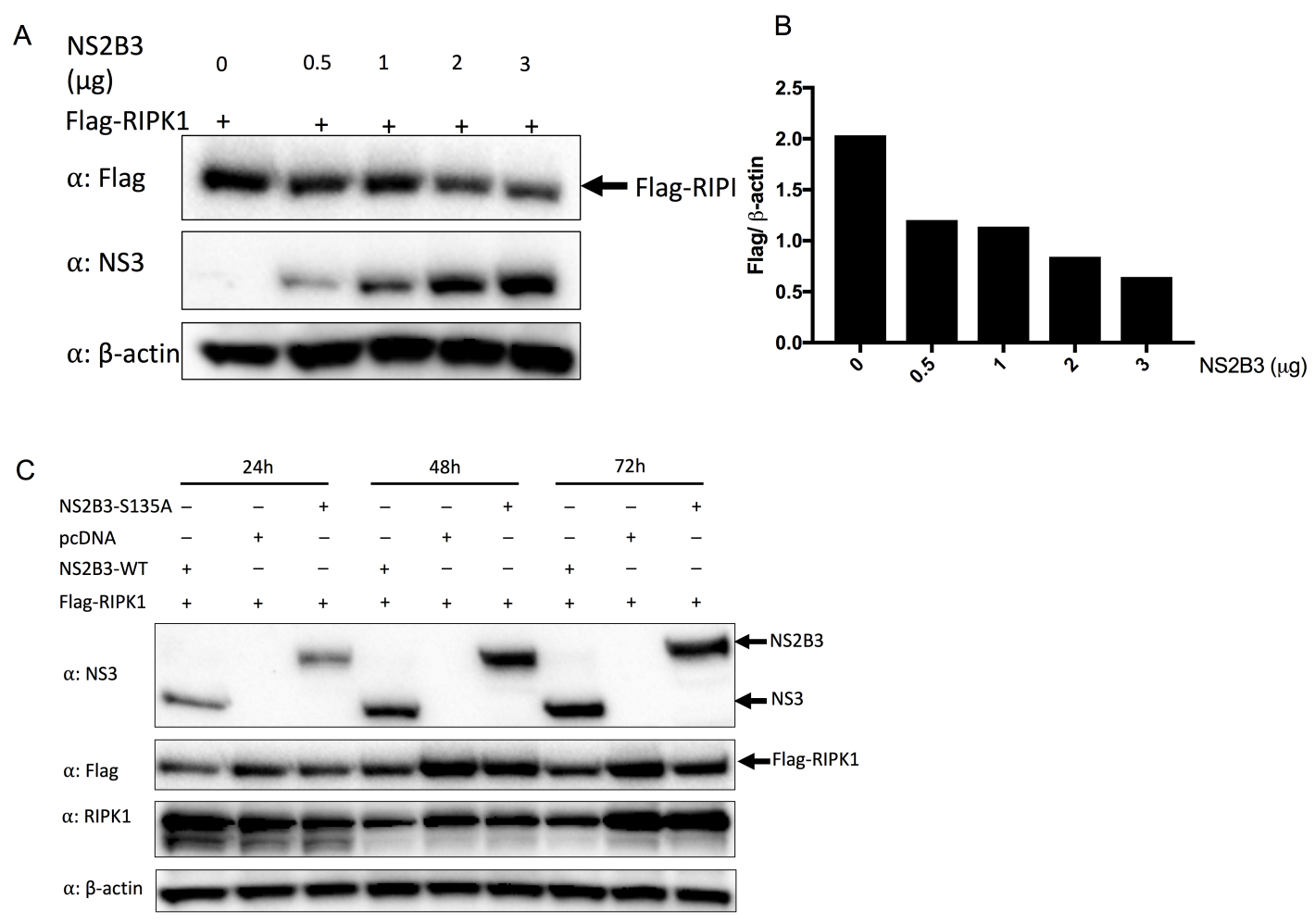

D
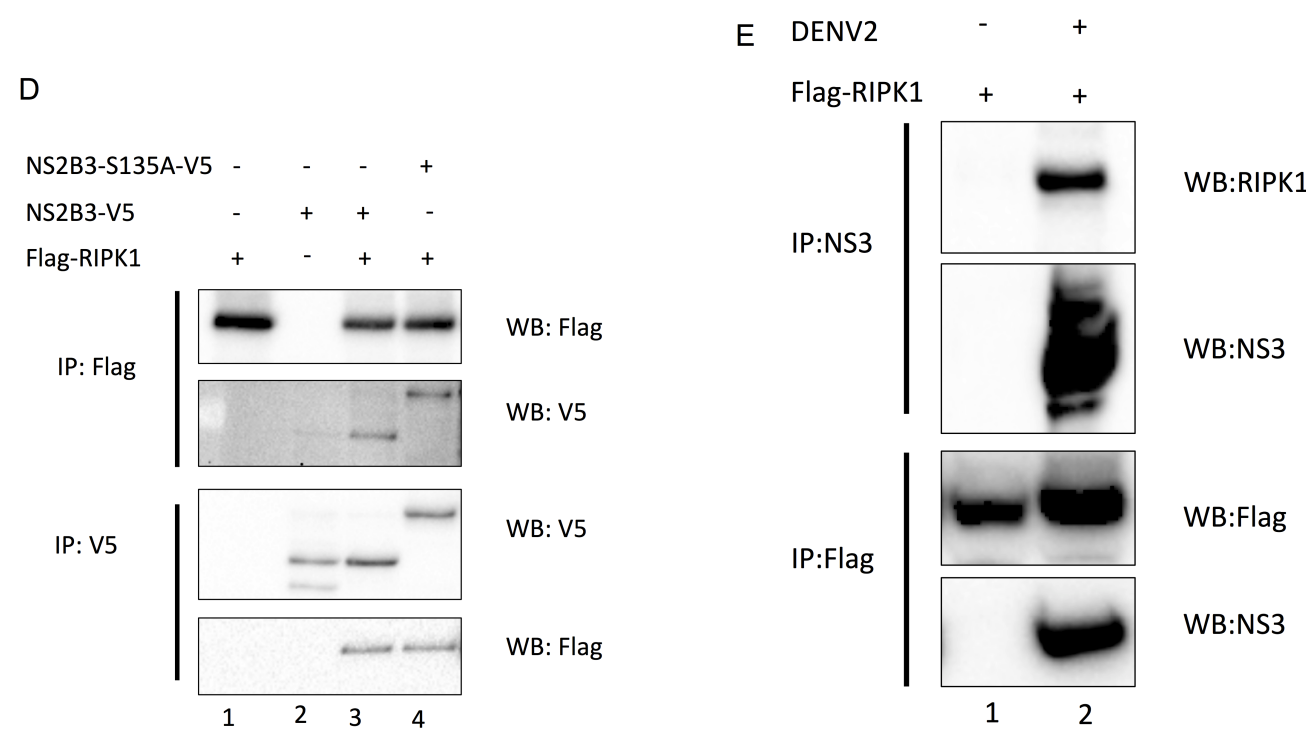

Figure 2. DENV NS3 protease interacts with and decreases RIPK1. (A) Western blot analysis of HEK 293T cells co-transfected with Flag-RIPK1 and increasing concentrations of a plasmid expressing the DENV NS2B3 protease complex. (B) 
Densitometric analysis of RIPK1 band intensities normalized to $\beta$-actin levels. Results are from a single experiment and are representative of at least three separate experiments. (C) Western blot analysis of HEK 293T cells co-transfected with FlagRIPK1 and plasmids expressing either WT NS2B3, NS2B3-S135A or an empty vector (pcDNA) and cultured for the indicated times. (D) Co-immunoprecipitation analyses of HEK 293T cells transiently overexpressing Flag-RIPK1 and WT NS2B3 or NS2B3S135A DENV protease complexes. (E) Co-immunoprecipitation analyses of HEK $293 \mathrm{~T}$ cells transfected with Flag-RIPK1 and mock (media) or DENV (MOI=1) infected for $48 \mathrm{hrs}$. IP = immunoprecipitation, IB = immunoblot. 


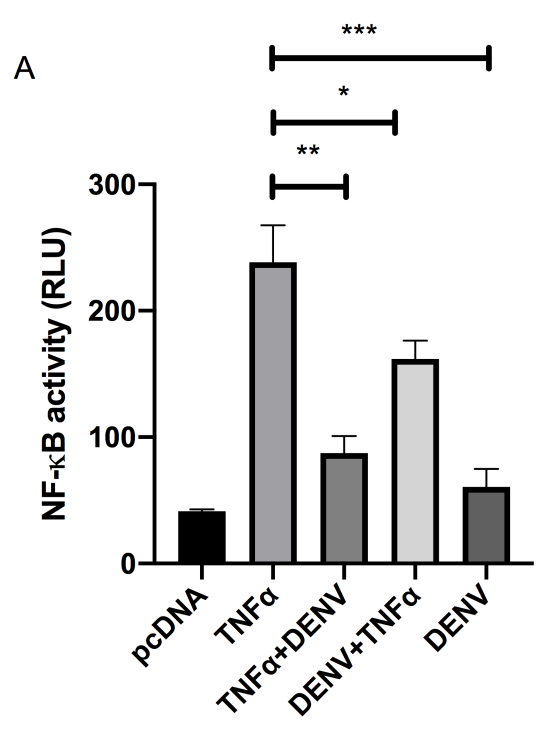

B

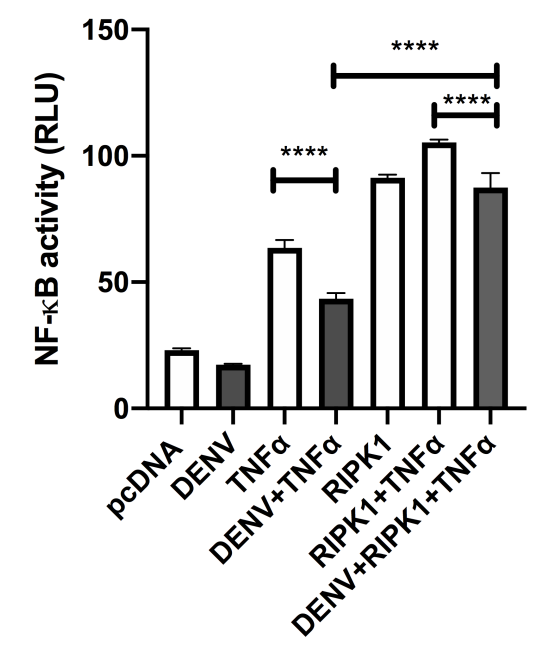

C

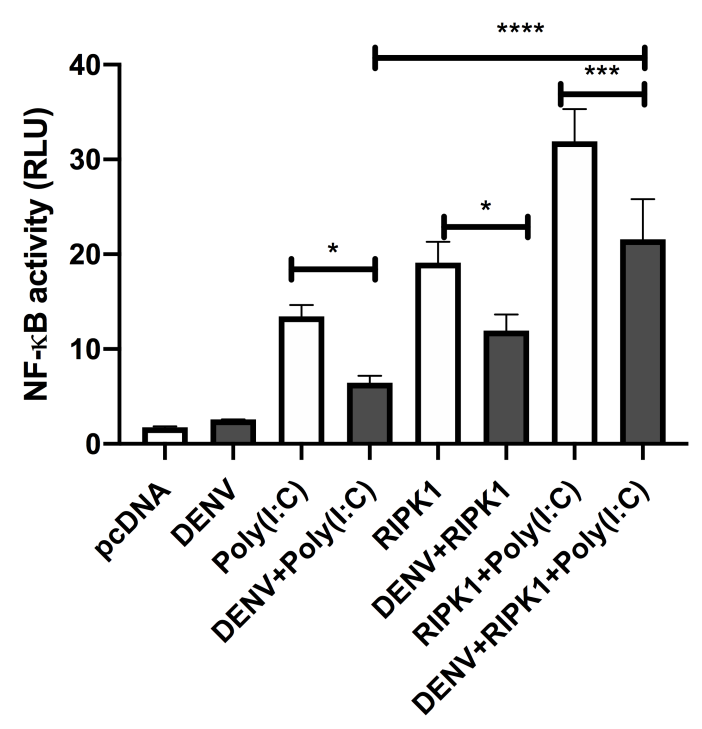

D

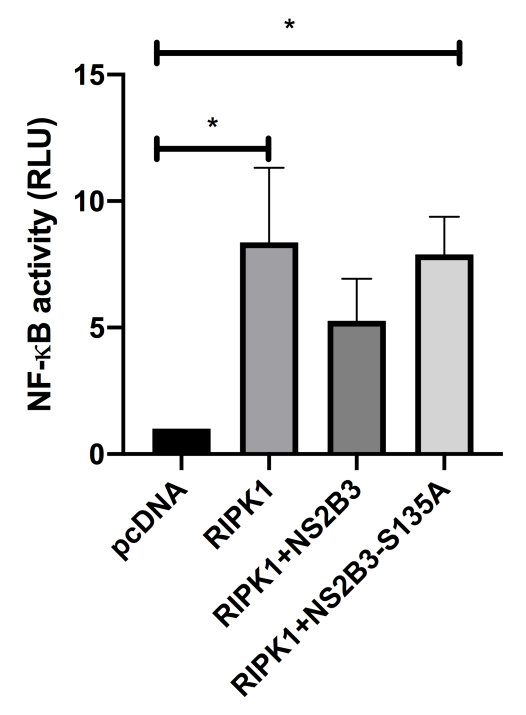


Figure 3. TNF $\alpha$ - and poly(I:C)-driven NF- $\mathrm{B}$ activation is impaired during DENV infection. (A) NF-кB luciferase activity was assessed in Huh7 cells cotransfected with a NF-кB luciferase reporter and a control Renilla luciferase reporter plasmid and stimulated with hTNF $\alpha(50 \mathrm{ng} / \mathrm{ml})$ before or after DENV2 infection and cultured for 48hrs (B) HEK $293 \mathrm{~T}$ cells were co-transfected with NF-кB luciferase reporter, Renilla luciferase reporter and Flag-RIPK1 followed by DENV2 infection (MOI=3). Following $\mathrm{TNF} \alpha(50 \mathrm{ng} / \mathrm{ml})$ treatment for $24 \mathrm{hrs}$, cells were lysed, and luciferase activity was measured at $72 \mathrm{hrs}$ post-infection. (C) NF- $\mathrm{\kappa B}$ luciferase activity was assessed in HEK 293T-TLR3 cells as in (D) and cells were stimulated with poly (I:C) $20 \mu \mathrm{g} / \mathrm{ml}$ for $24 \mathrm{hrs}$ before cell lysis. (D) HEK $293 \mathrm{~T}$ cells were co-transfected with NF-кB luciferase reporter, Renilla luciferase reporter, and Flag-RIPK1 along with WT DENV NS2B3 or NS2B3-S135A. Luciferase activity was detected at 48hrs post-transfection. Results are representative of at least three independent experiments and are expressed as mean $\pm \mathrm{SD}$ from three biological replicates. (One-way ANOVA, $\mathrm{P}<0.0001)$ 
S1

$\begin{array}{lllll} & \text { zVAD } & \text { zVAD } & \text { zVAD } & \text { STP } \\ \text { DMSO } & \text { 10uM } & \text { 20uM } & \text { 40uM } & 1 \text { 1uM }\end{array}$

DENV2

$\alpha:$ RIPK1

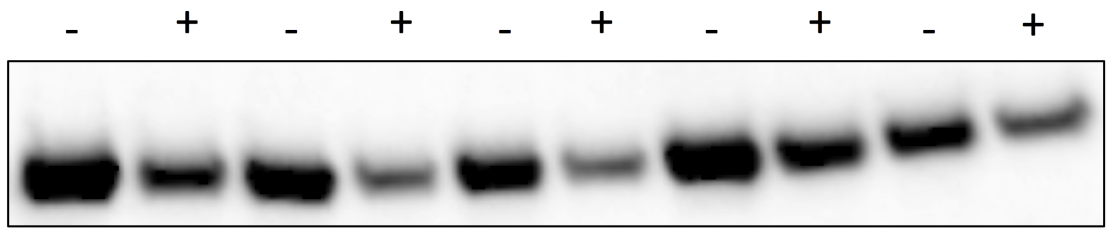

$\alpha$ : NS3

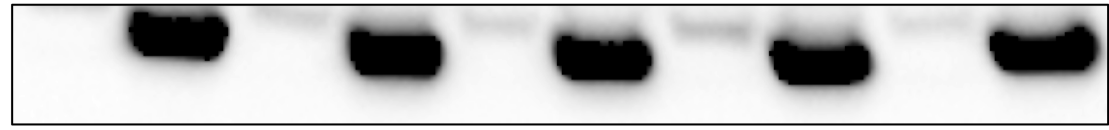

$\alpha:$ GAPDH

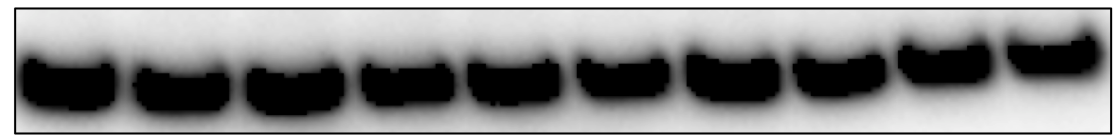

S2

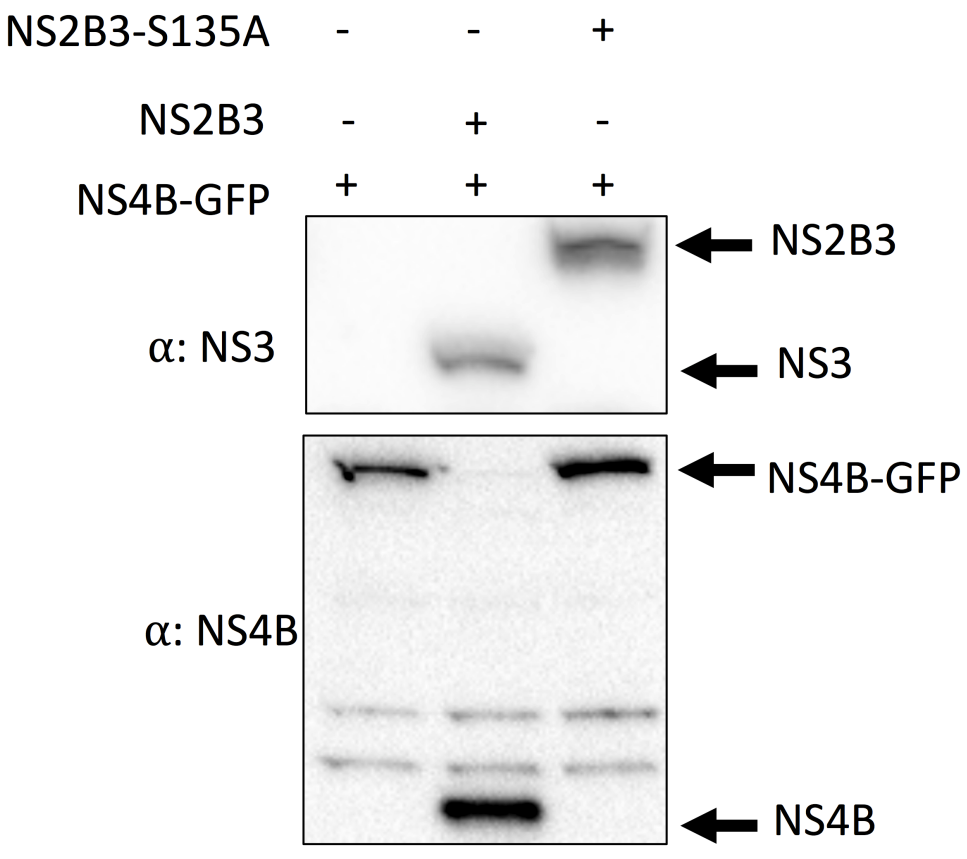




\section{Supporting information}

Figure S1. Caspase 8 does not contribute to RIPK1 decrease in DENV infection. Western blot analysis of RIPK1 levels in HUH7 cells with inhibition of caspase activity by zVAD-FMK or treated with DMSO or Staurosporine following $42 \mathrm{hrs}$ of DENV2 infection.

Figure S2. DENV NS2B3-S135A lacks protease activity. Western blot analysis of HEK 293T cells transfected with WT NS2B3 or NS2B3-S135A along with a substrate (NS4B5) for protease activity. Cell lysates were harvested 48hrs post-transfection and protein expression was analyzed by anti DENV NS3 or anti DENV NS4B. 


\section{Discussion}

RIPK1 is a critical regulator of cell death and inflammation, and acts as an important adapter protein downstream of several receptors including TNFR, TLR3, TLR4, and RIG-I (26). Recently an anti-viral role of RIPK1 has emerged as it is involved in modulating an inflammatory form of cell death, necroptosis, and is also implicated in modulating NF- $\mathrm{B}$ and IFN responses $(17,27,28)$. Therefore, we investigated the role of RIPK1 in DENV infection. We observed a pronounced reduction of RIPK1 during DENV infection in multiple cell types, including primary monocyte-derived dendritic cells. This effect could be reproduced by expression of the functionally active DENV protease, NS3. Furthermore, we demonstrated an inhibitory effect of DENV infection on NF-кB activation in response to TNFa and poly I:C by targeting RIPK1.

DENV is known to target host proteins to evade host innate immune responses. DENV NS5 protein is involved in degrading STAT2 to interfere with IFN responses (29). DENV protease complex NS2B3 interacts with and cleaves STING and downregulates the RLR pathway (7). DENV protease is also involved in cleaving mitochondrial proteins MFN1 and MFN2 and thereby impairs mitochondrial dynamics as well as efficient RLR signaling (8). Previous findings also show that protease cofactor NS2B interacts with cGAS and promotes it for autophagosome-mediated degradation (30). These strategies serve to enhance viral replication.

Our findings add RIPK1 to the list of host proteins targeted by the DENV protease. Targeting of RIPK1 has the potential to give an added advantage to the virus since RIPK1 mediates several crucial signaling pathways. RIPK1 has an $\mathrm{N}$ terminal 
kinase domain, a RHIM (RIP homotypic interaction motif) containing intermediate domain, and a $\mathrm{C}$ terminal death domain (DD). RIPK1 binds to the DD of FADD, TNFR1, TRADD (31-33). The RHIM domain of RIPK1 mediates interactions with other RHIM containing proteins such as RIPK3, TRIF, and ZBP1 $(13,34,35)$. Here, we observed a physical interaction between RIPK1 and DENV NS3. There may be other proteins involved in this NS3-RIPK1 complex. The domains and motifs of DENV NS3 and RIPK1 important for this interaction have to be determined. There have been a few published studies and databases on DENV-human protein-protein interactions (36,37), but none reported RIPK1 as a target of DENV protease, NS3. This could be due to the fact that endogenous RIPK1 remains undetected for Mass Spectrometry due to the significant reduction in protein levels by DENV.

Caspase 8 is known to negatively regulate RIPK1 by cleaving it following the induction of extrinsic apoptosis (23). However, decreased RIPK1 levels were seen during DENV infection even with inhibition of caspase 8 (S1). Furthermore, RIPK1 was not inhibited at the transcriptional level by DENV (Fig 1H). Interestingly, the catalytic activity of NS2B3 was important for RIPK1 reduction since catalytically inactive mutant NS2B3-S135A did not decrease RIPK1 efficiently. However, we were not able to detect a cleaved/degraded product of RIPK1 using either C-terminal or Nterminal targeting antibodies. These data suggest that the product of cleavage by NS2B3 is too small to detect or could have been further degraded rapidly by other cellular mechanisms such as proteasome-mediated or lysosome-mediated degradation. Nevertheless, we hypothesize that NS2B3 plays a direct role in decreasing RIPK1 levels based on the evidence of a physical interaction of DENV NS3 and RIPK1. The 
NS2B3-S135A mutant also interacted with RIPK1 demonstrating that the catalytic site is not required for this interaction. Similarly, both the active and inactive NS2B3 interacted with STING but only the active protease was able to effectively decrease its levels (7).

Increased serum TNFa levels have been reported in patients with dengue (38). The interaction of TNFa and TNFR1 results in the formation of complex I leading to NF- $\mathbf{k B}$ activation (39). NF- $\mathbf{k B}$ transcription factors regulate a large number of genes involved in immune responses. Therefore, signaling leading to NF-kB activation serves as an anti-viral immune mechanism. Viruses inhibit NF- $\mathbf{B}$ pathway activation to evade these host immune and inflammatory responses (40). DENV infection was shown to block NF- $\mathbf{B}$ activation downstream of TLR signaling resulting in downregulated cytokine production (41). Similar studies in Huh7 and monocytederived macrophages showed that DENV infection altered cellular responses to TNFa stimulation (42). However, the mechanism by which DENV caused these altered responses had not been defined. We demonstrated that DENV infection diminished

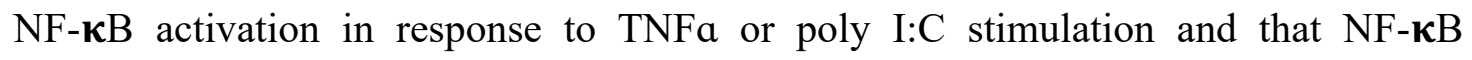
promoter activity drastically increased when RIPK1 was overexpressed both in the presence and the absence of DENV infection. We also demonstrated that increased NF- $\mathbf{B}$ luciferase activity in response to the over-expression of RIPK1 was significantly decreased with the over-expression of WT NS2B3 but not with NS2B3S135A. Together these results show that the levels of RIPK1 are critical for regulating upstream signals leading to NF- $\mathbf{B}$ activation and that DENV infection dampens NFкB transcription by targeting RIPK1. 
Liver injury is a common finding in DENV infection and can lead to organ failure. Apoptosis of hepatocytes following DENV infection is believed to contribute to this phenomenon (21). Recent findings show a protective role of RIPK1 in TNFa-mediated apoptosis in hepatocytes $(43,44)$. RIPK1 knockout mice showed enhanced sensitivity to $\mathrm{TNF} \alpha$-mediated apoptosis and inflammation. Induction of NF- $\mathbf{B}$ target gene transcripts was also suppressed in these mice. Therefore, we speculate that loss of RIPK1 during DENV infection may sensitize hepatocytes to cell death and inflammation, which could contribute to liver injury in DHF. We observed differences between DENV strains in their effect on RIPK1 levels. These differences could relate to differences in protease structures and might contribute to differences in disease manifestations but further analysis would be required to establish those associations $(45-47)$

To the best of our knowledge, this is the first description of DENV targeting RIPK1. This is also the first report of inhibition of NF- $\mathbf{k B}$ signaling by the DENV protease NS2B3 by targeting RIPK1. These findings open up new research directions on the interplay of DENV with various emerging functions of RIPK1. Further studies are required to shed light on cell- and context-dependent effects of RIPK1 reduction in vivo during DENV infection. Finally, we believe that these data expand knowledge of strategies used by DENV to evade innate immune responses. 


\section{Materials and methods}

\section{Cell culture and virus infection}

Huh7, HEK 293T cells stably expressing TLR3 ( generous gifts from Dr. Kate Fitzgerald), HEK 293T (Dharmacon, Inc.) Vero, Huh 7.5 (obtained from American Type Culture Collection (ATCC)) were maintained in Dulbecco's modified minimal essential medium and HepG2 (ATCC) cells were maintained in Eagle's Minimum Essential Medium, supplemented with $10 \%$ heat-inactivated fetal bovine serum (Sigma-Aldrich), 1\% penicillin-streptomycin (Sigma-Aldrich), 1\% non-essential amino acids (Lonza) and 1\% L-Glutamine solution (Sigma-Aldrich). All cells were incubated in a humidified chamber at $37{ }^{\circ} \mathrm{C}$ and $5 \% \mathrm{CO}$. Prototype DENV strains DENV1 Hawaii, DENV1 CO245/96, DENV2 16681, DENV2 New Guinea C (NGC), DENV3 CH53489, DENV3 CO360, DENV4 814669 and DENV4 H241 were originally obtained from the American Type Culture Collection, the Walter Reed Army Institute of Research or Armed Forces Research Institute for Medical Sciences (Bangkok, Thailand), and were passaged multiple times in C6/36 cells (ATCC, USA). Virus titers were determined by immunostained plaque assay on Vero cells $(25,48)$.

\section{Generation of MoDCs}

Peripheral blood mononuclear cells (PBMCs) were isolated from buffy coat of healthy donors obtained from Oklahoma Blood Institute (Oklahoma City, OK) by density gradient centrifugation on Ficoll- Paque Premium (GE Healthcare). Monocytes were isolated from PBMCs by positive selection using CD14+ microbeads (Miltenyi Biotec). Monocytes were cultured in RPMI 1640 medium supplemented with 10\% heat-inactivated FBS (Sigma-Aldrich), 1\% penicillin- streptomycin (Sigma-Aldrich), 
$50 \mathrm{ng} / \mathrm{mL}$ human interleukin-4 (IL-4) and $160 \mathrm{ng} / \mathrm{mL}$ human granulocyte-macrophage colony-stimulating factor (GM-CSF) for 5 days to generate monocyte-derived dendritic cells (MoDCs). Fresh medium with cytokines was added at day 3, and cells were infected with DENV2 at day 5.

\section{Antibodies and reagents}

The following primary antibodies were used for co-immunoprecipitation and western blot experiments: anti-Flag-HRP (sc-166355, Santa Cruz Biotechnology), mouse antiRIPK3 (sc-374639, Santa Cruz Biotechnology), anti- $\beta$-actin-HRP (ab20272, Abcam), anti-V5 tag (ab27671, Abcam), anti V5-HRP (R961-25, Invitrogen), anti-GAPDHHRP (MA515738) anti-DENV NS3 (GTX124252, GeneTex), anti-DENV NS4B (GTX103349, GeneTex), anti-RIPK1 (D94C12, Cell Signaling Technology) and mouse anti-DENV2 (MAB8702, EMD Millipore). Secondary antibodies used were goat anti-rabbit-HRP (32260, Thermo Scientific), anti-mouse-HRP (sc516102, Santa Cruz Biotechnology).

\section{Caspase 8 inhibition}

HUH7 cells were infected with DENV2 (MOI=1) and cultured for $48 \mathrm{hrs}$. Cells were treated with $10 \mu \mathrm{M}-40 \mu \mathrm{M}$ of a pan caspase inhibitor; z-VAD-FMK (SC-3067, Santa Cruz Biotechnology) or DMSO (BP231-100, Fisher Scientific) or $1 \mu \mathrm{M}$ of Staurosporine (S4400, Sigma Aldrich) for 6hrs before cell lysis. 


\section{Western Blot analysis}

Cells were lysed in RIPA buffer freshly supplemented with a protease and phosphatase inhibitor cocktail (Sigma aldrich). Lysates were incubated on ice for $30 \mathrm{~min}$ with vortexing every 5 minutes and centrifuged at $10,000 \mathrm{rpm}$ for $5 \mathrm{~min}$ at $4{ }^{\circ} \mathrm{C}$. Supernatants were used as total cell lysates. Protein concentrations were determined using Pierce BCA Protein Assay kit (Thermo Fisher Scientific) following manufacturer's instructions and measured using an Envision plate reader (PerkinElmer). BOLT LDS Sample Buffer and Reducing Agent (Thermo Fisher Scientific) were added to cell lysates at a final concentration of $1 \mathrm{x}$ and samples were denatured at $70{ }^{\circ} \mathrm{C}$ for $10 \mathrm{~min}$. Proteins were separated on $4-12 \%$ or $8 \%$ BOLT BisTris Plus gel (Thermo Fisher Scientific) and transferred onto nitrocellulose membranes using the Trans-Blot ${ }^{\circledR}$ TurboTM RTA Mini Nitrocellulose Transfer kit (Bio-Rad). Membranes were blocked in 5\% milk in phosphate buffered saline with $0.1 \%$ Tween 20 for $1 \mathrm{~h}$ at room temperature $(\mathrm{rt})$ followed by incubation with the appropriate primary antibody overnight at $4{ }^{\circ} \mathrm{C}$. Membranes were washed and incubated with the appropriate secondary antibody diluted in blocking buffer for 1 hour at rt. For $\beta$-actin and GAPDH analysis, membranes were stained for 1 hour with corresponding antibodies. Detection of blots was done using Amersham ECL Select Western Blotting Detection Reagent (GE Healthcare Life Sciences) following the manufacturer's guidelines and images were captured with ChemiDocTM XRS+ System (Bio-Rad). Detection and quantification of band intensities were performed using Image Lab 5.1 
(Bio-Rad).

\section{Co-Immunoprecipitation}

Cells were lysed with RIPA buffer containing a cocktail of protease and phosphatase inhibitors. Protein G dynabeads (Thermo Fisher Scientific) were incubated with either mouse anti-Flag (Santa Cruz), mouse anti-V5 (abcam) or mouse anti NS3 (Genetex) for $1 \mathrm{hr}$ at $\mathrm{rt}$. Then, cell lysates were incubated with antibody-coated beads overnight at $4^{\circ} \mathrm{C}$. The immunocomplex was eluted under denaturing conditions according to the manufacturer's recommendations, and then examined by Western blot analysis.

\section{Plasmids, and transfections}

The following plasmids were used in our study: pNS4B5-eGFP, pNS2B3-V5 (16). pNS2B3-S135A was created by site-directed mutagenesis (Quik Change II sitedirected mutagenesis kit, Agilent Technologies) using WT NS2B3 plasmid. The plasmid sequence was verified by DNA sequencing. Plasmids expressing Flag-RIPK1 and RIPK3-GFP were obtained from Addgene. The luciferase reporter constructs containing a tandem repeat of the consensus binding site for the transcription factor NF- $\mathbf{k B}$, and a Renilla reniformis luciferase were obtained from Strategene.

Transfection of cells with plasmids was performed using GeneJuice ${ }^{\circledR}$ Transfection Reagent (EMD Millipore), according to the manufacturer's instructions.

\section{RT-qPCR analysis}


Total RNA was extracted from cell pellets using the RNeasy Mini Kit (Qiagen). Quantitative RT- PCR was performed using iTaq Universal probes 1 step kit (Biorad) or iTaq Universal SYBR Green 1 step kit (Biorad) on a Bio-Rad CFX machine, and gene expression was normalized to $\beta$-actin expression level. Taqman gene expression assays (RIPK1) were purchased from Thermofisher Scientific. DENV primers were purchased from Integrated DNA Technology (IDT) and RT-qPCR was performed to detect relative DENV RNA in cell lysates (40).

\section{Luciferase reporter assays}

HEK 293T cells were plated in 96 well plates and were co-transfected with a NF-кB luciferase reporter, a Renilla luciferase reporter and, and a plasmid encoding Flagtagged RIPK1 using GeneJuice ${ }^{\circledR}$ Transfection Reagent (EMD Millipore), according to the manufacturer's protocol. Co-transfected cells were infected with DENV2 (NGC, MOI=3) and were cultured for $72 \mathrm{hrs}$ and were stimulated with $\mathrm{hTNFa}(50 \mathrm{ng} / \mathrm{ml})$.

Luciferase activity was quantified using the dual Glo luciferase assay system (Promega). HEK 293T cells stably expressing TLR3 were co-transfected and infected with DENV as described above and were stimulated with poly I:C $(20 \mu \mathrm{g} / \mathrm{ml})$ for 24hrs. At the end of the treatment, luciferase activity was measured using the dual Glo luciferase assay system (Promega).

\section{Statistical analysis}

The statistical analyses were performed using one-way analysis of variance (ANOVA), 
with Tukey's methods or the unpaired, two-tailed, Student's t-test. P values were calculated using Graphpad Prism 8 program. Differences were considered statistically significant at $\mathrm{P}$ values less than 0.05 . 


\section{Acknowledgements}

We would like to thank Dr. Kate Fitzgerald for generously providing HEK 293T cells stably expressing TLR3, and Dr. Drishya Diwaker for technical assistance. Research reported in this publication was supported by the National Institute of Allergy and

Infectious Diseases of the National Institutes of Health under award number P01AI034533. The content is solely the responsibility of the authors and does not necessarily represent the official views of the National Institutes of Health. 


\section{References}

1. Bhatt S, Gething PW, Brady OJ, Messina JP, Farlow AW, Moyes CL, et al. The global distribution and burden of dengue. Nature [Internet].

2013;496(7446):504-7. Available from: http://dx.doi.org/10.1038/nature12060

2. King AD, Nisalak A, Kalayanrooj S, Myint KS, Pattanapanyasat K, Nimmannitya S, et al. B cells are the principal circulating mononuclear cells infected by dengue virus. Southeast Asian J Trop Med Public Health [Internet]. 1999 Dec;30(4):718 - 728. Available from:

http://europepmc.org/abstract/MED/10928366

3. Silveira GF, Wowk PF, Cataneo AHD, dos Santos PF, Delgobo M, Stimamiglio MA, et al. Human T Lymphocytes Are Permissive for Dengue Virus Replication. J Virol. 2018;92(10):e02181-17.

4. Martina BEE, Koraka P, Osterhaus ADME. Dengue virus pathogenesis: An integrated view. Clin Microbiol Rev. 2009;22(4):564-81.

5. Low JGH, Ooi EE, Vasudevan SG. Current status of dengue therapeutics research and development. J Infect Dis. 2017;215(Suppl 2):S96-102.

6. Clum S, Ebner KE, Padmanabhan R. Cotranslational membrane insertion of the serine proteinase precursor NS2B-NS3(Pro) of dengue virus type 2 is required for efficient in vitro processing and is mediated through the hydrophobic regions of NS2B. J Biol Chem. 1997;272(49):30715-23.

7. Aguirre S, Maestre AM, Pagni S, Patel JR, Savage T, Gutman D, et al. DENV Inhibits Type I IFN Production in Infected Cells by Cleaving Human STING. PLoS Pathog. 2012;8(10).

8. Yu CY, Liang JJ, Li JK, Lee YL, Chang BL, Su CI, et al. Dengue Virus Impairs Mitochondrial Fusion by Cleaving Mitofusins. PLoS Pathog. 2015;11(12):1-24.

9. Ofengeim D, Yuan J. Regulation of RIP1 kinase signalling at the crossroads of inflammation and cell death. Nat Rev Mol Cell Biol. 2013;14(11):727-36. 
10. Upton JW, Kaiser WJ. DAI Another Way: Necroptotic Control of Viral Infection. Cell Host Microbe [Internet]. 2017;21(3):290-3. Available from: http://dx.doi.org/10.1016/j.chom.2017.01.016

11. Hsu H, Huang J, Shu HB, Baichwal V, Goeddel D V. TNF-dependent recruitment of the protein kinase RIP to the TNF receptor-1 signaling complex. Immunity. 1996 Apr;4(4):387-96.

12. Cusson-Hermance N, Khurana S, Lee TH, Fitzgerald KA, Kelliher MA. Rip1 mediates the trif-dependent Toll-like receptor 3- and 4-induced NF-??B activation but does not contribute to interferon regulatory factor 3 activation. $\mathrm{J}$ Biol Chem. 2005;280(44):36560-6.

13. Meylan E, Burns K, Hofmann K, Blancheteau V, Martinon F, Kelliher M, et al. RIP1 is an essential mediator of Toll-like receptor 3-induced NF $\kappa \mathrm{B}$ activation. Nat Immunol. 2004;5(5):503-7.

14. Micheau O, Tschopp J. Induction of TNF receptor I-mediated apoptosis via two sequential signaling complexes. Cell. 2003;114(2):181-90.

15. Cho YS, Challa S, Moquin D, Genga R, Ray TD, Guildford M, et al. Phosphorylation-Driven Assembly of the RIP1-RIP3 Complex Regulates Programmed Necrosis and Virus-Induced Inflammation. Cell [Internet]. 2009;137(6):1112-23. Available from:

http://dx.doi.org/10.1016/j.cell.2009.05.037

16. He S, Wang L, Miao L, Wang T, Du F, Zhao L, et al. Receptor Interacting Protein Kinase-3 Determines Cellular Necrotic Response to TNF- $\alpha$. Cell [Internet]. 2009;137(6):1100-11. Available from:

http://dx.doi.org/10.1016/j.cell.2009.05.021

17. Rajput A, Kovalenko A, Bogdanov K, Yang SH, Kang TB, Kim JC, et al. RIG-I RNA helicase activation of irf3 transcription factor is negatively regulated by caspase-8-mediated cleavage of the RIP1 protein. Immunity [Internet]. 2011;34(3):340-51. Available from: http://dx.doi.org/10.1016/j.immuni.2010.12.018

18. Wagner RN, Reed JC, Chanda SK. HIV-1 protease cleaves the serine-threonine 
kinases RIPK1 and RIPK2. Retrovirology. 2015;12(1):1-16.

19. Croft SN, Walker EJ, Ghildyal R. Human Rhinovirus $3 \mathrm{C}$ protease cleaves RIPK1, concurrent with caspase 8 activation. Sci Rep [Internet]. 2018;8(1):111. Available from: http://dx.doi.org/10.1038/s41598-018-19839-4

20. Liu X, Li Y, Peng S, Yu X, Li W, Shi F, et al. Epstein-Barr virus encoded latent membrane protein 1 suppresses necroptosis through targeting RIPK1/3 ubiquitination article. Cell Death Dis [Internet]. 2018;9(2). Available from: http://dx.doi.org/10.1038/s41419-017-0081-9

21. Samanta J. Dengue and its effects on liver. World J Clin Cases [Internet]. 2015;3(2):125. Available from: http://www.wjgnet.com/2307$8960 /$ full/v3/i2/125.htm

22. Ho LJ, Wang JJ, Shaio MF, Kao CL, Chang DM, Han SW, et al. Infection of human dendritic cells by dengue virus causes cell maturation and cytokine production. J Immunol. 2001 Feb;166(3):1499-506.

23. Lin Y, Devin A, Rodriguez Y, Liu ZG. Cleavage of the death domain kinase RIP by Caspase-8 prompts TNF-induced apoptosis. Genes Dev. 1999;13(19):2514 26.

24. Yu C-Y, Hsu Y-W, Liao C-L, Lin Y-L. Flavivirus Infection Activates the XBP1 Pathway of the Unfolded Protein Response To Cope with Endoplasmic Reticulum Stress. J Virol [Internet]. 2006;80(23):11868-80. Available from: http://jvi.asm.org/cgi/doi/10.1128/JVI.00879-06

25. Medin CL, Valois S, Patkar CG, Rothman AL. A plasmid-based reporter system for live cell imaging of dengue virus infected cells. J Virol Methods [Internet]. 2015;211:55-62. Available from:

http://dx.doi.org/10.1016/j.jviromet.2014.10.010

26. Weinlich R, Green DR. The Two Faces of Receptor Interacting Protein Kinase1. Mol Cell [Internet]. 2014;56(4):469-80. Available from:

http://dx.doi.org/10.1016/j.molcel.2014.11.001 
27. Jorgensen I, Rayamajhi M, Miao EA. Programmed cell death as a defence against infection. Nat Rev Immunol. 2017;17(3):151-64.

28. Dondelinger Y, Jouan-Lanhouet S, Divert T, Theatre E, Bertin J, Gough PJ, et al. NF-кB-Independent Role of IKK $\alpha /$ IKK $\beta$ in Preventing RIPK1 KinaseDependent Apoptotic and Necroptotic Cell Death during TNF Signaling. Mol Cell. 2015;60(1):63-76.

29. Ashour J, Laurent-Rolle M, Shi P-Y, Garcia-Sastre A. NS5 of Dengue Virus Mediates STAT2 Binding and Degradation. J Virol. 2009;83(11):5408-18.

30. Aguirre S, Luthra P, Sanchez-Aparicio MT, Maestre AM, Patel J, Lamothe F, et al. Dengue virus NS2B protein targets cGAS for degradation and prevents mitochondrial DNA sensing during infection. Nat Microbiol [Internet]. 2017;2(March):1-11. Available from: http://dx.doi.org/10.1038/nmicrobiol.2017.37

31. Stanger BZ, Leder P, Lee TH, Kim E, Seed B. RIP: A novel protein containing a death domain that interacts with Fas/APO-1 (CD95) in yeast and causes cell death. Cell. 1995;81(4):513-23.

32. Ermolaeva MA, Michallet MC, Papadopoulou N, Utermöhlen O, Kranidioti K, Kollias G, et al. Function of TRADD in tumor necrosis factor receptor 1 signaling and in TRIF-dependent inflammatory responses. Nat Immunol. 2008;9(9):1037-46.

33. Park YH, Jeong MS, Park HH, Jang SB. Formation of the death domain complex between FADD and RIP1 proteins in vitro. Biochim Biophys Acta Proteins Proteomics [Internet]. 2013;1834(1):292-300. Available from: http://dx.doi.org/10.1016/j.bbapap.2012.08.013

34. Sun X, Yin J, Starovasnik MA, Fairbrother WJ, Dixit VM. Identification of a novel homotypic interaction motif required for the phosphorylation of receptorinteracting protein (RIP) by RIP3. J Biol Chem. 2002;277(11):9505-11.

35. Kaiser WJ, Upton JW, Mocarski ES. Receptor-Interacting Protein Homotypic Interaction Motif-Dependent Control of NF- $\mathrm{kB}$ Activation via the DNADependent Activator of IFN Regulatory Factors. J Immunol. 
2008;181(9):6427-34.

36. Dey L, Mukhopadhyay A. DenvInt: A database of protein-protein interactions between dengue virus and its hosts. PLoS Negl Trop Dis. 2017;11(10):1-12.

37. Shah PS, Link N, Jang GM, Sharp PP, Zhu T, Swaney DL, et al. Comparative Flavivirus-Host Protein Interaction Mapping Reveals Mechanisms of Dengue and Zika Virus Pathogenesis. Cell. 2018;175(7):1931-1945.e18.

38. Yadav M, Kamath KR, Iyngkaran N, Sinniah M. Dengue haemorrhagic fever and dengue shock syndrome: are they tumour necrosis factor-mediated disorders? FEMS Microbiol Lett. 1991;89(1):45-9.

39. Aggarwal BB. Signalling pathways of the TNF superfamily: A double-edged sword. Nat Rev Immunol. 2003;3(9):745-56.

40. Zhao J, He S, Minassian A, Li J, Feng P. Recent advances on viral manipulation of NF-kB signaling pathway. Curr Opin Virol. 2015;15:103-11.

41. Chang TH, Chen SR, Yu CY, Lin YS, Chen YS, Kubota T, et al. Dengue virus serotype 2 blocks extracellular signal-regulated kinase and nuclear factor- $\mathrm{\kappa B}$ activation to downregulate cytokine production. PLoS One. 2012;7(8):4-11.

42. Wati S, Rawlinson SM, Ivanov RA, Dorstyn L, Beard MR, Jans DA, et al. Tumour necrosis factor alpha (TNF- $\alpha$ ) stimulation of cells with established dengue virus type 2 infection induces cell death that is accompanied by a reduced ability of TNF- $\alpha$ to activate nuclear factor $\kappa b$ and reduced sphingosine kinase-1 activity. J Gen Virol. 2011;92(4):807-18.

43. Farooq M, Filliol A, Simoes Eugénio M, Piquet-Pellorce C, Dion S, RaguenesNicol C, et al. Depletion of RIPK1 in hepatocytes exacerbates liver damage in fulminant viral hepatitis. Cell Death Dis [Internet]. 2019;10(1). Available from: http://dx.doi.org/10.1038/s41419-018-1277-3

44. Filliol A, Piquet-Pellorce C, Le Seyec J, Farooq M, Genet V, Lucas-Clerc C, et al. RIPK1 protects from TNF- $\alpha$-mediated liver damage during hepatitis. Cell Death Dis [Internet]. 2016;7(11):1-13. Available from: 
http://dx.doi.org/10.1038/cddis.2016.362

45. Chandramouli S, Joseph JS, Daudenarde S, Gatchalian J, Cornillez-Ty C, Kuhn P. Serotype-Specific Structural Differences in the Protease-Cofactor Complexes of the Dengue Virus Family. J Virol. 2010;84(6):3059-67.

46. Vaughn DW, Green S, Kalayanarooj S, Innis BL, Nimmannitya S, Suntayakorn S, et al. Dengue Viremia Titer, Antibody Response Pattern, and Virus Serotype Correlate with Disease Severity. (1):2-9.

47. Soo K, Khalid B, Ching S, Chee H. Meta-Analysis of Dengue Severity during Infection by Different Dengue Virus Serotypes in Primary and Secondary Infections. 2016;4-14.

48. Liu L, Wen K, Li J, Hu D, Huang Y, Qiu L, et al. Comparison of plaque- and enzyme-linked immunospot-based assays to measure the neutralizing activities of monoclonal antibodies specific to domain III of dengue virus envelope protein. Clin Vaccine Immunol. 2012;19(1):73-8. 


\section{CHAPTER 4}

\section{Additional mechanisms and implications of RIPK1 downregulation by DENV}

\section{DENV does not mediate RIPK1 degradation via proteasomes or lysosomes}

\section{Introduction}

The ubiquitin-proteasome and the autophagy-lysosome pathways are the two major-protein degradation routes in eukaryotic cells (1). Proteasomes are barrelshaped multi protein complexes that mediate degradation of short-lived and misfolded proteins (2). Most proteins are covalently modified with ubiquitin ( $\mathrm{Ub}$ ) before they are targeted for proteasomal degradation. Usually, three enzymes; ubiquitin-activating (E1), ubiquitin-conjugating (E2) and ubiquitin-ligating (E3), are involved in this process, as shown in Fig 1 (3).

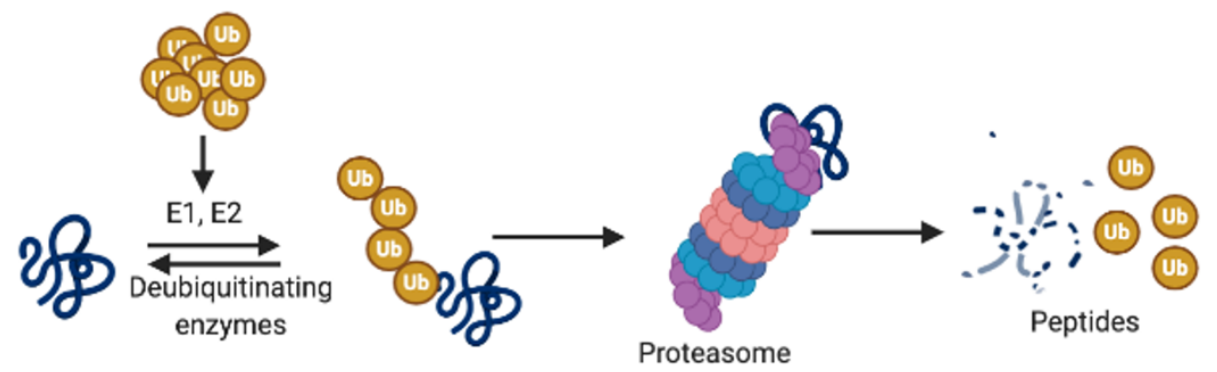

Figure 1. Schematic diagram of the ubiquitin-proteasome system. Specific substrates and misfolded proteins are degraded by the proteasome machinery following ubiquitination. 
There is evidence of DENV targeting the proteasome pathway to degrade key host proteins to evade host immune responses. The reduction in STAT2 protein levels by the DENV NS5 protein was blocked by treatment with the proteasome inhibitor, MG-132, indicating that intact proteasome activity was required for the STAT2 reduction (4). DENV NS2B3 cleaved mitochondrial proteins MFN1 and MFN2, and the cleaved fragments were further degraded by host proteasome machinery (5).

The degradation of cytoplasmic proteins or organelles via the lysosome is predominantly mediated by autophagy (6). This process involves the formation of autophagosomes/ autophagic vacuoles surrounding the proteins to be degraded (Fig 2). These vacuoles fuse with lysosomes to form autophago-lysosomes. The interior contents of autophago-lysosomes then get degraded by acidic lysosomal hydrolases. The cytosolic protein LC3-II, which is derived from LC3-I, is recruited to the outer membrane of the developing autophagosome and plays a major role in autophagosome elongation. Therefore, LC3-I to LC3-II conversion and LC3-II degradation detected by western blotting is used as a marker for autophagy (7). DENV has been shown to increase protein degradation via the autophagy-lysosome pathway. DENV protease cofactor NS2B interacted with and promoted autophagosome-mediated degradation of cGAS, which is a key component in the DNA sensing pathway (8). cGAS protein levels in the presence of NS2B increased upon treatment with an autophagy inhibitor (3MA) or lysosome inhibitors (Chloroquine/CLQ, $\mathrm{NH}_{4} \mathrm{Cl}$ ). 


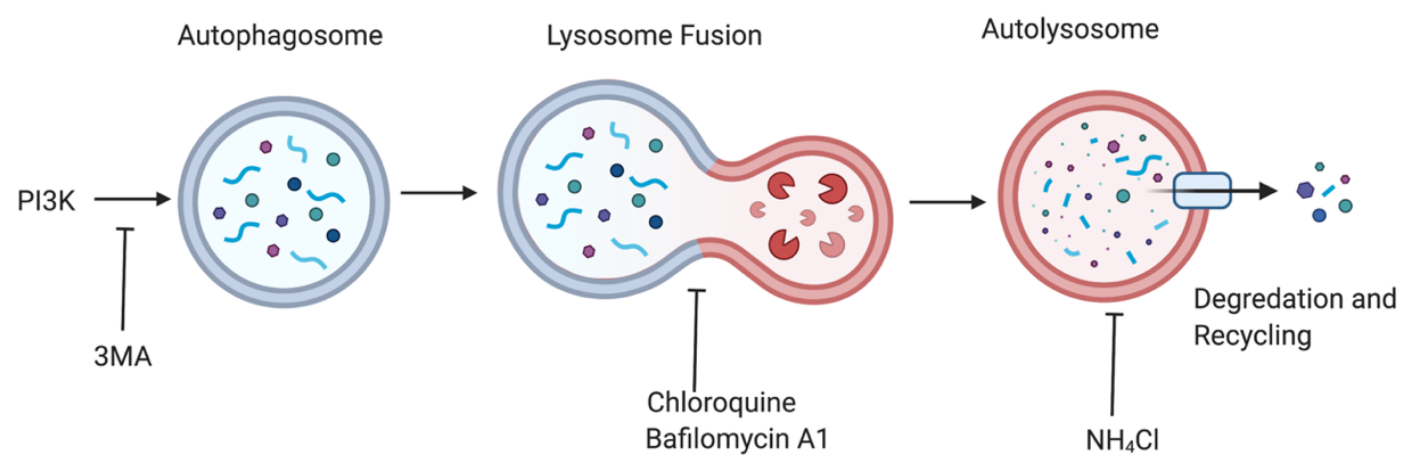

Figure 2. Schematic diagram of the autophagy-lysosome pathway with specific inhibitors. Upon initiating by PI3K, autophagosomes containing specific molecules/proteins to be degraded fuse with lysosomes. Lysosomal enzymes then degrade the contents in the autolysosome enabling recycling of nutrients. 3MA specifically inhibits autophagosome formation. Chloroquine and Bafilomycin A1 inhibit autophagosome-lysosome fusion. $\mathrm{NH}_{4} \mathrm{Cl}$ alters the $\mathrm{pH}$ in the autolysosome inhibiting enzymatic activation.

When RIPK1 is K48 poly-ubiquitinated by cIAP1/2 (cellular inhibitor of apoptosis $1 / 2$ ) downstream of TNFR1, it is degraded via the proteasome (9). RIPK1 can also be degraded via the lysosome by CHIP E3 ligase-mediated ubiquitylation (10). Since we detected decreased RIPK1 levels with DENV infection, we hypothesized DENV may promote RIPK1 degradation via proteasomal/lysosomal degradation pathways.

\section{Results and Discussion}

In order to test if RIPK1 is degraded by proteasomal/lysosomal degradation machinaries, Huh7 cells were infected with DENV2 (MOI=0.2 or MOI=1) for $24 \mathrm{hrs}$. Cells were then treated with MG132, CLQ, or the vehicle control, DMSO, for $24 \mathrm{hrs,}$ 
and the cell lysates were analyzed by western blotting (Fig. 3). As expected, based on the results presented in Chapter 2, RIPK1 levels significantly decreased with DENV2 infection. However, the RIPK1 levels did not recover with the inhibition of either the proteasome or the lysosome pathways. Chloroquine treatment clearly increased the LC3-II levels indicating efficient inhibition of lysosomal function (Fig 3 lanes 7-9). Taken together these data suggest that RIPK1 is not subjected to these cellular degradation machineries by DENV.

We were not able to detect a cleaved/degraded product following the DENV NS3-dependent decrease of RIPK1 by using either an N-terminal targeting or a Cterminal targeting antibody. It is possible DENV NS3 cleaves RIPK1, which still has to be resolved. Possibly the product of cleavage by NS2B3 is too small to detect or could have been further degraded rapidly by other cellular mechanisms such as proteasome-mediated or lysosome-mediated degradation. However, inhibition of the proteasome by MG132 or Bortezomib treatment following NS2B3 overexpression did not increase RIPK1 levels nor did it reveal smaller size bands for RIPK1 (data not shown).

We further investigated whether RIPK1 fragment(s) might be degraded via autophagy. In order to test this, we co-expressed RIPK1 and NS2B3 in cells cultured in the presence or absence of the autophagosome-formation inhibitor 3MA (11). Preliminary results demonstrated that RIPK1 levels still decreased in the presence of DENV NS3 despite 3MA treatment (Fig 4). Taken together these data suggest that RIPK1 was not degraded via either the proteasome or the lysosome after NS3mediated decrease. Therefore, it is possible that the resulting RIPK1 product/s from 
NS3-mediated cleavage could be too small to detect by western blotting. However, further studies are needed to elucidate the complete mechanism. For example, 3MA doses could be optimized and additional markers such as LC3-II levels could be used to confirm successful autophagy inhibition.

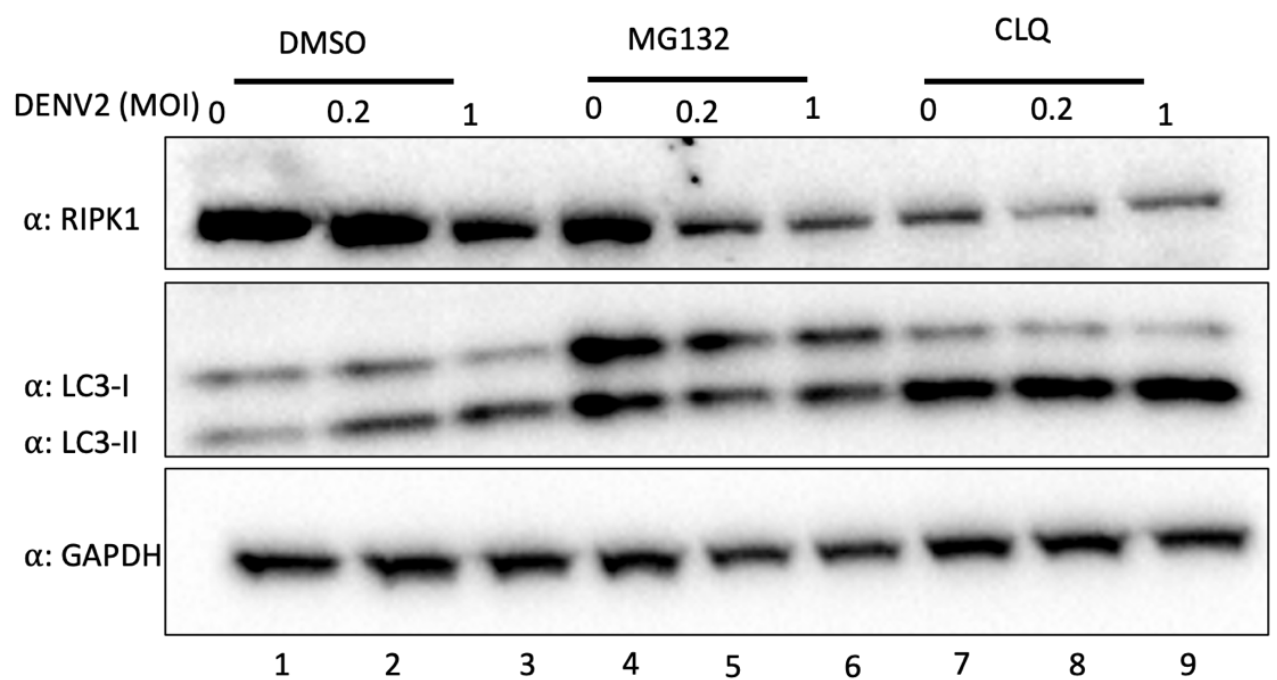

Figure 3. RIPK1 is not degraded via proteasomes or lysosomes during DENV infection. Huh7 cells were infected with DENV2 followed by proteasome and lysosome inhibition using MG132 or Chloroquine (CLQ), respectively. Cell lysates were harvested for western blot analysis using the indicated antibodies. GAPDH was used as a loading control. Representative data are shown from a minimum of 2 experiments for each inhibitor. 


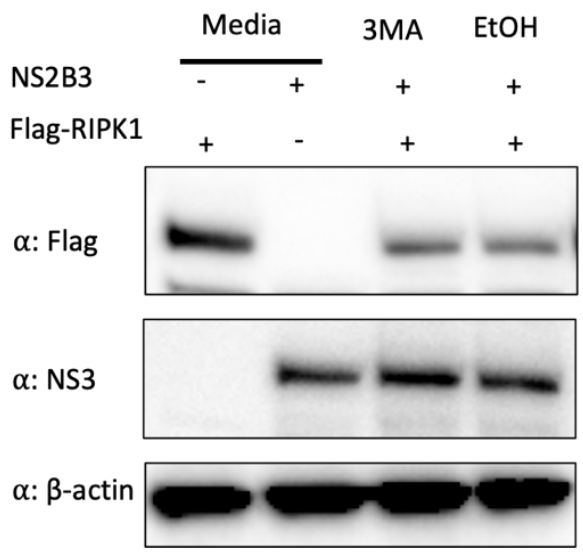

Figure 4. RIPK1 is not degraded via autophagy following NS2B3 expression.

Western blot analysis of RIPK1 levels following the inhibition of autophagy with 3MA using the indicated antibodies. Expression and efficient cleavage of NS2B3 is detected by $\alpha \mathrm{NS} 3$ antibody. $\beta$ actin is used as a loading control. 


\section{DENV suppresses TSZ-induced necroptosis}

\section{Introduction}

RIPK1 is involved in inducing cell death by necroptosis downstream of TNFR1, TLR3, and TLR4 (12). The kinase activity of RIPK1 is important for phosphorylation of RIPK3 (13). Phosphorylated RIPK3 in turn phosphorylates MLKL, which translocates to the plasma membrane (Fig 5). MLKL polymerizes itself and permeabilizes the plasma membrane, releasing PAMPs and DAMPs into the extracellular milieu. Other immune cells are then recruited to the site of necroptosis and initiate inflammatory responses (13). Necroptosis can be blocked by the RIPK1 kinase inhibitor Necrostatin-1 (14). The most established experimental protocol for the induction of necroptosis involves signaling through TNFR1. Treatment with TNF $\alpha$, Smac mimetic, and zVAD cocktail $(\mathrm{T} / \mathrm{S} / \mathrm{Z})$ is known to cause necroptosis in numerous cells $(15,16)$. Smac mimetic antagonizes cIAP proteins and diverts TNF $\alpha$ signaling from NF- $\kappa \mathrm{B}$ activation (17). Pan-caspase inhibitor $\mathrm{zVAD}$ then diverts signaling to induce necroptosis (18). As RIPK3 phosphorylation at S227 and MLKL phosphorylation at T357/S358 are critical for the this process, pRIPK3/ pMLKL are used as markers for detecting the induction of necroptosis (19). In order to sustain cell survival and to inhibit inflammatory responses, viruses have evolved many strategies to counteract necroptosis. Viruses have evolved proteins that target and decrease RIPK1 levels or block RIPKI interaction with RIPK3 by competitive binding to RIPK1 $(20,21)$. However, no investigations have been reported on necroptosis during DENV infection to date. 


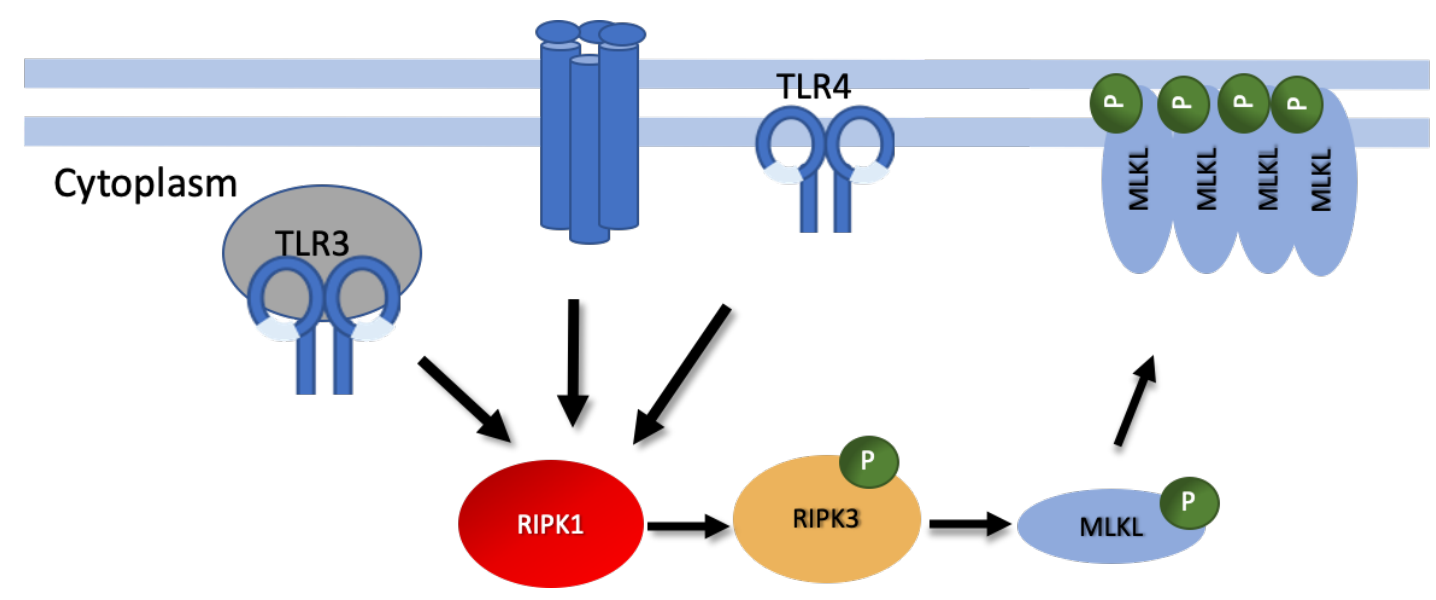

Figure 5. RIPK1-mediated necroptosis induction. Upon stimulation of TNFR1, TLR3 or TLR4, RIPK1 interacts with RIPK3 and they mutually phosphorylate each other in a complex known as the "necrosome". Phosphorylated RIPK3 phosphorylates MLKL. Phospho-MLKL translocates to the plasma membrane, polymerizes and compromises plasma membrane integrity by undefined mechanisms.

\section{Results and discussion}

We have observed cell condensation and fragmentation by microscopy in many cell lines following DENV infection, indicating cell death, especially after $24 \mathrm{hrs}$. Since RIPK1 levels significantly decreased during DENV infection we hypothesized that necroptosis was not a major cause of DENV-induced cell death. In order to confirm this, we compared the cell viability in different cell lines after treating with the specific RIPK1 inhibitor, Necrostatin-1 (Nec1) or the vehicle control DMSO followed by DENV infection. Cell viability was significantly decreased by DENV. However, consistent with our hypothesis, Nec-1 treatment did not increase cell survival after DENV infection (Fig 6A-E). These data suggest that necroptosis does 
not play a major role in DENV infection, perhaps to the benefit of the virus.

Next, we hypothesized DENV will suppress induced necroptosis. Since not all cell types are sensitized to undergo T/S/Z-induced necroptosis, we first tested if human U937 cells stably expressing DC-SIGN undergo necroptosis upon T/S/Z treatment (16). U937-DC-SIGN cells treated with T/S/Z had less viability after 6hrs of treatment (Fig 6F). This effect was not due to apoptosis, since cleaved caspases were not detected (Fig 6F). We next analyzed the level of T357/S358-phosphorylated MLKL as a marker for the induction of necroptosis. We detected a significant increase in $\mathrm{p}$-MLKL in T/S/Z-treated U937-DC-SIGN cells, confirming it's a good model to use for our studies (Fig 6F).

Next, to test the effect of DENV on necroptosis we treated DENV2-infected and uninfected human U937-DC-SIGN cells with necroptosis inducers (T/S/Z) and/or RIPK1 inhibitor Nec-1. T/S/Z induced an increase in p-MLKL in uninfected U937DC-SIGN cells which was significantly suppressed by treatment with Nec-1. In contrast, p-MLKL was hardly detected in DENV-infected cells following $\mathrm{T} / \mathrm{S} / \mathrm{Z}$ treatment (Fig 6G-H). Taken together, these data indicate that DENV does not signal for necroptosis induction. Furthermore, DENV infection inhibits $\mathrm{T} / \mathrm{S} / \mathrm{Z}$ induced necroptosis (Fig 6G-H). However, in order to confirm in vivo responses, it would be better to investigate the effect of DENV on necroptosis induction downstream of TLR3 and TLR4 signaling as well. 

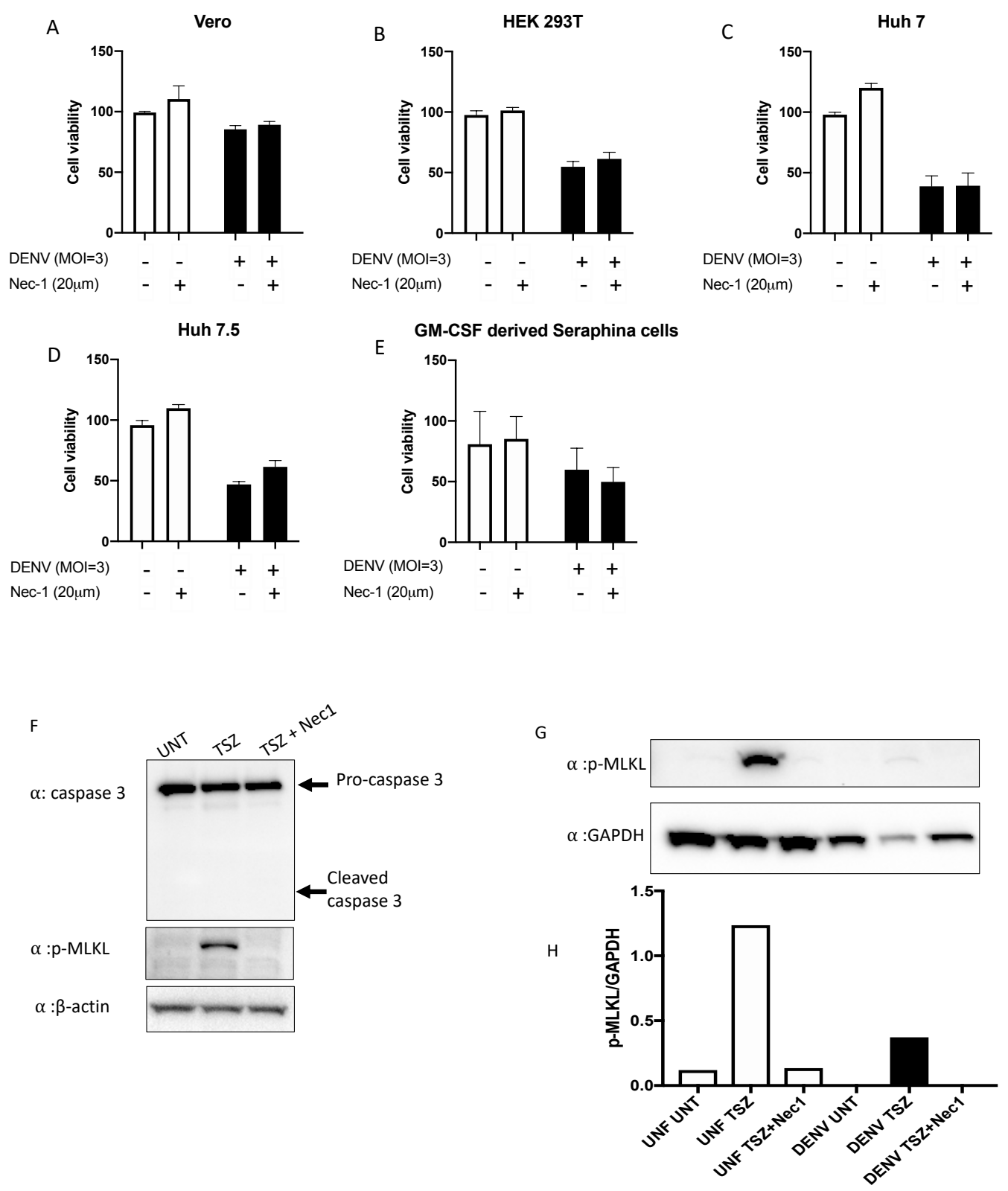

Figure 6. DENV suppressed necroptosis. (A-E) Indicated cell lines were treated with Nec-1 or DMSO followed by DENV2 infection for $48 \mathrm{hrs}$. Cell viability was measured by detecting ATP-producing cells with Cell Titer Glo assay. The viability of DMSOtreated uninfected cells is defined as 100\%. (F) U937-DC-SIGN cell were treated with 
TSZ, TSZ + Nec-1, or DMSO treatment for 6hrs, (G) U937-DC-SIGN cells were treated with DENV2 for $48 \mathrm{hrs}$ followed by TSZ, TSZ + Nec-1, or DMSO treatment for $6 \mathrm{hrs}$. Cell lysates were analyzed by western blotting using the indicated antibodies. (H) Densitometric analysis of p-MLKL band intensities normalized to $\beta$-actin levels. 


\section{RIPK1 expression does not affect DENV replication in vitro}

\section{Introduction}

Disruption of innate immune responses may give pathogens an advantage for establishing infection. RIPK1 is a central mediator of many cellular signaling pathways that are important in innate immune responses. Therefore, RIPK1 is an attractive target for pathogens. As we showed in Chapter 2, many other viruses target and inhibit RIPK1-mediated signaling. There is evidence that inhibition of RIPK1mediated pathways can enhance viral replication. For example, RIPK1 kinase activity-deficient mice had higher viral titers after infection with ZIKV and displayed greater susceptibility to WNV infection relative to wild type mice $(22,23)$. RHIM and IPAM domains of MCMV M45 proteins were found to be important for inhibition of RIPK1-mediated necroptosis (24). MCMV expressing M45 deficient of RHIM and/ or IPAM displayed lower viral titers in mice possibly due to intact RIPK1-mediated signaling. In light of this evidence, we hypothesized that RIPK1 expression would have a deleterious effect on DENV replication.

\section{Results and discussion}

Several approaches were used to investigate the effect of RIPK1 expression on DENV replication. First, we transfected a plasmid expressing Flag-RIPK1 in HEK293T cells and cultured for 24 hrs. We then infected RIPK1-overexpressing cells with DENV2. After an additional 48hrs supernatants from cells were collected. Cells were lysed and total RNA and total protein were extracted. Western blot assays were done to confirm RIPK1 overexpression and DENV infection. Total RNA was analyzed 
by qRT-PCR to quantify relative intracellular DENV RNA. Supernatants were used for immuno-stained plaque assay (25) to determine the titer of infectious DENV particles.

Western blot results confirmed RIPK1 overexpression. However, we observed a decrease in overexpressed RIPK1 levels with DENV infection (Fig 7A lanes 5,6 \& Fig 7B). We did not detect a difference in infectivity with overexpression of RIPK1 as shown by the intensity of bands corresponding to DENV NS3 (Fig 7A lanes 4,5,6). Relative intracellular DENV RNA levels increased by 69 hrs post-infection as compared to $20 \mathrm{hrs}$ post-infection even with the overexpression of RIPK1 (Fig 7C). A slight decrease in intracellular DENV RNA levels was observed with the overexpression of RIPK1 as compared to pcDNA control plasmid at both $20 \mathrm{hrs}$ and $69 \mathrm{hrs}$ post-infection. Viral titers in the supernatants of cells where RIPK1 was overexpressed were also slightly lower than in supernatants of control cell cultures at 20 hrs post-infection. However, neither of these differences (in intracellular viral RNA or viral titers) was statistically significant.

We next hypothesized further ablation of RIPK1 will benefit DENV replication. Thus, we next investigated the effect of endogenous RIPK1 expression on DENV replication. We transfected either a RIPK1-specific small interfering RNA (siRNA) or a scrambled siRNA as a control into HEK293T cells and subsequently infected the cells with DENV2 (MOI=2). Cells were harvested and total RNA was extracted at 24 hrs post-infection. qRT-PCR was done on total RNA to detect RIPK1 and DENV RNA levels. We observed $\sim 70 \%$ reduction in RIPK1 transcript levels with siRNA treatment relative to controls (untreated and control siRNA-treated), confirming the efficient knockdown of RIPK1 (Fig 8A). However, we observed no 
change in DENV RNA levels (Fig 8B). These preliminary results demonstrate that DENV replication is unaffected by RIPK1 knockdown. Experiments should be repeated to confirm this conclusion.

Overall our results indicate that RIPK1 expression does not directly affect DENV replication in vitro. However, further studies are needed before an important effect can be excluded. Strikingly most of the evidence on increased viral replication with inhibition of RIPK1-mediated signaling is from in vivo studies. Daniels et al. observed higher viremia in mice deficient in RIPK1 following ZIKV infection, however, they could not reproduce these results in vitro (24). Neither genetic nor pharmacological ablation of RIPK1 had an impact on ZIKV replication in bone marrow-derived macrophages or dendritic cells. These results indicate the inhibition of RIPK1-mediated signaling has different effects on viral replication in vivo vs in vitro. However, we evaluated DENV replication without inducing RIPK1 signaling by adding external stimuli such as TNF $\alpha$. Therefore, the effects of TNFR1 and TLR3 signaling pathways on DENV replication could be investigated since these pathways are inhibited by DENV. DENV titers/ RNA could be measured upon TNF $\alpha$ and poly (I:C) stimulation with and without RIPK1 overexpression. 

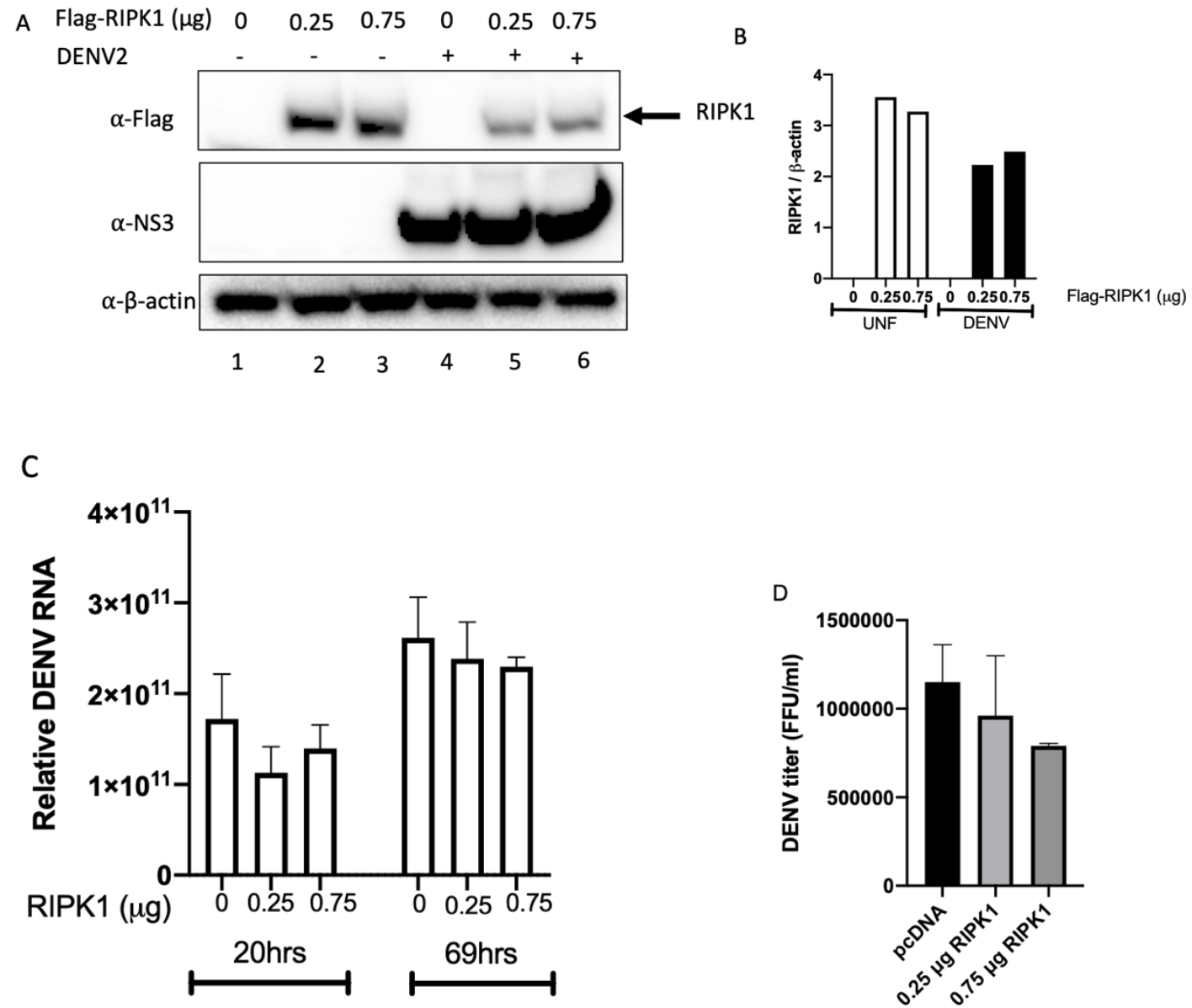

Figure 7. DENV replication is not affected by RIPK1 overexpression. (A) Western blot results of HEK293T cells transfected with either a Flag-RIPK1 plasmid $(0.25 \mu \mathrm{g}$ $/ 0.75 \mu \mathrm{g})$ or a pcDNA $(0.75 \mu \mathrm{g})$ control plasmid followed by DENV2 infection. Overexpressed RIPK1 levels were detected by a $\alpha$ Flag antibody while DENV infection was detected by probing with an $\alpha \mathrm{NS} 3$ antibody. $\beta$-actin was used as a loading control. Data are representative of a minimum of 3 experiments. (B) Densitometric analysis of RIPK1 band intensities normalized to $\beta$-actin levels from (A). Results are from a single experiment and are representative of at least three separate experiments. (C) RT-qPCR analysis of intracellular DENV RNA at $20 \mathrm{hrs}$ and 
69hrs post-infection. (D) Plaque assay of culture supernatants from DENV2-infected cells $20 \mathrm{hrs}$ following pcDNA or RIPK1 overexpression. Error bars represent standard error of the mean of three technical replicates from two experiments per condition. 
A

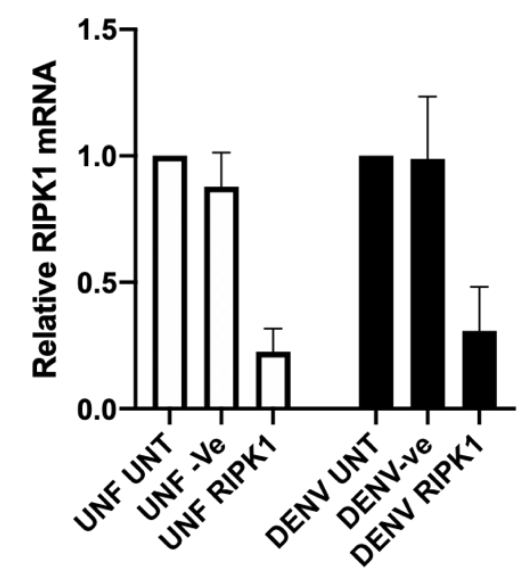

B

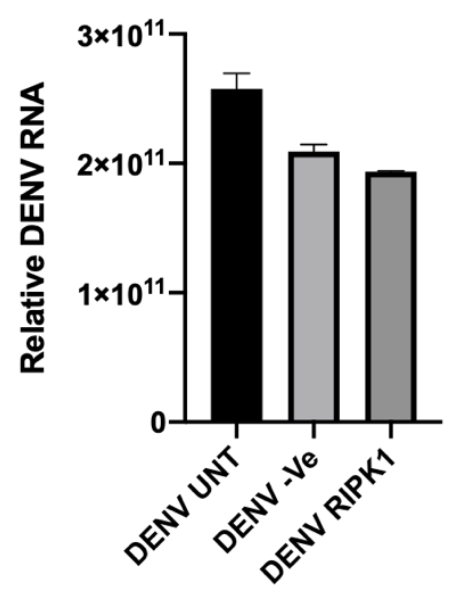

Figure 8. DENV Replication is not affected by silencing of endogenous RIPK1. RT-qPCR analysis of total RNA isolated from HEK293T cells untransfected (UNT) or transfected with either a RIPK1-specific siRNA (RIPK1) or scrambled siRNA (-Ve) followed by DENV infection for (A) RIPK1 mRNA or (B) intracellular DENV RNA at $24 \mathrm{hrs}$ post-infection. Data are mean $\pm \mathrm{SD}(\mathrm{n}=2$ experiments $) . \mathrm{UNF}=$ uninfected. 


\section{Materials and methods}

\section{Cell culture and virus infection}

Huh7 ( a generous gifts from Dr. Kate Fitzgerald), HEK 293T (Dharmacon, Inc.) and Vero, (obtained from American Type Culture Collection (ATCC)) were maintained in Dulbecco's modified minimal essential medium and supplemented with $10 \%$ heatinactivated fetal bovine serum (Sigma-Aldrich), 1\% penicillin-streptomycin (SigmaAldrich), 1\% non-essential amino acids (Lonza) and 1\% L-Glutamine solution (Sigma-Aldrich). All cells were incubated in a humidified chamber at $37{ }^{\circ} \mathrm{C}$ and $5 \%$ $\mathrm{CO}_{2}$. Prototype DENV strains DENV2 16681 was originally obtained from the American Type Culture Collection. Virus titers were determined by immunostained plaque assay on Vero cells $(25,26)$

\section{Western Blot analysis}

Cells were lysed in RIPA buffer freshly supplemented with a protease and phosphatase inhibitor cocktail (Sigma-Aldrich). Lysates were incubated on ice for 30 min with vortexing every 5 minutes and centrifuged at $10,000 \mathrm{rpm}$ for $5 \mathrm{~min}$ at $4{ }^{\circ} \mathrm{C}$. Supernatants were used as total cell lysates. Protein concentrations were determined using the Pierce BCA Protein Assay kit (Thermo Fisher Scientific) following manufacturer's instructions and measured using an Envision plate reader (PerkinElmer). BOLT LDS Sample Buffer and Reducing Agent (Thermo Fisher Scientific) were added to cell lysates at a final concentration of $1 \mathrm{x}$ and samples were denatured at $70{ }^{\circ} \mathrm{C}$ for $10 \mathrm{~min}$. Proteins were separated on $4-12 \%$ or $8 \%$ BOLT BisTris Plus gels (Thermo Fisher Scientific) and transferred onto nitrocellulose 
membranes using the Trans-Blot ${ }^{\circledR}$ Turbo $^{\text {TM }}$ RTA Mini Nitrocellulose Transfer kit (Bio-Rad). Membranes were blocked in 5\% milk in phosphate buffered saline with $0.1 \%$ Tween 20 for $1 \mathrm{~h}$ at room temperature (rt) followed by incubation with the appropriate primary antibody overnight at $4{ }^{\circ} \mathrm{C}$. Membranes were washed and incubated with the appropriate secondary antibody diluted in blocking buffer for 1 hour at rt. For $\beta$-actin and GAPDH analysis, membranes were stained for 1 hour with corresponding antibodies. Detection of blots was done using Amersham ECL Select Western Blotting Detection Reagent (GE Healthcare Life Sciences) following the manufacturer's guidelines, and images were captured with the ChemiDocTM XRS+ System (Bio-Rad). Detection and quantification of band intensities were performed using Image Lab 5.1 (Bio-Rad).

\section{Antibodies}

The following primary antibodies were used for western blot experiments: anti-FlagHRP (sc-166355, Santa Cruz Biotechnology), anti-Caspase 3 (sc-56053, Santa Cruz Biotechnology), anti- $\beta$-actin-HRP (ab20272, Abcam), anti-p-MLKL (ab187091, Abcam), anti-GAPDH-HRP (MA515738), anti-DENV NS3 (GTX124252, GeneTex), anti-RIPK1 (D94C12, Cell Signaling Technology), and anti-LC3B (2775S, Cell Signaling Technology). Secondary antibodies used were goat anti-rabbit-HRP (32260, Thermo Scientific) and anti-mouse-HRP (sc516102, Santa Cruz Biotechnology).

\section{Plasmids and transfection}

Overexpression of RIPK1 was done by transfecting $0.25 \mu \mathrm{g}$ or $0.75 \mu \mathrm{g}$ of a Flag-RIPK1 
plasmid (Addgene) or $0.75 \mu \mathrm{g}$ of a control plasmid (pcDNA) into HEK293T cells using Genejuice transfection reagent (EMD Millipore, cat\# 70967-3) according to manufacturer's protocols. siRNA targeting RIPK1 and siRNA negative control were purchased from ThermoFisher Scientific. Transfection of cells with siRNA was performed using Lipofectamine RNAiMAX transfection reagent according to the manufacturer's instructions (Thermofisher Scientific).

\section{Proteasome inhibition}

DENV2-infected or uninfected Huh7 cells were treated with $1 \mu \mathrm{M}$ MG132 for $24 \mathrm{hrs}$ or $100 \mathrm{nM}$ Bortezomib for $6 \mathrm{hrs}$. Control cells were treated with a similar concentration of DMSO. Cells were harvested and analyzed by western blotting.

\section{Autophagy inhibition}

Cells transfected with Flag-RIPK1 and DENV NS2B3 were treated with 3.3mM 3MA or an equal concentration of the vehicle control, EtOH, for 12 hrs. Cells were harvested and RIPK1 levels detected by western blotting.

\section{Lysosome inhibition}

DENV2-infected or uninfected Huh7 cells were treated with $10 \mu \mathrm{M}$ Chloroquine for 24 hrs or 100nM Bortezomib for 6 hrs. Control cells were treated with a similar volume of DMSO. Cells were harvested and analyzed by western blotting. 


\section{Cell viability assay}

Huh 7, Huh 7.5, Hek 293 T and Vero cells were plated in a 96 well plate. Cells were pretreated for $1 \mathrm{hr}$ with $20 \mu \mathrm{M} \mathrm{Nec}-1$ or DMSO. After $1 \mathrm{hr}$ cells were infected with DENV2 and cultured for 48hrs. Cells were then lysed by the addition of Cell titer Glo reagent (Promega) diluted 1:4 in Phosphate buffered saline (PBS). Cell lysates were transferred into a 96-well opaque plate and the luminescence was measured using an Envision plate reader (PerkinElmer). Values were averaged from 3 biological replicates and the values for uninfected DMSO-treated cells were defined as $100 \%$.

\section{Necroptosis assay}

U937-DC-SIGN cells were plated in a 24-well plate and infected with DENV2 $(\mathrm{MOI}=5)$ for $42 \mathrm{hrs}$. Cells were then treated with $20 \mu \mathrm{M}$ zVAD-FMK (Santa Cruz Biotechnology), 50ng/ml TNF $\alpha$ (Peprotech), and 10 $\mu \mathrm{M}$ Smac mimetic (Fisher Scientific) with and without $50 \mu \mathrm{M}$ Nec-1 (Sigma Aldrich) for 6 hrs. Cells were harvested by centrifugation at 1600rpm for 5 minutes and lysed with RIPA buffer supplemented with protease inhibitors. Cell lysates were analyzed by western blot.

\section{RT-qPCR analysis}

Total RNA was extracted from cell pellets using the RNeasy Mini Kit (Qiagen). Quantitative RT-PCR was performed using iTaq Universal probes 1-step kit (Biorad) or iTaq Universal SYBR Green 1-step kit (Biorad) on a Bio-Rad CFX machine, and gene expression was normalized to the $\beta$-actin expression level. Taqman gene expression assays (RIPK1 and $\beta$-actin) were purchased from Thermofisher Scientific. 
DENV primers were purchased from Integrated DNA Technology (IDT) and RT-qPCR was performed. Thermocycler protocol for PCR reactions was; 40 cycles of $10 \mathrm{~min}$ at $50^{\circ} \mathrm{C}, 3 \mathrm{~min}$ at $95^{\circ} \mathrm{C}, 15 \mathrm{sec}$ at $95^{\circ} \mathrm{C}$ and $30 \mathrm{sec}$ at $60^{\circ} \mathrm{C}$. Similar concentrations of total RNA were compared to detect relative DENV RNA in cell lysates based on a standard curve calculated using primers for DENV2 (40).

\section{DENV plaque assay}

Virus titers were determined by immunostained plaque assay on Vero cells as described in (25). First, serial $0.5 \log$ dilutions of virus-containing supernatants were added to Vero cells in a 96-well plate. After $2 \mathrm{hrs}$ of incubation, overlay media containing MEM and 2\% carboxymethyl cellulose was added to restrict viral spread. After $3 \mathrm{~d}$, viral plaques were detected using anti-Dengue virus complex antibody (MAB 8705, Millipore Sigma) followed by the secondary antibody, mIgH-HRP (906001, Southern Biotech). Spots were developed by the addition of the substrate solution (TMB Elispot substrate, Mabtech \#3651-10). Spots were counted by CTL ImunoSpot analyzer. 


\section{References}

1. Rubinsztein DC. The roles of intracellular protein-degradation pathways in neurodegeneration. Nature. 2006 Oct;443(7113):780-6.

2. Ciechanover A. The ubiquitin proteolytic system: from a vague idea, through basic mechanisms, and onto human diseases and drug targeting. Neurology. 2006 Jan;66(2 Suppl 1):S7-19.

3. Richly H, Rape M, Braun S, Rumpf S, Hoege C, Jentsch S. A series of ubiquitin binding factors connects $\mathrm{CDC} 48 / \mathrm{p} 97$ to substrate multiubiquitylation and proteasomal targeting. Cell. 2005 Jan;120(1):73-84.

4. Ashour J, Laurent-Rolle M, Shi P-Y, Garcia-Sastre A. NS5 of Dengue Virus Mediates STAT2 Binding and Degradation. J Virol. 2009;83(11):5408-18.

5. Yu CY, Liang JJ, Li JK, Lee YL, Chang BL, Su CI, et al. Dengue Virus Impairs Mitochondrial Fusion by Cleaving Mitofusins. PLoS Pathog. 2015;11(12):1-24.

6. Yorimitsu T, Klionsky DJ. Autophagy: molecular machinery for self-eating. Cell Death Differ. 2005 Nov;12 Suppl 2(Suppl 2):1542-52.

7. Mizushima N, Yoshimori T, Levine B. Methods in mammalian autophagy research. Cell. 2010 Feb;140(3):313-26.

8. Aguirre S, Luthra P, Sanchez-Aparicio MT, Maestre AM, Patel J, Lamothe F, et al. Dengue virus NS2B protein targets cGAS for degradation and prevents mitochondrial DNA sensing during infection. Nat Microbiol [Internet]. 2017;2(March):1-11. Available from: http://dx.doi.org/10.1038/nmicrobiol.2017.37

9. Peltzer N, Darding M, Walczak H. Holding RIPK1 on the Ubiquitin Leash in TNFR1 Signaling. Trends Cell Biol. 2016;26(6):445-61.

10. CHIP controls necroptosis.pdf.

11. Stroikin Y, Dalen H, Lööf S, Terman A. Inhibition of autophagy with 3methyladenine results in impaired turnover of lysosomes and accumulation of lipofuscin-like material. Eur J Cell Biol. 2004 Oct;83(10):583-90.

12. Ofengeim D, Yuan J. Regulation of RIP1 kinase signalling at the crossroads of inflammation and cell death. Nat Rev Mol Cell Biol. 2013;14(11):727-36.

13. Vandenabeele P, Galluzzi L, Vanden Berghe T, Kroemer G. Molecular mechanisms of necroptosis: An ordered cellular explosion. Nat Rev Mol Cell Biol [Internet]. 2010;11(10):700-14. Available from: 
http://dx.doi.org/10.1038/nrm2970

14. Degterev A, Hitomi J, Germscheid M, Ch'en IL, Korkina O, Teng X, et al. Identification of RIP1 kinase as a specific cellular target of necrostatins. Nat Chem Biol. 2008;4(5):313-21.

15. He S, Wang L, Miao L, Wang T, Du F, Zhao L, et al. Receptor Interacting Protein Kinase-3 Determines Cellular Necrotic Response to TNF- $\alpha$. Cell [Internet]. 2009;137(6):1100-11. Available from: http://dx.doi.org/10.1016/j.cell.2009.05.021

16. Cai Z, Jitkaew S, Zhao J, Chiang HC, Choksi S, Liu J, et al. Plasma membrane translocation of trimerized MLKL protein is required for TNF-induced necroptosis. Nat Cell Biol. 2014;16(1):55-65.

17. Safferthal C, Rohde K, Fulda S. Therapeutic targeting of necroptosis by Smac mimetic bypasses apoptosis resistance in acute myeloid leukemia cells. Oncogene. 2017 Mar;36(11):1487-502.

18. Li X, Yao X, Zhu Y, Zhang H, Wang H, Ma Q, et al. The Caspase Inhibitor ZVAD-FMK Alleviates Endotoxic Shock via Inducing Macrophages Necroptosis and Promoting MDSCs-Mediated Inhibition of Macrophages Activation. Front Immunol [Internet]. 2019;10:1824. Available from: https://www.frontiersin.org/article/10.3389/fimmu.2019.01824

19. Johnston A, Wang Z. Necroptosis: MLKL Polymerization. J Nat Sci. 2018 $\mathrm{Jul} ; 4(7)$.

20. Wagner RN, Reed JC, Chanda SK. HIV-1 protease cleaves the serine-threonine kinases RIPK1 and RIPK2. Retrovirology. 2015;12(1):1-16.

21. Mack C, Sickmann A, Lembo D, Brune W. Inhibition of proinflammatory and innate immune signaling pathways by a cytomegalovirus RIP1-interacting protein. Proc Natl Acad Sci U S A. 2008;105(8):3094-9.

22. Daniels BP, Kofman SB, Smith JR, Norris GT, Snyder AG, Kolb JP, et al. The Nucleotide Sensor ZBP1 and Kinase RIPK3 Induce the Enzyme IRG1 to Promote an Antiviral Metabolic State in Neurons. Immunity. 2019;50(1):6476.e4.

23. Daniels BP, Snyder AG, Olsen TM, Orozco S, Oguin TH, Tait SWG, et al. RIPK3 Restricts Viral Pathogenesis via Cell Death-Independent Neuroinflammation. Cell. 2017;169(2):301-313.e11.

24. Muscolino E, Schmitz R, Loroch S, Caragliano E, Schneider C, Rizzato M, et al. Herpesviruses induce aggregation and selective autophagy of host signalling proteins NEMO and RIPK1 as an immune-evasion mechanism. 
25. Liu L, Wen K, Li J, Hu D, Huang Y, Qiu L, et al. Comparison of plaque- and enzyme-linked immunospot-based assays to measure the neutralizing activities of monoclonal antibodies specific to domain III of dengue virus envelope protein. Clin Vaccine Immunol. 2012;19(1):73-8.

26. Medin CL, Valois S, Patkar CG, Rothman AL. A plasmid-based reporter system for live cell imaging of dengue virus infected cells. J Virol Methods [Internet]. 2015;211:55-62. Available from: http://dx.doi.org/10.1016/j.jviromet.2014.10.010 


\section{CHAPTER 5}

\section{Conclusion}

Activation of innate immunity due to the detection of viral replication products in the cell leads to the expression of hundreds of antiviral genes and proinflammatory cytokines and chemokines that control the spread of the infection. Because of this pivotal role in antiviral host defense, innate immune pathways are often targeted for inhibition by viruses. As summarized in Chapter 2, several viral proteins, including viral proteases, have been reported to modulate immune responses, allowing diverse families of viruses to modify the intra and extra-cellular environment to promote optimal conditions for replication and spread.

Here we have found that DENV significantly decreased RIPK1 protein levels in infected cells. Overexpression of the DENV protease, NS2B3, was sufficient to decrease RIPK1 levels demonstrating a direct role for NS3 in RIPK1 reduction. NS3 protease activity was fundamental for this effect, because the overexpression of a catalytically inactive protease mutant (NS2B3-S135A) did not result in a significant RIPK1 reduction. Additionally, both WT and protease mutant NS3 physically interacted with RIPK1. Furthermore, DENV inhibited NF- $\kappa$ B activation downstream of TNFR1 and TLR3 receptors by targeting RIPK1. Moreover, we detected DENV did not induce necroptosis and further suppressed T/S/Z-induced necroptosis in U937-DCSIGN cells. DENV infection did not induce proteasomal/lysosomal degradation of RIPK1. Finally, we did not detect a direct effect of RIPK1 on DENV viral replication. 


\section{Implications of inhibition of RIPK1 signaling in DENV infection}

RIPK1 is placed at a crucial point in controlling cell death and inflammation. RIPK1-mediated signaling governs the outcome of signaling pathways initiated by TNFR1, TLR3, TLR4 and RIG-I/MDA5. RIPK1 is involved in signaling for NF-кB activation, MAPK and IRF3/7 phosphorylation. NF-кB induces pro-apoptotic genes as well as pro-inflammatory cytokines and chemokines that are important for signaling other immune cells. MAPK signals for AP-1 transcription, which induces the expression of several important cytokines. IFN responses are critical for restricting viral replication. IFNs further signal for the induction of hundreds of antiviral genes via the JAK/STAT pathway. Apart from these outcomes, RIPK1 signaling is implicated in several cell death mechanisms. RIPK1 is involved in driving extrinsic apoptosis or necroptosis downstream of TNFR1, TLR3 and TLR4. Since all the abovementioned strategies act as anti-viral mechanisms, RIPK1 has emerged as an attractive target for inhibition by viruses. This is exemplified by the breadth of RIPK1 inhibition strategies that have evolved in numerous viruses. For example, HIV-1 and HRV-16 proteases cleave RIPK1 $(1,2)$. Human HSV-1 proteins ICP6 and ICP10, MCMV M45 protein, EBV LMP1 protein, and HTLV-1Tax protein all block protein-protein interactions of RIPK1 in signaling pathways by competitively binding to RIPK1 (3-6). Additionally, HSV-1 ICP6 and MCMV M45 selectively degrade RIPK1 via the autophagosome machinery (7). Furthermore, EBOV encodes miRNA that targets RIPK1 and decreases its transcript levels (8). RIPK1 kinase-inactive mice exhibited increased viral titers following ZIKV and VACV infection while displaying increased susceptibility to WNV infection (9-11). These data indicate the importance of RIPK1 
inhibition in virus infections.

DENV stimulates immune responses via TLR7, TLR3, MDA5 and RIG-I. DENV NS1 is known to stimulate TLR4 (12-14). These stimulations result in the secretion of IFN- $\alpha / \beta$ that renders other host cells resistant to subsequent DENV infections (15). The secretion of TNF $\alpha$ during DENV infection results in the stimulation of TNFR1. TNF $\alpha$ stimulation results in the activation of dendritic cells leading to increased expression of cell surface costimulatory and activation molecules and enhancement of their antigen-presenting function (16-18). However, DENV has been reported to block the activation of infected dendritic cells, which may reduce priming of CD4+ or CD8 $+\mathrm{T}$ cells. Interestingly, non-infected bystander monocytes and dendritic cells still can become activated during DENV infection (19). Gene expression analysis of acute dengue patients revealed lower levels of expression of genes associated with antigen processing, antigen presentation and $\mathrm{T}$ cell activation in DHF than in DF (20). Since RIPK1 is involved in TNF $\alpha$ signaling, we can speculate that inhibition of RIPK1 by DENV may decrease dendritic cell activation and maturation. Consequently, impaired antigen presentation and functionality of DENVinfected DCs may reflect a viral evasion strategy to impede host immune responses.

DENV infection was shown to block NF-kB activation downstream of TLR3 signaling, resulting in downregulated cytokine production (21). However, the mechanism by which DENV caused these altered responses had not been defined. Here, we demonstrated that DENV infection diminished NF- $\mathrm{kB}$ activation in response to poly I:C stimulation by targeting and decreasing RIPK1 levels downstream of TLR3. The effect of the impairment of this pathway on IFN production, apoptosis and 
necroptosis should be further investigated.

There is evidence of the importance of RIPK1 function in T and B cells as well. For example, robust cross-priming of $\mathrm{CD} 8+\mathrm{T}$ cells required intact RIPK1 signaling and NF-kB-induced transcription in dying cells (22). Another study found a kinase-independent function of RIPK1 that is important for mature T-cell survival and proliferation (23). RIPK1 function is also reported to be critical in B cell development; TLR4-stimulated RIPK1 ${ }^{-/}$B cells exhibited impaired NF- $\kappa$ B activation (24). Therefore, DENV-mediated inhibition of RIPK1 in T and B cells may play a role in altering critical immune pathways in these cells. Expanding our assays to study $\mathrm{T}$ and B cells may help decipher additional important roles of RIPK1-mediated signaling in DENV infection.

RIPK1 is involved in type I IFN production downstream of the RIG-I/MDA-5 pathway. Even though some studies could not detect a direct role of RIPK1 in IFN $\beta$ production, we were able to detect a convincing positive effect of RIPK1 overexpression on phosphorylation of IRF3 by western blotting. Additionally, we detected increased IFN $\beta$ transcript levels with overexpression of RIPK1. These preliminary findings suggest a positive effect of RIPK1 on type I IFN production which is known to directly downregulate viral replication. Thus, RIPK1 inhibition becomes extremely advantageous for DENV. Further studies could be carried out to test if DENV-mediated RIPK1 inhibition contributes to downregulated type I IFNs downstream of RIG-I/MDA5. However, even though it is not the primary route, NF$\kappa \mathrm{B}$ also induces IFN $\beta$ and IFN $\gamma$ (25-28). Thus, further investigations are needed to understand if DENV inhibits the secretion of IFN $\beta$ and IFN $\gamma$ by inhibiting NF-kB 
pathway downstream of TNFR1 and TLR3.

\section{Apoptosis in DENV infection}

Liver injury is a common finding in DENV infection and can lead to organ failure. Apoptosis of hepatocytes following DENV infection is believed to contribute to this phenomenon (29). Apoptotic cells have been found in the liver, brain and lung tissues from autopsy examinations of DHF and DSS patients (30). The mechanisms by which DENV induces apoptosis are not known and may differ between different cell types. Recent findings show a protective role of RIPK1 against TNFa-mediated apoptosis in hepatocytes $(31,32)$. RIPK1 knockout mice showed enhanced sensitivity to TNF $\alpha$-mediated apoptosis and inflammation. The induction of NF- $\mathbf{k B}$ target gene transcripts was also suppressed in these mice. Therefore, we speculate that the loss of RIPK1 during DENV infection may sensitize hepatocytes to cell death and inflammation, which could contribute to liver injury in DHF.

\section{Necroptosis in DENV infection}

Since viruses rely on the host cell machinery to propagate, host cell death is detrimental for viruses. Necroptosis is emerging as an important anti-viral mechanism for restricting viral replication. Apart from restricting viral propagation by destroying the cell, necroptosis is implicated in releasing intracellular DAMPs and PAMPs and promoting inflammation (33). RIPK1 kinase activity is important for necroptosis induction. Therefore, viruses target RIPK1 for inhibiting necroptosis. There is evidence that CMV, EBV and HIV-1 viruses inhibit necroptosis by targeting RIPK1 
using various mechanisms as shown in Fig 3 of chapter 2 . We observed that necroptosis was not induced in vitro upon DENV infection. Furthermore, DENV was able to suppress artificially induced necroptosis downstream of TNFRI, possibly due to low levels of RIPK1. However, whether DENV stimulation of TLR3/4 leads to necroptosis is still unknown. Further efforts should address if necroptosis downstream of TLR3/4 contributes to dengue disease pathogenesis.

\section{The effect of RIPK1 on DENV replication}

There is evidence supporting a direct correlation between peak viremia titer and dengue disease severity (34) suggesting that efficient viral replication contributes to dengue disease. Staining for DENV structural proteins and viral RNA in human autopsies from dengue patients confirmed viral replication in lymph nodes, spleen, lung and liver (19). This excessive viral replication reflects the capability of DENV to suppress innate immune mechanisms efficiently. Thus, inhibition of RIPK1-mediated signaling, may also benefit DENV replication.

Contrary to our expectations, we did not observe decreased intracellular viral RNA or infectious viral titers in the supernatants of cells when RIPK1 was overexpressed. Similarly, studies did not indicate a significant increase in intracellular viral RNA when endogenous RIPK1 was knocked down. Taken together, our observations do not support a direct link of RIPK1 levels affecting DENV replication. However, these experiments were done without stimulating the TNFR1. Thus, the effect of TNF $\alpha$-induced NF- $\mathrm{NB}$ activation on DENV replication should be further investigated. For this purpose, relative intracellular viral RNA and infectious viral 
titers in the supernatants of cells could be analyzed with overexpression of RIPK1 in the presence or absence of TNF $\alpha$ stimulation. Furthermore, the cytokines expressed by the induction of NF- $\mathrm{\kappa B}$ could be more important for setting an antiviral state in the intact tissue/organism by activating uninfected bystander cells and $\mathrm{T}$ and $\mathrm{B}$ cells. This effect is hard to achieve in cell culture. Also, some of the cell lines we used may not effectively secrete inflammatory cytokines. Thus, it would be plausible to use PBMC from patients for testing the effect of RIPK1 on viral replication. Expanding our findings using human dendritic cell subsets isolated from blood or tissues will be important to characterize the full spectrum of immune responses mediated by RIPK1 in DENV infection.

\section{DENV strain-specific effects on RIPK1}

Western blot results following infections with different strains of DENV revealed strain-specific effects on RIPK1 levels. DENV1 strain Hawaii, DENV2 strain 16681, and DENV2 strain NGC exhibited a significant decrease in RIPK1 levels in Huh7 cells. DENV1 strain C0245/96, DENV3 strain CH53489, and DENV3 strain C0360/96 displayed decreased RIPK1 levels, but this was not statistically significant. Interestingly, neither DENV4 strain 814669 nor H241 decreased RIPK1 significantly. These differences in effects on RIPK1 could be attributed to structural differences in the DENV protease complex, NS2B3. Crystal structure analysis of DENV protease complexes of DENV1, DENV2 and DENV4 revealed serotype-specific differences (35-37). Differences in substrate binding and substrate catalysis have also been attributed to structural differences between DENV proteases (35). Conformational 
changes undergone by NS2B upon substrate binding account for additional variation.

Differences in virulence in naturally circulating DENV strains and serotypes are speculated to contribute to dengue disease. For example, a study done on children with acute DENV infections reported secondary DENV2 caused more severe disease than DENV1 or DENV4, suggesting that virus genotype affects outcome (34). Altogether, our data indicate DENV strain-specific effects on RIPK1 reduction which could be responsible for differences in virulence exhibited by virus strains.

\section{Limitations and future experiments}

One limitation that was encountered in the study was the lack of availability of some commercial antibodies. None of the antibodies used could detect a cleaved product of RIPK1. Therefore, we concluded that the resulting fragment may be too small to detect by western blotting or may be further degraded. However, the exact mechanism of NS3-mediated cleavage/degradation of RIPK1 remains to be elucidated. We could not find a commercial antibody that could detect pro and cleaved caspase 8 efficiently. Because of this, understanding the role of RIPK1 in caspase 8 activation was limited.

Our studies were primarily done on immortalized cell lines and monocytederived dendritic cells. There are some caveats in using cell lines for understanding intricate biological signaling pathways. Generally, our findings are limited to one cell type, in cell culture, whereas many cells orchestrate to contribute to the outcome of infection in vivo. Even though some cell lines have intact NF-kB signaling, they may not secrete cytokines efficiently. RIPK1 signaling is regulated by cell-intrinsic as well 
as cell-extrinsic stimuli. Extra-cellular stimuli under natural conditions would be better reflected in in vivo models. Therefore, our study could be extended to PBMCs and include the investigation of the effects of NF- $\mathrm{kB}$ inhibition on cytokine secretion in infected as well as bystander cells. Similar studies have been done to investigate the effect of RIPK1 inhibition in other diseases. For example, qRT-PCR analysis of peripheral blood leukocytes from patients with Systemic Lupus Erythematosus revealed lower RIPK1 transcript levels than from healthy individuals. Serum TNF $\alpha$ and IL-2 levels were also significantly lower in the SLE patients than in the healthy individuals (38).

Additionally, it could be of interest to study the effect of "ADE" on RIPK1 inhibition and cytokine expression by DENV. This could be achieved by infection of cells in the presence of cross-reactive DENV antibodies. Furthermore, it would be interesting to see in vivo effects of RIPK1 inhibition on DENV at an organismal level. However, DENV fails to antagonize mouse immune responses. WT mice usually do not sustain DENV replication or develop disease symptoms as seen in DHF $(15,40)$. Therefore, understanding immune evasion strategies and the disease pathogenesis of DENV has been mostly limited to in vitro and ex vivo assays.

We observed a physical interaction between RIPK1 and DENV NS3. However, we do not know what motifs of both proteins are important for this interaction. RIPK1 is known to interact with other RHIM domain-containing proteins. Some viral proteins are known to contain RHIM-like domains. To investigate important motifs for this interaction, co-immunoprecipitation studies could be done with overexpression of DENV NS2B3 and RHIM-mutant RIPK1 plasmid. Furthermore, we do not know if 
any other proteins are involved in the RIPK1-NS3 complex. For example, DENV NS5 is known to interact with STAT2 and proteins of the ubiquitination machinery, resulting in STAT2 ubiquitination and degradation (41). Given that RIPK1 is posttranslationally modified by ubiquitination (42), the involvement of other proteins in the NS3-RIPK1 complex can be speculated. Mass spectrometry and proteomics analysis could reveal such complex formation during DENV infection. MCMV and HSV-1 viral proteins contain "IPAM" motifs that induce protein aggregates. RIPK1 was shown to aggregate and get degraded in the presence of MCMV M45 protein and HSV-1 ICP6 protein. Such effects have not been tested in DENV so far. Therefore, it would be interesting to check if DENV could induce host proteins to aggregate including RIPK1.

Additionally, the effect of RIPK1 inhibition on uninfected bystander cells should be investigated. Since RIPK1 inhibition leads to less cytokine secretion and inhibition of necroptosis, we can speculate that fewer bystander cells would be stimulated/activated, rendering them susceptible to DENV infection.

There is evidence of a link between dysregulation of RIPK1 and the pathogenesis of inflammatory and neurogenerative diseases such as multiple sclerosis (MS), ALS, Alzheimer's disease and inflammatory bowel disease (43). RIPK1 is emerging as a promising therapeutic target for treating such diseases. DENV infection in patients with such pre-existing conditions may be more likely to result in severe dengue disease due to further inhibition of RIPK1-mediated signaling. Thus, understanding the inhibition of RIPK1 signaling in viral disease pathogenesis will be helpful in treating other diseases as well. 
Additional in silico analyses could be performed to investigate various aspects of NS3-RIPK1 interaction. DENV protease is known to recognize and cleave substrate sequences having a small amino acid following two basic residues $(44,45)$. A manual homology search for such sequences in RIPK1 could be carried out using bioinformatic tools such as DNASTAR Laser gene software. Site directed mutagenesis could be performed to mutate putative cleavage sites on RIPK1 experimentally. Further co-transfection experiments could be performed using DENV NS2B3 and plasmids encoding mutated RIPK1, which will be helpful for verifying if DENV NS3 cleaves RIPK1.

Viral proteins are known to interact with RIPK1 via RHIM domains. For example, CMV M45 protein interacts with RIPK1 via the RHIM domain. Furthermore, CMV M45 and HSV-1 ICP6 proteins induce RIPK1 aggregation and degradation via IPAM motif. Therefore, it would be interesting to investigate if such motifs exist in DENV NS3. Therefore, in silico analyses such as sequence comparisons and homology search for RHIM and IPAM motifs could be done. These analyses will potentially uncover DENV NS3 interactions between other RHIM containing host proteins such as TRIF

In summary, this research has identified RIPK1 as a novel target of DENV NS3. These findings expand the knowledge of strategies used by DENV to evade innate immune responses. Manipulation of host cell RIPK1 by DENV may contribute to the disease pathogenesis as illustrated by model I and II. 


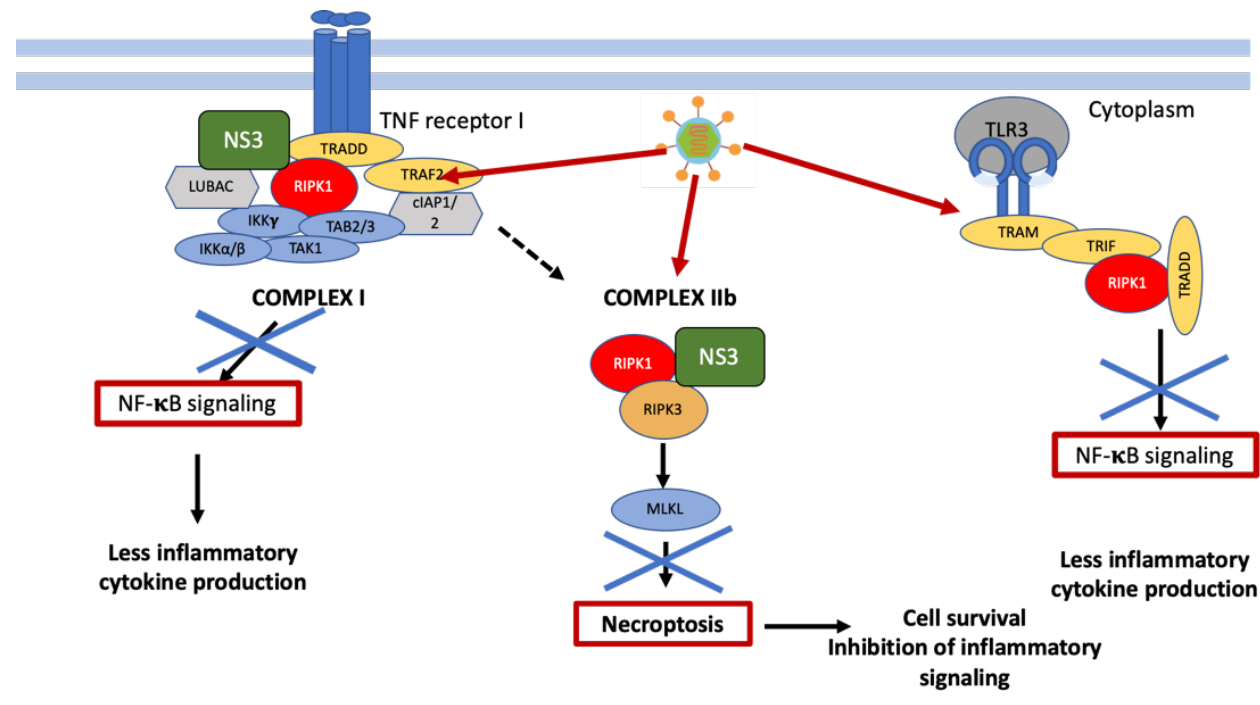

Figure 1. Model 1: Cell-intrinsic effects of RIPK1 inhibition by DENV. DENV NS3 protein interacts with and decreases RIPK1 levels. TNFR1- and TLR3-stimulated $\mathrm{NF}-\kappa \mathrm{B}$ activation is impaired due to the NS3-mediated RIPK1 reduction. This may result in the downregulation of many antiviral genes resulting in decreased production of cytokines and chemokines. Cell death downstream of TNFR1 is also blocked by DENV due to decreased RIPK1 levels. This may result in increased cell survival allowing more efficient viral replication. The inhibition of necroptosis may also suppress the release of DAMPs and PAMPs from the cell. 
Intact RIPK1 signaling

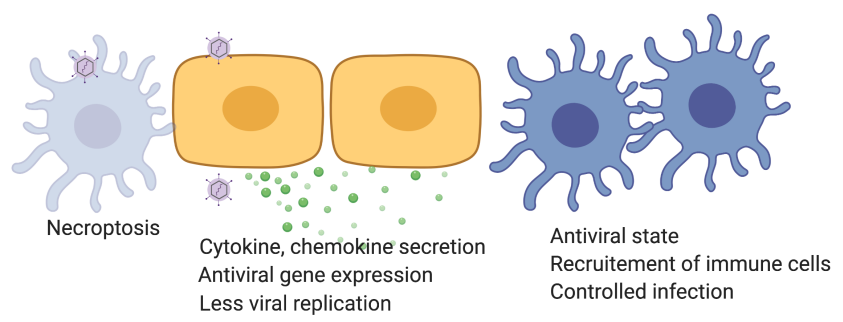

Inhibition of RIPK1 signaling

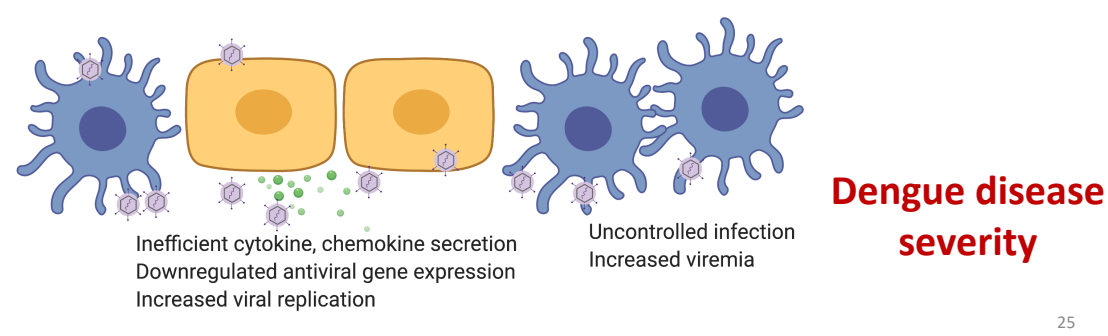

Figure 2. Model II: The effects of RIPK1 inhibition at a tissue/organism level.

Inhibition of NF- $\kappa \mathrm{B}$ activation by DENV may result in downregulated cytokine/chemokine/IFN secretion. Inhibition of necroptosis may result in cell survival, benefiting viral replication. These effects may result in increased virus production. Bystander cell activation and recruitment of $\mathrm{T}$ and $\mathrm{B}$ cells may be negatively affected by the inefficient cytokine/chemokine production. Uninfected cells could become susceptible to further infection by DENV. Therefore, controlling virus infection may be unsuccessful. The virus may spread into other cells/tissues/organs. Taken together, increased viremia and altered immune responses may contribute to severe dengue disease. 


\section{References}

1. Wagner RN, Reed JC, Chanda SK. HIV-1 protease cleaves the serine-threonine kinases RIPK1 and RIPK2. Retrovirology. 2015;12(1):1-16.

2. Pascal S, Urs F. Rhinovirus 3C protease suppresses apoptosis and triggers caspase-independent cell death. 2018;9.

3. Guo H, Omoto S, Harris PA, Finger JN, Bertin J, Gough PJ, et al. Herpes simplex virus suppresses necroptosis in human cells. Cell Host Microbe [Internet]. 2015;17(2):243-51. Available from: http://dx.doi.org/10.1016/j.chom.2015.01.003

4. Upton JW, Kaiser WJ, Mocarski ES. Cytomegalovirus M45 cell death suppression requires receptor-interacting protein (RIP) homotypic interaction motif (RHIM)-dependent interaction with RIP1. J Biol Chem. 2008;283(25):16966-70.

5. Liu X, Li Y, Peng S, Yu X, Li W, Shi F, et al. Epstein-Barr virus encoded latent membrane protein 1 suppresses necroptosis through targeting RIPK1/3 ubiquitination article. Cell Death Dis [Internet]. 2018;9(2). Available from: http://dx.doi.org/10.1038/s41419-017-0081-9

6. Hyun J, Ramos JC, Toomey N, Balachandran S, Lavorgna A, Harhaj E, et al. Oncogenic Human T-Cell Lymphotropic Virus Type 1 Tax Suppression of Primary Innate Immune Signaling Pathways. J Virol. 2015;89(9):4880-93.

7. Muscolino E, Schmitz R, Loroch S, Caragliano E, Schneider C, Rizzato M, et al. Herpesviruses induce aggregation and selective autophagy of host signalling proteins NEMO and RIPK1 as an immune-evasion mechanism.

8. Teng Y, Wang Y, Zhang X, Liu W, Fan H, Yao H. Systematic Genome-wide Screening and Prediction of microRNAs in EBOV During the 2014 Ebolavirus Outbreak. Nat Publ Gr [Internet]. 2015;(May):1-17. Available from: http://dx.doi.org/10.1038/srep09912

9. Daniels BP, Snyder AG, Olsen TM, Orozco S, Oguin TH, Tait SWG, et al. RIPK3 Restricts Viral Pathogenesis via Cell Death-Independent Neuroinflammation. Cell. 2017;169(2):301-313.e11.

10. Daniels BP, Kofman SB, Smith JR, Norris GT, Snyder AG, Kolb JP, et al. The Nucleotide Sensor ZBP1 and Kinase RIPK3 Induce the Enzyme IRG1 to Promote an Antiviral Metabolic State in Neurons. Immunity. 2019;50(1):6476.e4.

11. Polykratis A, Hermance N, Zelic M, Roderick J, Kim C, Van T-M, et al. Cutting 
Edge: RIPK1 Kinase Inactive Mice Are Viable and Protected from TNFInduced Necroptosis In Vivo. J Immunol. 2014;193(4):1539-43.

12. Heil F, Hemmi H, Hochrein H, Ampenberger F, Kirschning C, Akira S, et al. Species-specific recognition of single-stranded RNA via toll-like receptor 7 and 8. Science. 2004 Mar;303(5663):1526-9.

13. Tsai Y-T, Chang S-Y, Lee C-N, Kao C-L. Human TLR3 recognizes dengue virus and modulates viral replication in vitro. Cell Microbiol. 2009 Apr;11(4):604-15.

14. Modhiran N, Watterson D, Muller DA, Panetta AK, Sester DP, Liu L, et al. Dengue virus NS1 protein activates cells via Toll-like receptor 4 and disrupts endothelial cell monolayer integrity. Sci Transl Med. 2015 Sep;7(304):304ra142.

15. Shresta S, Kyle JL, Snider HM, Basavapatna M, Beatty PR, Harris E. Interferon-dependent immunity is essential for resistance to primary dengue virus infection in mice, whereas T- and B-cell-dependent immunity are less critical. J Virol. 2004 Mar;78(6):2701-10.

16. Luft T, Pang KC, Thomas E, Hertzog P, Hart DN, Trapani J, et al. Type I IFNs enhance the terminal differentiation of dendritic cells. J Immunol. 1998 Aug;161(4):1947-53.

17. Philpott NJ, Nociari M, Elkon KB, Falck-Pedersen E. Adenovirus-induced maturation of dendritic cells through a PI3 kinase-mediated TNF-alpha induction pathway. Proc Natl Acad Sci U S A. 2004 Apr;101(16):6200-5.

18. Trevejo JM, Marino MW, Philpott N, Josien R, Richards EC, Elkon KB, et al. TNF-alpha -dependent maturation of local dendritic cells is critical for activating the adaptive immune response to virus infection. Proc Natl Acad Sci U S A. 2001 Oct;98(21):12162-7.

19. Schmid MA, Diamond MS, Harris E. Dendritic cells in dengue virus infection: Targets of virus replication and mediators of immunity. Front Immunol. 2014;5(DEC):1-10.

20. Sun P, García J, Comach G, Vahey MT, Wang Z, Forshey BM, et al. Sequential waves of gene expression in patients with clinically defined dengue illnesses reveal subtle disease phases and predict disease severity. PLoS Negl Trop Dis. 2013;7(7):e2298.

21. Chang TH, Chen SR, Yu CY, Lin YS, Chen YS, Kubota T, et al. Dengue virus serotype 2 blocks extracellular signal-regulated kinase and nuclear factor- $\kappa \mathrm{B}$ activation to downregulate cytokine production. PLoS One. 2012;7(8):4-11. 
22. Yatim N, Jusforgues-Saklani H, Orozco S, Schulz O, Da Silva RB, Reis E Sousa $\mathrm{C}$, et al. RIPK1 and NF-kB signaling in dying cells determines crosspriming of CD8+ T cells. Science (80- ). 2015;350(6258):328-34.

23. Dowling JP, Cai Y, Bertin J, Gough PJ, Zhang J. Kinase-independent function of RIP1, critical for mature T-cell survival and proliferation. Cell Death Dis. 2016 Sep;7(9):e2379.

24. Zhang J, Zhang H, Li J, Rosenberg S, Zhang EC, Zhou X, et al. RIP1-mediated regulation of lymphocyte survival and death responses. Immunol Res. 2011 Dec;51(2-3):227-36.

25. Sica A, Tan TH, Rice N, Kretzschmar M, Ghosh P, Young HA. The c-rel protooncogene product c-Rel but not NF-kappa B binds to the intronic region of the human interferon-gamma gene at a site related to an interferon-stimulable response element. Proc Natl Acad Sci U S A. 1992 Mar;89(5):1740-4.

26. Sica A, Dorman L, Viggiano V, Cippitelli M, Ghosh P, Rice N, et al. Interaction of NF-kappaB and NFAT with the interferon-gamma promoter. J Biol Chem. 1997 Nov;272(48):30412-20.

27. Hiscott J, Alper D, Cohen L, Leblanc JF, Sportza L, Wong A, et al. Induction of human interferon gene expression is associated with a nuclear factor that interacts with the NF-kappa B site of the human immunodeficiency virus enhancer. J Virol. 1989 Jun;63(6):2557-66.

28. Lenardo MJ, Fan CM, Maniatis T, Baltimore D. The involvement of NF-kappa $\mathrm{B}$ in beta-interferon gene regulation reveals its role as widely inducible mediator of signal transduction. Cell. 1989 Apr;57(2):287-94.

29. Samanta J. Dengue and its effects on liver. World J Clin Cases [Internet]. 2015;3(2):125. Available from: http://www.wjgnet.com/23078960/full/v3/i2/125.htm

30. Apoptosis DC. Dendritic Cell Apoptosis and the Pathogenesis of Dengue. 2012;2736-53.

31. Farooq M, Filliol A, Simoes Eugénio M, Piquet-Pellorce C, Dion S, RaguenesNicol C, et al. Depletion of RIPK1 in hepatocytes exacerbates liver damage in fulminant viral hepatitis. Cell Death Dis [Internet]. 2019;10(1). Available from: http://dx.doi.org/10.1038/s41419-018-1277-3

32. Filliol A, Piquet-Pellorce C, Le Seyec J, Farooq M, Genet V, Lucas-Clerc C, et al. RIPK1 protects from TNF- $\alpha$-mediated liver damage during hepatitis. Cell Death Dis [Internet]. 2016;7(11):1-13. Available from: http://dx.doi.org/10.1038/cddis.2016.362 
33. Humphries F, Yang S, Wang B, Moynagh PN. RIP kinases: Key decision makers in cell death and innate immunity. Cell Death Differ [Internet]. 2015;22(2):225-36. Available from: http://dx.doi.org/10.1038/cdd.2014.126

34. Vaughn DW, Green S, Kalayanarooj S, Innis BL, Nimmannitya S, Suntayakorn S, et al. Dengue Viremia Titer, Antibody Response Pattern, and Virus Serotype Correlate with Disease Severity. (1):2-9.

35. Chandramouli S, Joseph JS, Daudenarde S, Gatchalian J, Cornillez-Ty C, Kuhn P. Serotype-Specific Structural Differences in the Protease-Cofactor Complexes of the Dengue Virus Family. J Virol. 2010;84(6):3059-67.

36. Erbel P, Schiering N, D'Arcy A, Renatus M, Kroemer M, Lim SP, et al. Structural basis for the activation of flaviviral NS3 proteases from dengue and West Nile virus. Nat Struct Mol Biol. 2006;13(4):372-3.

37. Luo D, Xu T, Hunke C, Grüber G, Vasudevan SG, Lescar J. Crystal Structure of the NS3 Protease-Helicase from Dengue Virus. J Virol. 2008;82(1):173-83.

38. Guo R, Tu Y, Xie S, Liu XS, Song Y, Wang S, et al. A Role for ReceptorInteracting Protein Kinase-1 in Neutrophil Extracellular Trap Formation in Patients with Systemic Lupus Erythematosus: A Preliminary Study. Cell Physiol Biochem. 2018;45(6):2317-28.

39. Foletta VC, Segal DH, Cohen DR. Transcriptional regulation in the immune system : all roads lead to AP-1. 1998;63(February):139-52.

40. Rothman AL. Preface. Curr Top Microbiol Immunol. 2009;338(1):45-55.

41. Ashour J, Laurent-Rolle M, Shi P-Y, Garcia-Sastre A. NS5 of Dengue Virus Mediates STAT2 Binding and Degradation. J Virol. 2009;83(11):5408-18.

42. Peltzer N, Darding M, Walczak H. Holding RIPK1 on the Ubiquitin Leash in TNFR1 Signaling. Trends Cell Biol. 2016;26(6):445-61.

43. Degterev A, Ofengeim D, Yuan J. Targeting RIPK1 for the treatment of human diseases. Proc Natl Acad Sci U S A. 2019;116(20):9714-22.

44. Preugschat F, Yao CW, Strauss JH. In vitro processing of dengue virus type 2 nonstructural proteins NS2A, NS2B, and NS3. J Virol. 1990 Sep;64(9):436474 .

45. Yusof R, Clum S, Wetzel M, Murthy HM, Padmanabhan R. Purified NS2B/NS3 serine protease of dengue virus type 2 exhibits cofactor NS2B dependence for cleavage of substrates with dibasic amino acids in vitro. J Biol Chem. 2000 Apr;275(14):9963-9 